\title{
Detecção de disfagia na fase aguda do acidente vascular cerebral isquêmico. Proposição de conduta baseada na caracterização dos fatores de risco
}

Tese apresentada à Faculdade de Medicina de Ribeirão Preto da Universidade de São Paulo para obtenção do Título de Doutora em Ciências Médicas - Área de Concentração: Neurologia e Neurociências.

Orientador: Dr. Osvaldo Massaiti Takayanagui 
AUTORIZO A REPRODUÇÃO E DIVULGAÇÃO TOTAL OU PARCIAL DESTE TRABALHO, POR QUALQUER MEIO CONVENCIONAL OU ELETRÔNICO, PARA FINS DE ESTUDO E PESQUISA, DESDE QUE CITADA A FONTE.

Okubo, Paula de Carvalho Macedo Issa

Detecção de disfagia na fase aguda do acidente vascular cerebral isquêmico. Proposição de conduta baseada na caracterização dos fatores de risco. Ribeirão Preto, 2008.

131 p.: il.; $30 \mathrm{~cm}$

Tese de Doutorado, apresentada à Faculdade de Medicina de Ribeirão Preto / USP. Área de concentração: Neurologia e Neurociências.

Orientador: Takayanagui, Osvaldo Massaiti.

1. Acidente cerebrovascular. 2.Transtorno de deglutição. 3. Disfagia. 4. Avaliação clínica. 
FOLHA DE APROVAÇÃO

Paula de Carvalho Macedo Issa Okubo

Detecção de disfagia na fase aguda do acidente vascular cerebral isquêmico. Proposição de conduta baseada na caracterização dos fatores de risco.

Tese apresentada à Faculdade de Medicina de Ribeirão Preto da Universidade de São Paulo para obtenção do Título de Doutora em Ciências Médicas.

Área de Concentração: Neurologia e Neurociências.

Aprovada em:

Banca Examinadora

Prof. Dr. Osvaldo Massaiti Takayanagui

Instituição: FMRP-USP

Assinatura:

Prof. Dr. Ayrton Roberto Massaro

Instituição: UNIFESP

Assinatura:

Prof. Dr. José Antônio Livramento

Instituição: USP-SP

Assinatura:

Prof. Dr. Roberto Oliveira Dantas

Instituição: FMRP-USP

Assinatura:

Profa. Dra. Luciana Vitaliano Voi Trawitzki

Instituição: FMRP-USP

Assinatura: 


\section{DEDICATÓRIAS}

Ao meu filho Pedro, meu pedido de perdão pelos momentos em que me ausentei para finalizar este sonho. Minha eterna gratidão por ter vindo ao mundo em um momento tão especial da minha vida, mostrando-me o verdadeiro significado da palavra amor, trazendo-me à realização plena enquanto mulher e mortal.

"Que louca e estranha é a existência,

Soma momentos de alegria intensa

Para renovar forças já enfraquecidas

A fim de que possa sair vitoriosa na porfia.

Nesta insana luta do dia a dia,

Recebo a notícia de um primeiro sinal:

Sou eu, Vovô, que cheguei de viagem

Daquela que nosso Pai permitia na eternidade.

Vim, ainda com asas dos querubins, Abençoar o lar de Papai e Mamãe,

$E$ deste Pedro que ali passa a morar,

Para a família com amor constituir.

E nós, querido neto, que jubilosos

Festejamos tua chegada triunfal,

Rogamos que teu encarne represente

A vitória de teu espírito sobre o mal.

Sede, neste plano, o gladiador

A derrotar as intempéries do mundo

E podendo somar de ti cada ação

Pois que eivadas, sempre, de doação.

Faça, então, que estas conquistas

Sejam as alegrias de teus pais,

Que elas iluminem os olhos de todos mais

Até que ao Criador tiveres que retornar."

(Vovô Issa) 
Aos meus Pais que sempre estão presentes, contribuindo, incondicionalmente, para que eu alcance meus objetivos. Sem vocês, com certeza minhas conquistas não teriam o mesmo valor. Vocês são meus maiores exemplos de vida!

Mamãe, mais uma vez, meu muito obrigado pela integral disponibilidade em me proporcionar momentos de tranqüilidade permitindo a conclusão desta tese.

"A somatória dos anos que se sucedem Diante do caminhar constante da vida, Descreve o perfil daqueles que assumem Cumprir sua missão de forma destemida.

Nobre e altiva, humilde e carinhosa, Recebe amor e estimula a consciência, Quer sendo a eterna esposa,

Ou a mãe de insuperável paciência.

É esta razão imensurável, No dia a dia de nossas atribulações, A ouvir de forma interminável,

Teu nome repetido em nossas ações.

É a deusa bendita a abençoar A saída e o labor das filhas, $E$ do marido que te quer amar Como sua segura e única ilha.

Assim, és tu, Cármen Sílvia,

Mãe e mulher maravilha:-

Somas muito de anjo amparador

E tens tudo para receber nosso amor."

(José Antônio Issa) 
Papai, agradeço sempre e sempre a paciência na correção do português. Tua habilidade para a língua e o discurso é um dom invejável. Poder ilustrar minha tese com seus dizeres foi uma imensa satisfação!

"De quimeras mil iniciei a construção

De um universo que representasse meu ser.

Na santa inocência do recém iniciado

Mal me conscientizara que a vida tinha começado.

Propus-me a desenvolver o culto de mim mesmo

Inebriado com as forças que me vinham

Dos conceitos soberbos que conseguia aurir

Na faina diária de meu aprimoramento.

A crença de grandioso se fortaleceu em meu íntimo.

Então, quanto mais rijo, forte e intocável

Tinha a certeza de me ter tornado,

Recebi do Senhor a mensagem crucial:

Ai te levei, ai te cuido e ai te tenho,

Ai permanecer te permito... se fores forte até a morte!"

(O Iniciando - José Antônio Issa) 
Às minhas irmãs e sempre amigas, Cláudia e Renata, que, em escolhas profissionais tão opostas à minha, não poupam esforços em me compreender, desdobrando-se em me ajudar: do simples olhar carinhoso ao endurecimento das palavras para meu crescimento pessoal.

Aos meus cunhados, Rodrigo e André, pela paciência que me dispensaram nos enfrentamentos do cotidiano, demonstrando que sua união com minhas irmãs, aliada a nós, faz-nos bastar uns aos outros.

"A amizade é um encontro de sons e imagens

Que fortalecem os laços profundos

Ou arrebenta os encontros casuais

Fortalecendo aqueles e denunciando estes.

Aqueles, pelo seu poder,

Perpetuam as idéias de conviver

E fazem imortal a vida dos homens

No caminhar do espírito de luz pela terra;

Estes registram as insanidades

De uma grande falsidade

Que é a amizade sem amor.

Assim, que se esqueça deste

E sejam fortalecidos aqueles

Para que a amizade seja a arte de amar."

(Amigos - José Antônio Issa) 
Ao meu marido Denny, que mesmo pela dificuldade em abarcar o motivo da pouca atenção a ele despendida, suportou meu estresse. Amo você!

"Vou, rodopio e volto...

Caminho, veloz e voraz

Em direção ao infinito,

À procura da verdade.

Nestas idas e vindas,

Sempre a tentar o impossivel,

Registro a ansiedade

Da conclusão do destino.

De repente, perdido no universo

Desta luta insana,

Enxergo a luz de tua mão.

Vejo, então, que nada foi em vão:

Enquanto ia e voltava,

O Pai meu destino traçava."

(Destino Traçado - José Antônio Issa) 


\section{AGRADECIMENTOS}

Não poderia iniciar diferente, senão agradecer, inicialmente, a Deus por ter permitido que eu terminasse este trabalho mesmo diante de tantos atropelos: uns saudáveis, outros um tanto dolorosos, mas todos vitoriosos. Com certeza foi a presença da força Divina que possibilitou o enfrentamento das intempéries da vida, não me deixando desistir dos meus ideais. Pai, obrigada por sua luz!

Aos pacientes internados na Unidade de Emergência e seus familiares, que me permitiram realizar este estudo, mesmo diante de situações de muita tensão em que não sabiam o que ia acontecer daquele momento em diante. Enquanto eu traçava meu estudo, aprendia inúmeros valores de vida.

Aos residentes em neurologia do HCFMRP-USP que sempre estiveram disponíveis para me auxiliar na identificação do paciente agudo. Meu carinho é bastante especial por vocês. Minha satisfação é imensa quando deixam transparecer que, de alguma forma, contribuo na formação de vocês enquanto profissionais.

A todos os funcionários da sala de politraumatizados, de urgência, estabilização clínica e enfermaria da UEFMRP-USP pela compreensão e gentileza enquanto eu coletava meus dados.

À Dra. Soraia Ramos Cabette Fábio, pelos poucos e ricos momentos em que discutimos assuntos relacionados à interface neurologia/fonoaudiologia. Você é a grande responsável pela conclusão deste trabalho. Deixo meu respeito e admiração enquanto profissional, tanto quanto minha satisfação em tê-la como colega de trabalho.

Ao meu orientador, Prof. Dr. Osvaldo Massaiti Takayanagui, pela disponibilidade em que me atendia, sempre disposto a tentar solucionar os obstáculos pertinentes à pesquisa da maneira mais simples e sutil, traços que lhe são peculiares. A tranqüilidade que a mim transmitiu teve um significado ímpar. 
Ao Prof. Dr. Roberto Oliveira Dantas, que mais uma vez me presenteou ao aceitar constituir minha banca, acrescentando-me valiosos conhecimentos durante a correção deste trabalho.

À Profa. Dra. Luciana Vitaliano Voi Trawitzki pelos comentários extremamente pertinentes durante a leitura desta tese. Acima de tudo, obrigada por participar deste momento tão significante em minha vida, enquanto, na verdade, este mesmo momento, visto em outro paradigma, deveria ser só seu. Festejemos!

Ao Prof. Dr. José Antônio Livramento pela prontidão a mim despendida. Mesmo através de contatos restritos, contribuiu com sugestões extremamente cabíveis para a melhoria deste trabalho e para meu crescimento pessoal, não deixando de referenciar palavras positivas. Poucas são as pessoas que conseguem transmitir ensinamentos de forma tão sublime.

Ao Prof. Dr. Ayrton Massaro meu agradecimento em ter conseguido driblar seus compromissos para que estivesse presente na conclusão desta tese.

À minha colega de trabalho e amiga Danielle Ramos, com quem divido a paixão pela área e os momentos de luta no plano profissional e pessoal. Qualquer que seja a denominação desta dupla que constituímos, fica aqui meu reconhecimento e agradecimento em poder formá-la. Que possamos cada vez mais nos fortalecer no enfrentamento das passagens terrenas a nós predestinadas.

A todas as profissionais do Setor de Fonoaudiologia do HCFMRP-USP no auxílio, troca de informações, conhecimento e, principalmente, tolerância ao mau humor. Em especial, agradeço às secretárias, Sandra e Juliana, pela paciência e compreensão.

À Lígia Salami e ao Davi Aragon do CEMEQ (Centros de Métodos Quantitativos) da FMRP-USP, minha gratidão pela realização da análise estatística. 
“A vida se constrói de momentos fastos e outros nefastos; a anteposição e a soma de ambos permitem o raciocínio lógico e nos leva à construção de um universo só nosso e que, somado ao de outros seres assim formados, criam um mundo racional e de felicidades inigualáveis (...) Jamais lamentem o que foram; somem, sempre, as experiências como forma de crescimento pessoal”. 
OKUBO, P.C.M.I. Detecção de disfagia na fase aguda do acidente vascular cerebral isquêmico. Proposição de conduta baseada na caracterização dos fatores de risco. 2008. 131f. Tese de Doutorado - Faculdade de Medicina da Universidade de São Paulo, Ribeirão Preto, 2008.

A disfagia orofaríngea é uma manifestação comum apresentada na fase aguda do acidente vascular cerebral (AVC). A aspiração decorrente das dificuldades de deglutição é um sintoma que deve ser considerado devido à freqüente presença de pneumonias aspirativas que podem influenciar na recuperação do paciente trazendo complicações ao seu quadro clínico em geral e até mesmo risco de morte. A caracterização clínica precoce das alterações de deglutição pode auxiliar na definição de condutas e evitar a administração de dieta por via oral oferecendo riscos ao paciente. O presente estudo teve por objetivo, propor a via mais segura de alimentação na fase aguda do acidente vascular cerebral isquêmico (AVCI) com o intuito de minimizar complicações, utilizando a escala de AVC proposta pelo "National Institutes of Health", o NIHSS e considerando alguns fatores de risco para disfagia na clínica apresentada por estes pacientes, com a formulação de um algoritmo. Para tanto, foram avaliados 50 pacientes internados na Unidade de Emergência do Hospital das Clínicas da Faculdade de Medicina de Ribeirão Preto da Universidade de São Paulo com diagnóstico de AVCI confirmado, clinicamente, por um médico neurologista, dentro de, no máximo, 48 horas entre o início dos sintomas e a avaliação. Os pacientes foram avaliados desde que se enquadrassem nos critérios propostos, sendo 25 do gênero feminino e 25 do masculino, com idade média de 64,90 anos (variação de 26 a 91 anos). Uma anamnese foi realizada antes da participação do paciente no estudo, para que fosse assegurada a ausência de história de dificuldades de deglutição anteriores ao quadro atual. A avaliação clínica fonoaudiológica foi realizada à beira do leito através de um protocolo constituído por dados de identificação do paciente, data do início dos sintomas, data de entrada no hospital, escore da escala de coma de Glasgow (ECG) e do NIHSS obtidos na avaliação neurológica inicial e no dia da avaliação, fatores de risco para AVC, achados clínicos obtidos na avaliação neurológica do paciente, resultado do exame de imagem (tomografia computadorizada ou ressonância magnética). A segunda parte foi destinada à escala do NIHSS e, por fim, a terceira parte constou da avaliação da deglutição, sendo subdividida em estrutural e funcional. Para a avaliação funcional da deglutição foram utilizadas as consistências alimentares pastosa, líquida e sólida (quando possível, dependendo das condições apresentadas pelo paciente). $\mathrm{O}$ volume da oferta também dependeu das possibilidades apresentadas: aqueles pacientes que não ofereciam condições clínicas para a 
realização da avaliação, como os que se encontravam com intubação orotraqueal, estado de sonolência profunda ou em estado de coma, esta foi contra-indicada. Após a avaliação clínica, com a obtenção dos dados estruturais e funcionais, concluiu-se se a avaliação clínica da deglutição apresentava-se normal ou alterada. A partir de então, era concluído sobre a possibilidade de introdução de dieta por via oral. Para a análise estatística foi utilizado o teste exato de Fisher, verificando a associação entre as variáveis. Para avaliar se o escore do NIHSS caracterizaria um indicador de fator de risco para a disfagia, foi construída a curva ROC visando obter características quanto à sensibilidade e especificidade da escala para este propósito. Os resultados demonstraram que a disfagia é uma manifestação freqüente na fase aguda do AVCI, presente em 32\% dos pacientes analisados. A avaliação clínica da deglutição é um método confiável de detecção das dificuldades de deglutição. Entretanto, os fatores preditivos de risco para a função devem ser ponderados, devendo ser considerada a gravidade do quadro, o nível de consciência e a presença de comorbidades pré-existentes. A hipertensão arterial sistêmica (HAS) demonstrou ser o principal fator de risco para o AVC apresentada por $72 \%$ dos pacientes, seguida do tabagismo (36\%), etilismo $(20 \%)$ e diabete melito $(20 \%)$. Gênero e hemisfério cerebral acometido não tiveram associação estatisticamente significante com a presença de disfagia. Idade, NIHSS, ECG, alterações de fala e linguagem e topografia da lesão são fatores preditivos de disfagia apresentando diferenças estatisticamente significantes. Pacientes com lesões em território carotídeo apresentaram maior prevalência quanto à presença de disfagia (58,88\%). O NIHSS apresenta alta sensibilidade (88\%) e especificidade (85\%) para detecção de disfagia considerando 12 como valor de corte para sua existência. A formulação de um algoritmo para detecção de disfagia na fase aguda do AVCI poderá auxiliar na definição de condutas quanto à melhor via de administração da dieta enquanto se aguarda uma avaliação fonoaudiológica especializada. 
OKUBO, P.C.M.I. Detection of dysphagia during the acute phase of ischemic cerebrovascular accident. Proposition of behavior based on the characterization of risk factors. 2008. 131f. Ph.D. Dissertation - Faculdade de Medicina da Universidade de São Paulo, Ribeirão Preto, 2008.

Oropharyngeal Dysphagia is a common manifestation presented in the acute phase of cerebrovascular accident (CVA). The aspiration resulting from the difficulties of deglutition is a symptom that should be considered due to the frequent occurrence of aspirative pneumonia that could influence the patient's recovery, causing complications to the general clinical and even the risk of death. The early clinical characterization of deglutition alterations can help to specify the proper behavior and to avoid the prescription of a diet that could offer the patients risks. The present study had as objective to propose the most secure feeding for the patient in the acute phase of the ischemic cerebrovascular accident (ICVA) with the aim to minimize complications, using the CVA scale proposed by the National Institutes of Health (NIHSS) and considering some risk factors of dysphagia in the practice presented by these patients, with the creation of an algorithm. Thus, 50 inpatients were evaluated at the Unidade de Emergência do Hospital das Clínicas da Faculdade de Medicina de Ribeirão Preto da Universidade de São Paulo with clinically confirmed ICVA diagnosis by a neurologist, within, at most, 48 hours from the onset of the symptoms and the evaluation. The patients were assessed randomly as long as, in which 25 were women and 25 were men, and 64,90 years old were the average ages (variation from 26 to 91 years old). An anamnesis was carried out before the patient's participation in the study, so that the previously absence of the history of deglutition difficulties was ensured. The clinical phonoaudiological assessment was carried out on bed side through a protocol constituted by patients identification data, symptoms onset date, admission date in the hospital, Glasgow Coma Scale (GCS) and NIHSS score obtained in the initial neurological evaluation and in the evaluation's day, risk factors for CVA, clinical findings obtained from the patient's neurological evaluation, result of the screenings (computed tomography or magnetic resonance imaging). The second part was designed to the NIHSS scale and, the third part was constituted by the clinical deglutition evaluation, subdivided in structural and functional. For the functional deglutition evaluation the pasty, liquid and solid feeding consistencies were used (when possible, depending on the conditions presented by the patient). The volume of the offer also depended on the presented possibilities: those patients who did not present clinical conditions for the evaluation, such as the ones who were with orotraqueal intubation, deep sleep state or coma; it was counter-indicated. After the clinical evaluation, with the structural 
and functional data obtained, it was concluded whether the clinical deglutition evaluation was normal or altered. Since then, it was concluded the possibility of a diet prescription. For the statistical analysis the Fisher exact test was used to verify the association between variables. To evaluate if the NIHSS score would characterize a risk factor indicator for dysphagia, the curve ROC was built aiming to obtain characteristics related to the sensitivity and specificity of the scale for this purpose. The study allowed us to conclude that dysphagia is a frequent manifestation in the acute phase of ICVA, present in $32 \%$ of the analyzed patients. The clinical deglutition evaluation is a reliable method of difficulties deglutition detection. However, the predicting risk factors for the function should be balanced and the severity of the clinical picture, the consciousness level and the presence of preexistent comorbidities should be considered. The systemic arterial hypertension (SAH) demonstrated to be the main risk factor for the CVA presented by $72 \%$ of the patients, followed by tabagism (36\%), alcoholism (20\%) e diabetes mellitus (20\%). Gender and damaged cerebral hemisphere did not have a statistically significant association to the presence of dysphagia. Age, NIHSS, GCS, speaking and language alterations and lesion topography are predicting factors of dysphagia presenting statistically significant differences. Patients with lesions in the carotid territory presented more prevalence regards the presence of dysphagia (58,88\%). NIHSS presents high sensitivity (88\%) and specificity $(85 \%)$ to the detection of dysphagia considering 12 as the cutoff value for its existence. The creation of an algorithm to detect dysphagia in the acute phase of ICVA will be able to help the definition of the proper behavior regards the prescription of a diet while a specialized speech pathological evaluation is awaited.

Keywords: cerebrovascular accident, deglutition disorder, dysphagia, clinical evaluation. 


\section{LISTA DE ILUSTRAÇÕES}

Página

Figura 1: Proposta de algoritmo para detecção de presença de disfagia grave na fase aguda do AVCI.

Figura 2: Algoritmo para detecção de presença de disfagia grave na fase aguda do AVCI 


\section{LISTA DE TABELAS}

Página

Tabela 1 - Associação entre idade e disfagia.

Tabela 2 - Assoaciação entre gênero e disfagia

Tabela 3 - Associação entre escore obtido no National Institutes of Health Stroke Scale (NIHSS) e disfagia.

Tabela 4 - Associação entre escore obtido na escala de coma de Glasgow e disfagia

Tabela 5 - Associação entre alteração de comunicação e disfagia.

Tabela 6 - Associação entre topografia da lesão e disfagia.

Tabela 7 - Associação entre hemisfério cerebral e disfagia

Tabela 8 - Associação entre topografia da lesão, escore do NIHSS e disfagia.

Tabela 9 - Resultados da curva ROC, valores preditivos positivos e preditivos negativos 


\section{LISTA DE GRÁFICOS}

Página

Gráfico 1 - Curva ROC relacionando o escore do NIHSS e disfagia.

70

Gráfico 2 - Sensibilidade e especificidade relacionadas ao escore do NIHSS............ 


\section{ABREVIATURAS E SIGLAS}

AIT: Ataque isquêmico transitório

AO: Abertura ocular

AVC: Acidente vascular cerebral

AVCH: Acidente vascular cerebral hemorrágico

AVCI: Acidente vascular cerebral isquêmico

DCV: Doença cerebrovascular

ECG: Escala de coma de Glasgow

HAS: Hipertensão arterial sistêmica

HIV: Human Immunodeficiency Virus

MRM: Melhor resposta motora

MRV: Melhor resposta verbal

NIHSS: National institutes of health stroke scale

NINDS: National institutes of neurological disorders and stroke

RAPIDS: Royal Adelaide prognostic index for dysphagia stroke

SNC: Sistema nervoso central

TOAST: The trial of org 10172 in acute stroke treatment 


\section{SUMÁRIO}

Página

\section{Resumo}

\section{Abstract}

Listas

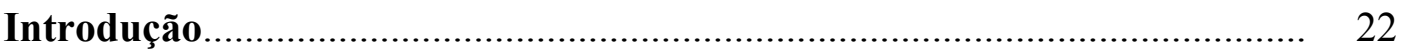

Acidente vascular cerebral................................................................ 23

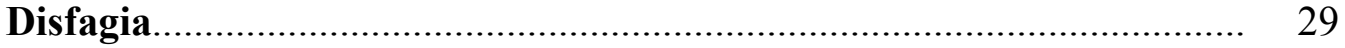

Acidente vascular cerebral e Disfagia................................................. 37

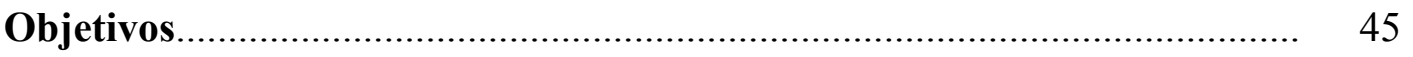

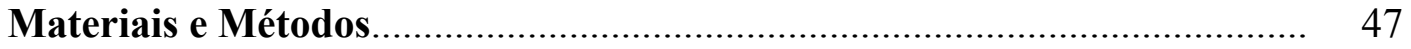

Considerações Éticas....................................................................... 48

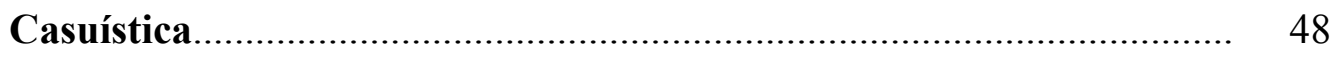

Procedimentos Realizaos.................................................................... 49

Análise dos Dados...................................................................... 55

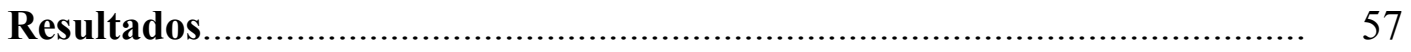

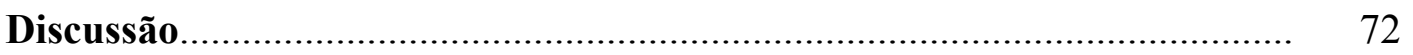

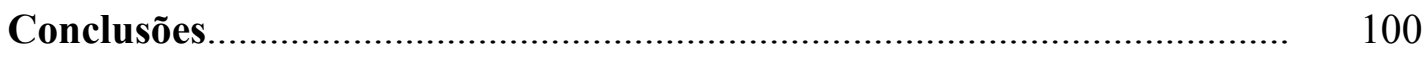

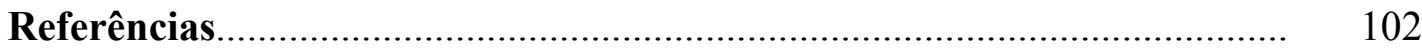

Bibliografia Consultada..................................................................... 113

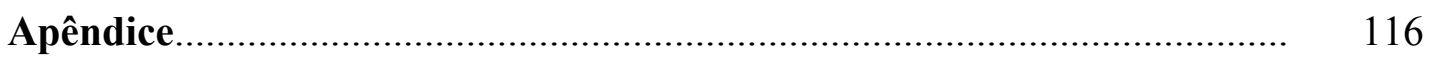

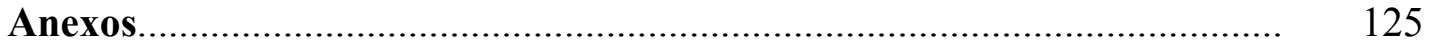




\section{ACIDENTE VASCULAR CEREBRAL}

As doenças do aparelho circulatório acarretam altas taxas de mortalidade no Brasil, sendo que, em relação a cerca de $60 \%$ dos óbitos informados no país em 1998, estas constituíram 32,4\% das causas. Este grupo é liderado pelas doenças cerebrovasculares (DCV) que apresentam um índice de mortalidade de 51,6 por 100.000 habitantes (MINISTÉRIO DA SAÚDE - INDICADORES E DADOS BÁSICOS - BRASIL, 2006). Dentre as DCV, destacase o acidente vascular cerebral (AVC).

As DCV representam uma causa importante de morbidade e invalidez, fazendo do AVC a causa principal de incapacidade neurológica e crônica na população adulta (ANDRÉ, 1999; CAMBIER; MASSON; DEHEN, 1999; KELLEY, 2003).

O AVC é definido como insulto do sistema nervoso central (SNC) cuja etiologia primária é vascular. Essa definição abrange os acidentes vasculares dos hemisférios cerebrais, das estruturas subcorticais, do tronco cerebral, do cerebelo e da medula espinhal. Existem dois grupos principais de AVC: o primariamente isquêmico (AVCI) e o primariamente hemorrágico (AVCH). O AVCI é responsável por, aproximadamente, $80 \%$ dos casos, compreende a embolia cerebral (aproximadamente 30\%), a trombose de grandes artérias (cerca de 30\%) e a trombose de pequenos vasos arteriais (aproximadamente 20\%), a qual também é conhecida como derrame do tipo lacunar. A segunda grande categoria de AVC, representada pelo $\mathrm{AVCH}$, corresponde, aproximadamente, a $20 \%$ dos casos e compreende as hemorragias intracerebrais (cerca de 14\%) e as hemorragias subaracnóideas (em torno de 6\%) (KELLEY, 2003).

O ataque vascular cerebral pode ser definido como um déficit neurológico focal súbito devido a uma lesão vascular. Este termo evoluiu nas últimas décadas para incluir lesões 
causadas por distúrbios hemodinâmicos e da coagulação, mesmo que não se tenham alterações detectáveis nas artérias ou veias (ANDRÉ, 1999).

A circulação cerebral depende fundamentalmente de dois sistemas nutridores: o sistema carotídeo, dominante e responsável pela irrigação dos três quartos anteriores dos hemisférios cerebrais, através das artérias cerebrais anterior e média e da artéria coroideana anterior; e o sistema vertebrobasilar, que vasculariza o tronco cerebral, cerebelo, e a porção posterior dos hemisférios cerebrais através da artéria cerebral posterior. Estes dois sistemas anastomosam-se na base do encéfalo, para formar o polígono de Willis (ANDRÉ, 1999; CAMBIER; MASSON; DEHEN, 1999; KELLEY, 2003; NOBRE, 2004). Este oferece, assim, uma passagem à circulação de um lado a outro (CAMBIER; MASSON; DEHEN, 1999).

A apresentação clínica e a evolução de pacientes com lesões nos territórios destes dois sistemas diferem substancialmente, sendo importante sua distinção precoce (CAMBIER; MASSON; DEHEN, 1999). A localização e extensão do AVC é de grande importância no que se refere às manifestações decorrentes do mesmo, assim como os fatores de prognóstico. Por exemplo, os AVCs dos hemisférios cerebrais podem manifestar-se por cefaléia, alteração do estado de consciência, distúrbios de linguagem (incluindo a afasia e a disartria), falhas homônimas dos campos visuais, comprometimento das funções cognitivas (incluindo apraxia e agnosia), assim como a disfunção sensitivo-motora no dimídio oposto. Os sintomas e sinais referentes ao tronco cerebral ou cerebelo consistem em disartria, disfagia, ataxia, diplopia, vertigens, náuseas, diversos tipos de nistagmo e crises de queda súbita, sobretudo quando existe uma combinação de vários desses sintomas. Além disso, a presença de certas manifestações clínicas facilita a localização da lesão cerebral (KELLEY, 2003).

Um sistema para categorização dos subtipos de AVCI principalmente baseado na etiologia foi desenvolvido pelo The Trial of Org 10172 in Acute Stroke Treatment (TOAST), descrevendo cinco subtipos de AVCI: ateroesclerose de grande artéria, cardioembolismo, 
oclusão de pequenos vasos, AVC de outras etiologias determinadas e AVC de etiologia indeterminada. Este sistema de classificação é fácil de ser utilizado e tem uma boa concordância interobservadores, permitindo aos investigadores descrever respostas ao tratamento entre importantes subgrupos de pacientes com AVCI (ADAMS et al., 1993).

Muitos pacientes têm recuperado sua função neurológica após o AVCI, mas o conhecimento do tempo de curso e de extensão da recuperação é limitado (WITYK et al., 1994).

Para a avaliação clínica do paciente com acometimento neurológico, várias escalas podem ser utilizadas para estabelecer o grau de comprometimento. Dentre elas, cita-se a escala de coma de Glasgow (ECG), inicialmente criada para avaliar o nível de consciência depois de trauma encefálico, também é aplicada a outras diferentes situações; e a escala de AVC proposta pelo National Institutes of Health, utilizada, exclusivamente, a pacientes que sofrerem esta injúria.

A ECG foi publicada em 1974 por Graham Teasdale e Bryan J. Jenett, professores de neurologia da University of Glasgow.

É uma escala neurológica que mostra uma forma confiável e objetiva de avaliar o estado de consciência de uma pessoa, de modo inicial ou na avaliação contínua. Seu valor também é de grande utilidade na previsão de eventuais seqüelas. O paciente é avaliado pelos critérios da escala, contendo: abertura ocular (AO), melhor resposta verbal (MRV) e melhor resposta motora (MRM). O resultado apontado, que varia de 3 a 15, fornece o escore da ECG, realizando-se após, a interpretação desta pontuação. Um escore menor que 8 é comumente aceito como ponto crítico das alterações do nível de consciência e como a pontuação que define um indivíduo em estado de coma.

O National Institutes of Health elaborou uma escala de gravidade do AVC, o NIHSS (National Institutes of Health Stroke Scale), para servir de indicador objetivo do grau de 
deficiência que o paciente apresenta no primeiro exame. É uma escala de medida de déficits do AVC agudo durante uma triagem, aceito amplamente como instrumento clínico.

A escala é simples, válida, reprodutível e segura. Permite a obtenção de sinais neurológicos e a identificação de mudanças clínicas ou resposta potencial à terapêutica (BROTT et al., 1989; LYDEN et al., 1999). É uma medida quantitativa de déficits neurológicos relacionados ao AVC com credibilidade e validade estabelecida para o uso em pesquisas clínicas prospectivas (KASNER et al., 1999; WILLIAMS; YILMAZ; LOPEZ-YUNEZ, 2000).

Inicialmente foram descritos 15 itens de avaliação neurológica e 51 itens de pontuação, incluindo nível de consciência, movimento dos olhos, déficits do campo visual e envolvimento sensório e motor (BROTT et al., 1989; LYDEN et al., 1999).

Muitas versões foram feitas a partir de modificações do NIHSS original visando sua aplicabilidade em estudos distintos, porém a escala mais utilizada é a escala simplificada do NIHSS descrita por Lyden et al. (1999), que constitui de 15 itens selecionados tendo uma pontuação máxima de 42 pontos.

O exame pode ser realizado rapidamente, requerendo uma média de, aproximadamente, 6 minutos (BROTT et al., 1989) e pode ser facilmente aplicado por médicos e não médicos, requerendo pouco treino (GOLDSTEIN; SAMSA, 1997; LYDEN et al., 1999; GOLDSTEIN et al., 2001).

Algumas críticas são feitas à escala. Woo et al. (1999) descreveram que dos 42 pontos dos escores do NIHSS, sete estão diretamente relacionados à avaliação da linguagem quando comparados apenas com dois pontos relacionados a negligência. Sendo esta, portanto, mais sensível a lesões localizadas no hemisfério esquerdo (dominante para a linguagem).

Entretanto, vários pesquisadores estudaram a aplicabilidade e validade do NIHSS (ADAMS et al., 1999; LYDEN et al., 1999). Lyden et al. (1999) utilizaram dados do National Institutes of Neurological Disorders and Stroke (NINDS) tPA Stroke Trial para determinar se 
o NIHSS era válido quando aplicado em pacientes tratados com o ativador de plasminogênio tecidual e para explicar a estrutura clinimétrica básica do NIHSS. Concluíram que a escala parece ser válida em pacientes com AVC agudo e para achados de diferenças relacionadas ao tratamento. A escala foi válida quando utilizada serialmente na fase aguda, após três meses, e demonstrou boa concordância com o resultado de outras escalas.

Adams et al. (1999) compararam o escore do NIHSS como preditor de prognóstico no período de sete dias a três meses do AVC isquêmico. Concluíram que o escore do NIHSS fornece informação diagnóstica podendo ser utilizado por médicos, pacientes e familiares, permitindo também ser utilizado como critério de inclusão ou exclusão de pacientes em tratamentos para AVC. Os dados demonstraram que pacientes com comprometimentos graves (escore do NIHSS > 15) têm menos que $20 \%$ de chance de obter uma recuperação excelente. Concluíram então, que, até o momento, o escore do NIHSS continua sendo o preditor mais poderoso de probabilidade da recuperação de um paciente após o AVCI. Um escore $\geq 16$ prediz uma alta probabilidade de morte ou severa incapacidade, enquanto que um escore $\leq 6$ prediz uma boa recuperação. Os dados demonstraram que a linha de base para o escore do NIHSS correlaciona fortemente com os subtipos diagnósticos proposto pelo TOAST. Em geral, pacientes com AVC lacunar têm menor escore quando comparados com AVC de outras causas e apenas este subtipo, segundo a classificação de TOAST, apresenta prognóstico de recuperação independente do escore do NIHSS. Em particular, os exames de imagem devem fornecer informações adicionais na avaliação clínica de pacientes que apresentam escores do NIHSS nos extremos da escala $(<5$ ou $>15)$.

Apesar do uso freqüente da escala de classificação clínica em estudos multicêntricos terapêuticos de triagens de AVC, geralmente não existiam métodos aceitáveis para treinar e certificar investigadores com o uso de instrumentos consistentes. Lyden et al. (1994) propuseram um treino para examinadores através do método de um videotape como tarefa 
efetiva, para padronização do exame, oferecendo um certificado aos examinadores antes da aplicação clínica.

Para tanto, foram produzidas três fitas. A primeira consiste em 45 minutos de programa de treinamento (training tape) e a $2^{\mathrm{a}}$ e a $3^{\mathrm{a}}$ são para certificação (certification tapes 1 e 2). Foram filmados cinco pacientes na primeira fita de certificação e seis pacientes na segunda e utilizados 4 examinadores diferentes para o total de 11 pacientes.

Os autores concluíram que esse método de treino é uma tarefa efetiva para treinar neurologistas e não-neurologistas ao uso breve, exame padronizado e então, certificar os investigadores antes de iniciar a triagem clínica. Essa certificação pode ser usada para demonstrar adequação do processo de treinamento e sugerir modificações futuras na escala necessárias à melhora da reprodutibilidade e acurácia (LYDEN et al., 1994).

Originalmente, o NIHSS foi projetado pelo National Institutes of Health e o material de vídeo utilizado foi desenvolvido pelo NINDS. Este criou o primeiro currículo eletrônico de acesso livre ao público, validado e desenvolvido especificamente para o uso na internet visando o treinamento da escala e a certificação para sua aplicação ${ }^{1}$.

O programa consiste de um módulo de instrução/demonstração e de um módulo de certificação, consistindo na avaliação de seis pacientes. Ao término deste último módulo, há a certificação de conclusão, em que o examinador deverá ser capaz de compreender os itens de avaliação da escala para quantificar déficits em pacientes com AVC, identificar e avaliar os déficits neurológicos, aplicar consistentemente os escores apropriados para estes déficits e utilizar a escala para avaliar mudanças contínuas nos quadros neurológicos.

\footnotetext{
${ }^{1}$ http://nihss-english.trainingcampus.net/uas/modules/trees/windex.aspx
} 


\section{DISFAGIA}

A deglutição normal é uma complexa e dinâmica atividade neuromuscular que depende de um conjunto de comportamentos fisiológicos resultando no transporte eficiente e seguro de alimentos da boca até o estômago (DRAY; HILLEL; MILLER, 1998; MACEDOFILHO, 1998).

Os componentes corticais da dinâmica da deglutição são responsáveis pela programação e organização do sincronismo das atividades motoras, sendo que estas informações serão posteriormente conduzidas por alguns nervos encefálicos ao sistema muscular.

Participam da função da deglutição estruturas rígidas compostas por ossos como o hióide, o esfenóide, a mandíbula e as vértebras cervicais; músculos e tecidos: músculos constritores faríngeos, palato mole, língua, epiglote, esôfago, cartilagens cricóide e tireóide e os músculos do pescoço; e nervos cranianos como o trigêmeo ( $\mathrm{V}$ - motor e sensitivo), o facial (VII - motor e sensitivo), o glossofaríngeo (IX - motor e sensitivo), o vago ( $\mathrm{X}$ - motor e sensitivo), o hioglosso (XII - motor) e o espinal-cervical 1-3 (motor). Considerando a necessidade do pescoço estar bem posicionado para uma deglutição harmoniosa, participa também dessa função, o nervo acessório (XI - motor) (MARCHESAN, 1999).

A deglutição é um processo contínuo, mas, para melhor compreensão, pode ser dividida em três fases: a oral, a faríngea e a esofágica. A fase oral é, principalmente, voluntária. Alimentos sólidos são triturados pelos dentes e misturado a saliva, lubrifica o alimento triturado e permite que fragmentos, na textura apropriada para a deglutição, já lubrificados, sejam moldados dentro de um bolo. Após essa etapa, há o transporte do bolo para a faringe. É na fase oral também, que se inicia o processo de absorção dos nutrientes 
(LOGEMANN, 1990; SHAY; SHIP, 1995; ZOHAR et al., 1998). O reflexo palatal previne que o alimento entre na nasofaringe. Diferentes texturas são deglutidas diferentemente. Os alimentos são contidos dentro da cavidade oral por uma criação de pressão subatmosférica, e através da força da língua contra o palato duro, o alimento é propelido para dentro da faringe em duas outras fases (ZOHAR et al., 1998).

Durante a primeira fase, a língua é moldada dentro de um sulco longitudinal pelos músculos longitudinal superior e genioglosso. Este sulco torna-se um espaço tubular quando o palato duro e a língua ficam em contato. O dorso da língua é forçado para cima pela contração do músculo lingual transverso. O alimento é forçado para trás e para dentro da faringe. A segunda fase se inicia com os dentes se ocluindo, a contração do milohióide, e a suspensão do assoalho bucal. A parte posterior da língua é forçada para trás dentro da faringe, empurrando o alimento para dentro da faringe. A fase faríngea é um mecanismo reflexo controlado por receptores localizados na parede posterior da faringe, pelas tonsilas e a base da língua, os quais são estimulados pelos alimentos. As aberturas pertencendo à via aérea, à nasofaringe e à laringe devem ser fechadas quando o alimento passa através do sistema alimentar para prevenir a passagem do bolo para dentro da via aérea. Isso resulta da ação do esfíncter nasofaringeal e laríngeo. A respiração em inibição reflexa é seguida pelo fechamento velofaríngeo, fechamento glótico e elevação laríngea com deslocamento anterior (ZOHAR et al., 1998).

Shay e Ship (1995) acrescentaram, ainda, que três tarefas fisiológicas essenciais são realizadas pela cavidade oral: o início da alimentação, a produção da fala e a proteção contra bactérias.

Dodds, Logemann e Stewart (1990a) subdividiram a deglutição em quatro fases: preparatória, oral, faríngea e esofágica. A fase preparatória envolve a mastigação de um bolo alimentar e o mistura com a saliva. O bolo alimentar é moldado (formado) e posicionado na 
língua prontamente para a deglutição. Durante a fase oral, o bolo é propelido da cavidade oral para dentro da faringe. A fase faríngea envolve o transporte do bolo alimentar da orofaringe para dentro do esôfago. Logemann (1990) descreveu que o estímulo exato necessário e mecanismos sensoriais usados no disparo da deglutição faríngea não são claramente definidos.

A deglutição requer controle neuromuscular fino de estruturas na cavidade oral, faringe, laringe e esôfago para que o alimento seja reduzido a uma consistência apropriada e que possa ser transportado da boca ao estômago (LOGEMANN, 1990).

Vários são os fatores envolvidos na deglutição. Podem ser importantes o tamanho da partícula e a quantidade do alimento na boca, em parte da saliva e outra do próprio alimento, bem como o gosto e a forma deste (SILVA-NETTO, 2003).

Qualquer interrupção no processo da deglutição pode ocasionar dificuldades, levando a um quadro caracterizado como disfagia que, em algumas condições, pode ser a primeira manifestação clínica da doença (FEIJÓ; RIEDER, 2003).

Os sintomas mais freqüentes de alterações nas fases oral e faríngea da deglutição incluem dificuldade de iniciar a deglutição, disfagia cervical, regurgitação nasal, tosse e engasgos. Anormalidades funcionais nas fases preparatória e oral da deglutição são causadas por movimentos anormais de língua e, ocasionalmente, pela alteração no tecido mole da língua ou cavidade oral, incluindo uma dificuldade em formar o bolo ou mantê-lo acima da língua. Normalmente, a fase oral da deglutição passa por uma tranqüila transição a uma rápida fase faríngea com transporte do bolo através da faringe. Em alguns pacientes, entretanto, a fase faríngea pode ser mais lenta.

Um número de fatores pode contribuir para alteração no transporte do bolo na fase faríngea: ausência ou redução do movimento hióide, ausência ou redução do movimento laríngeo, movimento palatal inadequado, atraso ou ausência da fase faríngea, aumento 
unilateral de resíduo em valécula e/ou recessos piriformes, movimentos anormais de epiglote, penetração e/ou aspiração laríngea e abertura anormal do esfíncter esofágico superior. Nesse último, a incompleta abertura pode prejudicar o transporte do bolo, levando a um excessivo resíduo faríngeo, e causando aspiração tardia. O movimento anterior lento do hióide pode contribuir para uma abertura incompleta desse esfíncter, mas isso, raramente, ocorre como um achado isolado (DODDS; LOGEMANN; STEWART, 1990b).

Brandt (1986); Castell (1995); Hollinshed (1994); Marchesan (1995); Nasi et al. (1998) descreveram que a disfagia consiste na dificuldade de deglutir, em perda na progressão ordenada do alimento da boca para o estômago. Trata-se de um sintoma de uma doença em curso, podendo ocorrer em qualquer idade e se dar de forma imprecisa, lenta ou ambas. Pode ser classificada pela sua localização: alterações orofaríngeas, da boca até o esfíncter cricofaríngeo (disfagia orofaríngea ou alta), alterações esofágicas, abaixo do esfíncter cricofaríngeo (disfagia esofágica ou baixa).

Disfagia orofaríngea pode ser resultado de um número de problemas locais, neurológicos ou musculares. Alteração estrutural local como a disfunção do esfíncter esofágico superior ou divertículo faringoesofágico, ocorre quando a habilidade de transferir o alimento da boca ao esôfago é prejudicada. Disfagia esofageana é o resultado de qualquer obstrução mecânica (como tumor) do órgão ou alteração na motilidade que afeta a própria função muscular do esôfago. Tipicamente, a disfagia obstrutiva mostra-se como a dificuldade na deglutição de sólidos, progredindo ao líquido no curso da doença. A disfagia que resulta de disfunção neuromuscular, tipicamente, é apresentada com problemas na deglutição de líquidos e sólidos (GORMAN; MORRIS; KAISER, 1994).

A incoordenação do mecanismo da deglutição pode resultar em aspiração de alimentos ou regurgitação nasal. Assim, a disfagia orofaríngea, geralmente, é associada com tosse após a 
deglutição, dificuldade respiratória, infecção pulmonar (BRANDT, 1986), comprometendo tanto a parte respiratória do indivíduo como a sua nutrição (SANTINI, 1999).

Danos neurológicos ou estruturais e muitas outras doenças podem causar anormalidades em um ou mais dos eventos fisiológicos nos estágios oral e faríngeo da deglutição, criando problemas (LOGEMANN, 1990).

Hollinshed (1994) descreveu que existem muitas causas da disfagia como distúrbios neurológicos, musculares e da placa motora (AVC, traumas cranioencefálicos, doença de Alzheimer, outras demências, doença de Parkinson, distrofia muscular, miastenia gravis, entre outras), pós-operatórios e traumáticos, doenças congênitas, inflamatórias, degenerativas, etc. Quando estes são evidentes, a disfagia, muitas vezes, é vista como problema de importância secundária.

A disfagia pode ser causada por inúmeras doenças incluindo o AVC. Nestes pacientes, ela é caracterizada pela dificuldade em transportar, de forma segura, alimentos ou líquidos da boca até o estômago sem que haja aspiração, podendo envolver dificuldade na fase oral da deglutição, na preparação do bolo, como dificuldade na mastigação e nos movimentos de língua (SCOTTISH INTERCOLLEGIATE GUIDELINES NETWORK, 2004).

Terré e Mearin (2006) descreveram que, além da qualidade de vida, pacientes com disfagia também têm prejuízo quanto ao seu prognóstico.

A disfagia pode causar aspirações silenciosas que não são percebidas e, com isso, o alimento ou a saliva entra no canal aéreo e, em seguida, nos pulmões. A princípio isto não causa nenhum sintoma, mas, ao longo do tempo, pode ocorrer edema pulmonar ou crescimento de germes patológicos, que causam pneumonia. A aspiração pode ter conseqüências graves e até mesmo fatais (MARCHESAN, 1995).

A pneumonia aspirativa é um fenômeno multifatorial e um preditor isolado não causa esta doença. Langmore et al. (1998) descreveram que disfagia e aspiração são necessárias, 
mas não são condições suficientes para o desenvolvimento de pneumonia. Fatores de risco que predispõem e contribuem na patogênese da pneumonia aspirativa foram identificados em quatro categorias maiores: status médico/saúde, status oral/dental, status funcional e status de alimentação/deglutição. Deve-se olhar além de um fator isolado, como a disfagia, e focar o tratamento em todos os fatores relevantes.

Logemann (2000) descreve que pelo fato da aspiração ser multifatorial, deve-se considerar: rebaixamento do nível de consciência, imobilidade, presença de sonda nasoentérica, traqueostomia ou ventilação mecânica, localização do AVC, redução da sensibilidade laríngea e tosse voluntária anormal.

Para McCullough, Wertz e Rosenbek (2001) a aspiração é um dos muitos sinais que definem a disfagia orofaríngea, sendo assim, a identificação de sua presença é de grande importância na avaliação clínica.

Uma vez que a disfagia é identificada, clínicos podem intervir na prevenção de aspiração utilizando variações na consistência dos alimentos (HINCHEY et al., 2005).

As dificuldades de deglutições podem ser avaliadas, clinicamente, por fonoaudiólogos e um exame instrumental (objetivo) pode ser necessário para sua elucidação diagnóstica.

A caracterização das alterações de deglutição deve ser realizada por uma avaliação clínica inicial, sendo de fundamental importância que esta preceda qualquer avaliação instrumental, pois, é através dela que obteremos dados relacionados à função, neste momento, comprometida.

Vários autores descrevem as limitações inerentes à avaliação clínica, referindo que não possibilita a observação da fisiologia da deglutição, além de não quantificar a aspiração (McCULLOUGH et al., 2005). Estes mesmos autores, em um estudo com 165 pacientes que sofreram AVCI, em um espaço de tempo de seis semanas, relacionaram sinais observados durante a avaliação clínica com a presença de aspiração confirmada durante a avaliação 
videofluoroscópica da deglutição. Concluíram que os resultados da avaliação clínica demonstraram uma probabilidade na detecção de aspiração através de sinais isolados ou associados entre si, fornecendo dados valiosos quando considerada a função da deglutição. Identificaram quatro importantes sinais de riscos para a aspiração como disartria, tosse voluntária insuficiente, tosse e mudança na qualidade vocal após a deglutição. Porém, os autores descreveram que ainda é necessária a realização de exames complementares para o direcionamento terapêutico e de outros trabalhos voltados à descrição destes dados não instrumentais.

Terré e Mearin (2006) estudaram 138 pacientes após a fase aguda do primeiro episódio de AVC, em média, três meses após o evento, realizando a avaliação clínica e videofluoroscópica da deglutição. Consideraram como fatores preditivos para disfagia, durante a avaliação clínica, a alteração no reflexo de vômito, presença de tosse durante a deglutição e mudança na qualidade vocal. Quando observados na videofluoroscopia encontraram correlação significativa entre alteração na qualidade vocal e penetração no vestíbulo laríngeo, não havendo correlação entre tosse e presença de aspiração. Não conseguiram correlacionar, com segurança, ausência de reflexo de vômito ou de sensibilidade de véu palatino com disfagia. Concluíram que a avaliação clínica à beira do leito foi imprecisa no diagnóstico de aspiração e aspiração silente e, na opinião destes, o exame de videofluoroscopia é essencial para a avaliação destes pacientes.

Apesar de não poder detectar todos os aspectos relacionados à disfagia, como a presença absoluta de aspiração laringotraqueal ou não, McCullough et al. (2005) descreveram que, na prática, a avaliação clínica da deglutição serve para muitos outros propósitos, alguns dos quais incluem a documentação da postura durante a alimentação, quantidade de alimento ingerido, eficiência da alimentação (tempo de consumo de uma refeição), necessidade de 
equipamentos adaptativos para a alimentação e prazer total decorrente do ato de comer e beber.

Os métodos objetivos mais solicitados e utilizados habitualmente por profissionais que trabalham com disfagia alta (orofaríngea) são a nasovideoendoscopia e a videofluoroscopia, que avaliam a dinâmica da deglutição, as estruturas anatômicas e possibilitam ao profissional a verificação do resultado das manobras facilitadoras posturais e de limpeza de recessos faríngeos, assim como a escolha da consistência do alimento mais adequado ao paciente. A avaliação endoscópica tem por finalidade observar as características da mucosa, avaliação estrutural e funcional da deglutição e a sensibilidade. Tem por objetivo localizar, topograficamente, as alterações mais evidentes e significantes durante a função da deglutição (MANRIQUE, 1999).

Hoje é conhecido que a videofluoroscopia é o método "gold standard" na detecção de alterações orofaríngeas da deglutição. Seu principal objetivo é determinar se o paciente pode alimentar-se de modo seguro por via oral, se apresenta condições de suprir suas necessidades nutricionais e de hidratação básicas, ou se é necessária a indicação de meios alternativos de alimentação. Ela é importante para o esclarecimento da presença de aspiração ou microaspiração (aspiração silenciosa), e também para a verificação do resultado das manobras facilitadoras posturais e de limpeza dos recessos faríngeos, assim como para a escolha da consistência de alimento mais adequado ao paciente. Este procedimento é indicado a pacientes com distúrbios neurológicos, do trato digestivo, submetidos à cirurgia de cabeça e pescoço ou que apresentem queixa de dificuldade de deglutição (GONÇALVES; VIDIGAL, 1999).

Outro método freqüentemente solicitado é a manometria, para elucidação diagnóstica de fenômenos motores que ocorrem no esôfago, espontaneamente ou em conseqüência de 
estímulos. Sua maior indicação ocorre para o paciente com disfagia quando os exames radiológico e endoscópico não foram completamente esclarecedores (DANTAS, 1998).

\section{ACIDENTE VASCULAR CEREBRAL E DISFAGIA}

A disfagia é claramente uma manifestação comum nos pacientes com AVC e apresenta um risco significante (PERRY; LOVE, 2001). Dentro deste contexto, a disfagia orofaríngea afeta mais da metade dos pacientes na fase aguda (SINGH; HAMDY, 2006), podendo ser um marcador independente de piora na recuperação após o AVC (SMITHARD et al., 1996).

Além de ser uma manifestação comum após o AVC, causa incapacidade, mas seu impacto no prognóstico a longo prazo para complicações potenciais e a recuperação da disfunção da deglutição permanecem incertos (MANN; HANKEY; CAMERON, 1999).

A ocorrência deste tipo de disfagia tem sido descrita em, aproximadamente, 30 a $42 \%$ de pacientes com AVC na fase aguda necessitando de internação. Desses pacientes, inicialmente acometidos, aproximadamente, 50\% apresentam recuperação espontânea para uma deglutição normal dentro de uma semana após o início do quadro (BARER, 1989; KIDD et al., 1995). Entretanto, esses pacientes que permanecem com dificuldades após a primeira semana mostram recuperação muito lenta da disfagia orofaríngea. A prevalência do diagnóstico clínico da disfagia em pacientes no primeiro mês após o AVC tem sido descrita entre 2 a $21 \%$ e pode permanecer em 7\% dos pacientes após três meses de AVC (BARER, 1989; KIDD et al., 1995; TEASELL; BACH; McRAE, 1994). 
Kidd et al. (1995) estudaram 60 pacientes com AVC admitidos no hospital dentro de 72 horas através da avaliação clínica e videofluoroscópica e acompanharam estes pacientes em tempos distintos de evolução (sete e 14 dias; e ainda uma reavaliação foi feita três meses após) visando observar a história natural e conseqüências clínicas da aspiração nestes pacientes. Os resultados constataram que, na primeira avaliação, 25 (42\%) apresentaram disfagia, $10(19 \%)$ persistiram com o sintoma após uma semana e apenas quatro (10\%) apresentaram disfagia após duas semanas. Na reavaliação após três meses, apenas três ainda apresentavam este quadro. Os resultados também demonstraram que muitos pacientes com disfagia na fase aguda do AVC que aspiravam tinham essa manifestação acompanhada com redução da sensibilidade faríngea e severidade do AVC. A aspiração silenciosa estava presente em cinco (8\%) pacientes. Concluíram que a disfagia tende a ser resolvida nos 14 dias que sucedem o AVC e sua presença, provavelmente, reflete no aumento da severidade do AVC.

É sabido que problemas de deglutição seguidos do AVC são comuns, sendo descrito que a disfagia pode persistir, recorrer em alguns pacientes, ou ser desenvolvida durante o curso da doença, pois muitos pacientes recebem medicações durante sua hospitalização que podem rebaixar o nível de consciência e aumentar os riscos de aspirações. Em um estudo prospectivo de 121 pacientes com AVC avaliados dentro de 24 horas do início do quadro, encontrou-se que 51\% destes apresentaram risco de aspiração na sua admissão hospitalar; muitos problemas foram solucionados em sete dias, embora ainda alguns pacientes $(27 \%)$ tenham persistido com riscos de aspirarem; acima de seis meses, a maioria dos problemas tinha sido solucionada, $6 \%$ apresentavam dificuldades persistentes e $3 \%$ desenvolveram dificuldades com a evolução do quadro de AVC até seis meses (SMITHARD et al., 1997).

Smithard et al. (1998) realizaram um estudo prospectivo de 94 pacientes comparando a avaliação da deglutição padronizada à beira do leito por médicos e fonoaudiólogos com a 
videofluoroscopia. Encontraram que acima da metade dos pacientes estudados foram identificados como apresentando riscos de aspiração na deglutição após a avaliação fonoaudiológica e $41 \%$ após a avaliação médica.

Daniels et al. (1998) estudaram 55 pacientes com AVCI dentro de cinco dias do início do evento, através da avaliação clínica e videofluoroscópica da deglutição com o objetivo de determinar a freqüência e preditores clínicos de aspiração nestes pacientes. Observaram que a disfagia ocorreu em $36(65 \%)$ dos pacientes, sendo que $13(36 \%)$ tinham disfagia moderada a severa e severa, 10 (28\%) disfagia moderada e $13(36 \%)$ disfagia leve. O resultado do estudo sugeriu que muitos pacientes com AVC têm um alto risco de aspirarem dentro dos primeiros dias.

Broadley et al. (2005) realizaram um estudo para validar um indicador de prognóstico para disfagia em AVC denominado Royal Adelaide Prognostic Index for Dysphagia Stroke (RAPIDS) utilizando características clínicas e radiográficas. Encontraram que 53\% dos pacientes apresentaram disfagia, sendo que 34\% destes tinham disfagia transitória e recuperaram a função dentro de 14 dias, 19\% tinham disfagia prolongada.

Barros, Fábio e Furkim (2006) avaliaram 27 pacientes na fase aguda do AVC encontrando que 13 pacientes (48\%) apresentavam disfagia.

Singh e Hamdy (2006) descreveram que embora acima de metade dos pacientes com AVC apresentarão disfagia, muitos terão recuperado a função da deglutição dentro de um período de dias a semanas, sendo que dentro de um mês, muitos a realizarão de forma segura. A alta incidência e o notável índice de recuperação podem ser explicados pela distribuição bilateral do controle da musculatura da deglutição no córtex motor. Após um AVC hemisférico, a adaptação neuroplástica permite que o controle da musculatura da deglutição seja reorganizado pelo hemisfério cerebral não afetado. 
Langdon, Lee e Binns (2007) realizaram um estudo em 80 pacientes com diagnóstico de AVCI e constataram que há uma redução de $62,5 \%$ para $51,2 \%$ da presença de disfagia entre os pacientes, no período de uma semana do evento.

A disfagia é um problema comum e sério após o AVC envolvendo ambos hemisférios cerebrais ou o tronco cerebral. Devido ao fato do envolvimento dos nervos cranianos baixos na deglutição, muitos artigos pontuam que este mecanismo não é significativamente afetado em danos causados em um hemisfério cerebral isolado (BARER, 1989).

A aspiração decorrente das dificuldades de deglutição é um fenômeno transiente em muitos casos de AVC; está associada com uma alta incidência de infecção do trato respiratório baixo, mas a mortalidade encontrada em pacientes que apresentam este quadro não está significativamente associada nem com infecção do trato respiratório ou aspiração por si só (KIDD et al., 1995).

Os distúrbios respiratórios são as causas mais freqüentes de complicações no AVC. Broncopneumonia, pneumonia lombar, embolia pulmonar e acúmulo de secreção traqueobrônquica são os eventos mais freqüentes, todos podendo levar a insuficiência respiratória. A restrição ao leito, pouca movimentação, limitada expansão da caixa torácica, disfagia, uso de sonda naso-gástrica e instituição de ventilação mecânica são os fatores responsáveis pela alta incidência de infecções respiratórias nestes pacientes (RADANOVIC, 2000).

A pneumonia é uma importante complicação do AVCI e aumenta a mortalidade em três vezes. Acredita-se que esta complicação possa ser atribuída à aspiração de secreção oral ou de alimentos ingeridos por via oral na presença de graus variados de disfagia. A estimativa de que estas mortes seriam imputadas à presença de pneumonia, poderia ser afastada se àqueles pacientes que apresentassem quadros de $\mathrm{AVC}$ relacionados a disfagia fossem cuidadosamente avaliados e medidas preventivas fossem tomadas (HINCHEY et al., 2005; KATZAN et al., 2003). 
Muitos fatores, incluindo a severidade do AVC, nível de consciência, função pulmonar pré-mórbida, capacidade de tosse, mobilidade, higiene oral e freqüência da aspiração, contribuem para o desenvolvimento da pneumonia aspirativa (SMITH et al., 2000).

A investigação clínica do paciente logo após o AVC é fundamental, e sinais como disfonia, dificuldades na deglutição de saliva ou alimentos e estado de alerta diminuídos sugerem grande risco de aspiração e de complicações respiratórias (SANTINI, 1999).

Como visto, há grande incidência de distúrbios de deglutição durante a fase aguda do AVC e, conseqüentemente, de aspiração e desenvolvimento de pneumonia, sendo importante sua complicação no quadro, resultando em aumento do tempo de hospitalização e morte (LANGDON; LEE; BINNS, 2007; LOGEMANN, 2000; PACIARONI et al., 2004; SINGH; HAMDY, 2006; TEASELL et al., 2002; TERRÉ; MEARIN, 20060).

Diferentes impactos podem ocorrer após o AVC incluindo, assim, a disfagia como dificuldade de alimentação em uma longa perspectiva. As dificuldades de alimentação são conseqüências comuns seguidas deste quadro neurológico e podem causar complicações como má nutrição, desidratação, aspiração, sufocamento, pneumonia e morte (MANN; HANKEY; CAMERON, 1999; SMITHARD et al., 1996; WESTERGREN, 2006). Desta forma, a detecção de eventual disfagia é de fundamental importância com o propósito de adotar condutas adequadas para que estas sejam compensadas. Para isto, é necessário um método simples de avaliação à beira do leito, aplicável no dia-a-dia da prática clínica (WESTERGREN, 2006).

Muitos pacientes com AVC, felizmente, se recuperam e a disfagia melhora significativamente ou desaparece após dias ou semanas. Apesar disso, a maioria dos estudos que avaliam esta função foi realizada pouco tempo após o episódio de AVC, enquanto pouca informação existe na fase pós aguda em pacientes sem recuperação, como sendo, mais adiante, propensos a complicações recorrentes (TERRÉ; MEARIN, 2006). 
As estimativas quanto à prevalência da disfagia no AVC têm essa variabilidade, entre outras, devido às diferenças na definição da disfagia, métodos de avaliação da função, relação entre o tempo de AVC e a avaliação da deglutição, número e tipo de AVC estudados (PACIARONI et al., 2004).

Diversas medidas gerais devem ser adotadas diante do paciente que apresenta o quadro completo do infarto cerebral agudo. Dentre elas encontra-se a proteção das vias aéreas, adoção de precauções contra a aspiração e exame da capacidade de deglutição (KELLEY, 2003). Se essas medidas não forem, cautelosamente, adotadas, o período de hospitalização de pacientes se estende, aumentando os riscos de infecções e outras intercorrências, além do custo de manutenção desse paciente no âmbito hospitalar.

A disfagia, portanto, tem implicações prognósticas e deveria ser avaliada em todos os pacientes apresentando sintomas de um AVC (SINGH; HAMDY, 2006).

A persistência das alterações de deglutição afeta o funcionamento físico e social, qualidade de vida para os pacientes e seus cuidadores, oportunidades de reinserção social e utilização de recursos de cuidados em saúde. Um problema persistente no estudo da disfagia em pacientes com AVC é a variabilidade na documentação de seus sintomas e o seu impacto funcional (CRARY; MANN; GROHER, 2005).

Dessa forma, fundamentando a importância da detecção de dificuldades de alimentação no paciente com AVC, consideramos de grande valor a indicação de meios alternativos de alimentação durante a fase aguda, objetivando a redução de complicações, quando evidenciado um quadro clínico sugestivo de dificuldades.

Bath, Bath e Smithard (2002) realizaram um levantamento bibliográfico através de pesquisa de artigos existentes, sendo a última revisão efetivada em 1999, a respeito de estudos realizados para o manejo de pacientes disfágicos com AVC, em particular, como deveriam se 
alimentar e como se deveria tratar a disfagia na fase aguda ou subaguda do AVC (até três meses) e confirmaram a existência de poucos relatos a respeito.

Nas últimas décadas, uma enorme variabilidade de recursos tem sido investida em pesquisas, no mundo todo, na tentativa de reduzir a morbidade e mortalidade dos pacientes com AVC. Várias modalidades terapêuticas têm sido preconizadas, todas objetivando minimizar o grau de lesão neuronal que ocorre após uma oclusão ou sangramento arterial (RADANOVIC, 2000).

Muitos estudos foram realizados utilizando a escala de AVC (o NIHSS), como indicador de recuperação (ADAMS et al., 1999), medidor de severidade e recuperação com a derivação da escala (TIRSCHWELL et al., 2002), estudos retrospectivos (KASNER et al., 1999; WILLIAMS; YILMAZ; LOPEZ-YUNEZ， 2000; BUSHNELL; JOHNSTON; GOLDSTEIN, 2001), progressão no AVC agudo (DeGRABA et al., 1999), como preditor de disposição hospitalar (SCHLEGEL et al., 2003) e a comparação com outras escalas (MUIR et al., 1996). Entretanto, nenhum estudo foi realizado com o intuito de caracterizar, com o uso do NIHSS, dificuldades de deglutição, embora seja conhecido que, na prática clínica, diversos quadros de pneumonias aspirativas nos quadros agudos de AVC, poderiam ser evitados se não fossem oferecidos alimentos aos pacientes com demasiada precocidade.

Embora o NIHSS seja uma escala amplamente aceita, abordando a avaliação clínica de diversos aspectos relacionados ao quadro neurológico, vemos que neste não é incluída a avaliação de uma função tão comumente encontrada nos quadros típicos de AVC: a deglutição. Por outro lado, outras escalas funcionais como a escala de Rankin e índice de Barthel modificado foram utilizadas em estudos sobre a presença de disfagia pós AVC (CRARY; MANN; GROHER, 2005).

As alterações de deglutição se encontram presentes na prática dos profissionais que atuam com pacientes neurológicos, especialmente naqueles que sofreram AVC, tornando de 
suma importância o estabelecimento de critérios de avaliação que facilitem a identificação dos achados clínicos, contribuindo para a definição de condutas apropriadas.

Vivemos em uma realidade em que a maior parte dos pacientes com AVC recebe o primeiro atendimento em centros onde não existem especialistas ou serviços de neurologia (RADANOVIC, 2000), dificultando a abordagem precoce neste paciente, minimizando as seqüelas neurológicas. Além disso, as alterações de deglutição são, muitas vezes, subestimadas, não sendo dada a devida atenção na fase aguda do AVC, mesmo quando estes pacientes são admitidos em centros hospitalares, onde, na falta do profissional capacitado para esta avaliação no momento da internação, são oferecidos alimentos por via oral ao paciente sem mesmo garantir se esta função foi prejudicada ou não.

Gresham (1990) avaliou 160 pacientes com AVC à beira do leito, num período de 24 horas de admissão hospitalar e iniciou a intervenção fonoaudiológica, quando necessária. Demonstrou que 54\% dos pacientes apresentaram alterações de deglutição, sendo estas identificadas como uma combinação de sintomas muito maior que a apresentação de um sintoma isolado. Destes pacientes com disfagia, $75,5 \%$ estavam se alimentando por via oral.

Assim, objetivamos com o uso do NIHSS, através de pontuações de itens hipoteticamente relevantes na avaliação da adequada deglutição e, considerando alguns fatores de risco na clínica apresentada por pacientes, propor, durante a fase aguda, a indicação de via alternativa de alimentação ou não, enquanto o paciente aguarda a avaliação fonoaudiológica da deglutição mais detalhada, com a formulação de um algoritmo. 


\section{OBJETIVO GERAL}

Nosso trabalho teve como objetivo, com o uso da escala de AVC, identificar fatores de risco para disfagia e propor a via mais segura de alimentação na fase aguda do AVCI.

\section{OBJETIVOS ESPECÍFICOS}

- Verificar a incidência de disfagia através da avaliação clínica fonoaudiológica.

- Avaliar se idade, gênero, escore do NIHSS e da ECG, alterações de fala e linguagem, topografia da lesão e hemisfério cerebral acometido poderiam caracterizar fatores de risco para dificuldades de deglutição, na determinação de presença ou não de disfagia.

- Determinar a sensibilidade e a especificidade do NIHSS na detecção de disfagia.

- Verificar a viabilidade da formulação de um algoritmo que possa auxiliar na melhor conduta quanto à via de administração da dieta. 
MATERIAIS E MÉTODOS 


\section{CONSIDERAÇÕES ÉTICAS}

Foi oferecida uma carta de informação da pesquisa aos pacientes e/ou responsáveis, sendo esclarecido todo o procedimento da avaliação, tendo todos os participantes assinado o termo de consentimento. O estudo foi analisado pelo Comitê de Ética em Pesquisa, sendo aprovado no processo HCRP n ${ }^{\circ} 8954$ / 2004.

\section{CASUÍSTICA}

Nossa casuística constituiu-se de um estudo transversal e prospectivo. Foram avaliados 50 pacientes internados na Unidade de Emergência do Hospital das Clínicas da Faculdade de Medicina de Ribeirão Preto da Universidade de São Paulo (UEHCFMRP-USP) com diagnóstico de AVCI confirmado, clinicamente, por um médico neurologista através da história clínica do paciente, avaliação neurológica e resultado de exames de imagem (tomografia computadorizada ou ressonância magnética) de acordo com a classificação do Trial of ORG 10172 in Acute Stroke Treatment (TOAST) idealizado para classificar pacientes de acordo com o subtipo de AVCI na prática clínica (GOLDSTEIN et al., 2001), dentro de, no máximo, 48 horas entre o início dos sintomas e a avaliação fonoaudiológica. Os pacientes foram avaliados, desde que se enquadrassem nos critérios propostos, sendo 25 do gênero feminino e 25 do masculino, com idade média de 64,90 anos (variação de 26 a 91 anos). Aqueles pacientes que não apresentavam indicação para a realização da avaliação clínica da deglutição foram incluídos no estudo com a aplicação somente do NIHSS e primeira parte do 
protocolo de avaliação clínica, sendo considerada, antecipadamente, a impossibilidade de alimentação por via oral.

Foram excluídos do estudo pacientes que apresentassem quadro de $\mathrm{AVCH}$ devido à diferença entre a severidade do quadro inicial e evolução clínica, idade inferior a 18 anos, história de dificuldades de deglutição anteriores ao quadro atual e tempo do início dos sintomas superior a 48 horas. Para tanto, os pacientes foram cuidadosamente triados através da anamnese (com o próprio paciente ou responsável) ou de revisão do prontuário médico, antes de sua participação no estudo.

\section{PROCEDIMENTOS REALIZADOS}

O estudo foi idealizado com a criação de um algoritmo que pudesse indicar, durante a fase aguda do AVC, a presença ou não de disfagia (figura1), considerando-se o escore da ECG, a presença de alterações da fala e linguagem, a topografia da lesão e o escore do NIHSS, constituindo-se, desta forma, um esquema para indicação ou não de via alternativa de alimentação nesta fase.

A ECG, embora tenha sido concebida para o uso em pacientes com trauma encefálico, é comumente utilizada como parte do exame neurológico nos centros de AVC, avaliando a abertura ocular, a resposta verbal e a resposta motora. Nesta escala, quanto maior sua pontuação, melhor estará o paciente, sendo a mínima de 3 pontos e a máxima de 15 . Portanto, para o algoritmo, considerou-se o escore de 14 ou 15. Nos pacientes que apresentam quadros de alterações de linguagem, a resposta motora pode ficar prejudicada. Nestes casos, observase, na prática clínica, que são desconsiderados os valores para a resposta verbal, adicionando à 
pontuação a letra "A", significando "afasia", ou, naqueles em que não há produção oral devido a um impedimento mecânico, como em pacientes traqueostomizados ou intubados, utilizam-se a letra "T" (traqueostomia, tubo).

Para a fala e linguagem, considerou-se a presença de disartria ou afasia leve, respectivamente, cuja denominação quanto ao grau de comprometimento é considerada pelo NIHSS, sendo adotado este critério, pois, supostamente, a probabilidade de se encontrar presença de disfagia nestes casos, é menor quando comparados a um comprometimento maior, ou seja, moderado e grave para ambos.

Na topografia da lesão, fez-se menção à divisão da vascularização cerebral, sendo que, poderia ser esperado que AVCs em território carotídeo tivessem menos chances de apresentarem disfagia em relação àquelas lesões em território vertebrobasilar.

A pontuação do NIHSS foi sugerida após a análise da escala pela pesquisadora e a neurologista responsável pelo Setor de Doenças Cerebrovasculares da Instituição onde foi realizado o estudo, sendo selecionados os itens que, hipoteticamente, poderiam influenciar na adequada função da deglutição ou itens que se relacionam com a extensão e território da lesão, como no acometimento da região vertebrobasilar, não sendo pontuados os demais itens. Para este estudo, utilizou-se a tradução e adaptação da escala de AVC do NIH proposta por Caneda et al. (2006), em concordância similar a de sua versão em inglês, inclusive de suas debilidades (anexo B).

Foram obtidos, para tanto, o escore $<12$ como referência para ausência de disfagia e $\geq$ 12 para a presença desta, tendo-se como território cerebral acometido a região carotídea. Para o acometimento de território vertebrobasilar, consideraram-se como todos apresentando fator de risco para presença de disfagia.

Voltando-se à escala, temos: item $1 \mathrm{a}=\mathbf{1}$, o rebaixamento do nível de consciência demonstra um fator de risco para disfagia; 1 e e 1c não pontuado (não predizem fator de 
risco); 2 = 1, já prediz em relação à extensão e localização da lesão (remetendo ao acometimento de mais de um terço da artéria cerebral média ou lesão de tronco cerebral); 3 não pontuado devido a correlação com área puramente visual; item $4=\mathbf{2}$, a presença de uma paralisia parcial (paralisia total ou quase total da face inferior) poderia interferir na função da deglutição, principalmente na fase oral desta; $5 a, 5 b, 6 a$ e $6 b=1$ para cada subitem, pois estão correlacionados com extensão e localização da lesão, totalizando 4 pontos; $7=\mathbf{1}$, prediz lesão cerebelar, portanto em região vertebrobasilar; item 8, não pontuado, pois avalia sensibilidade periférica, não tendo correlação com disfagia; $9=\mathbf{1}$, quadros leves e moderados de afasia podem levar a quadros concomitantes de disfagia quando comparados a sua incidência em afasias leves; $10=\mathbf{1}$, a presença de disartria leve a moderada, trazendo alterações oromiofuncionais, pode resultar em disfagia, comprometendo, em primeira instância, a fase oral da deglutição; $11=1$, prediz em relação à extensão e localização da lesão, tendo que a presença de heminegligências em lesões extensas envolvem hemisfério cerebral direito.

FIGURA 1: Proposta de algoritmo pra deteç̧ão de presença de disfagia grave na fase aguda do AVCI.

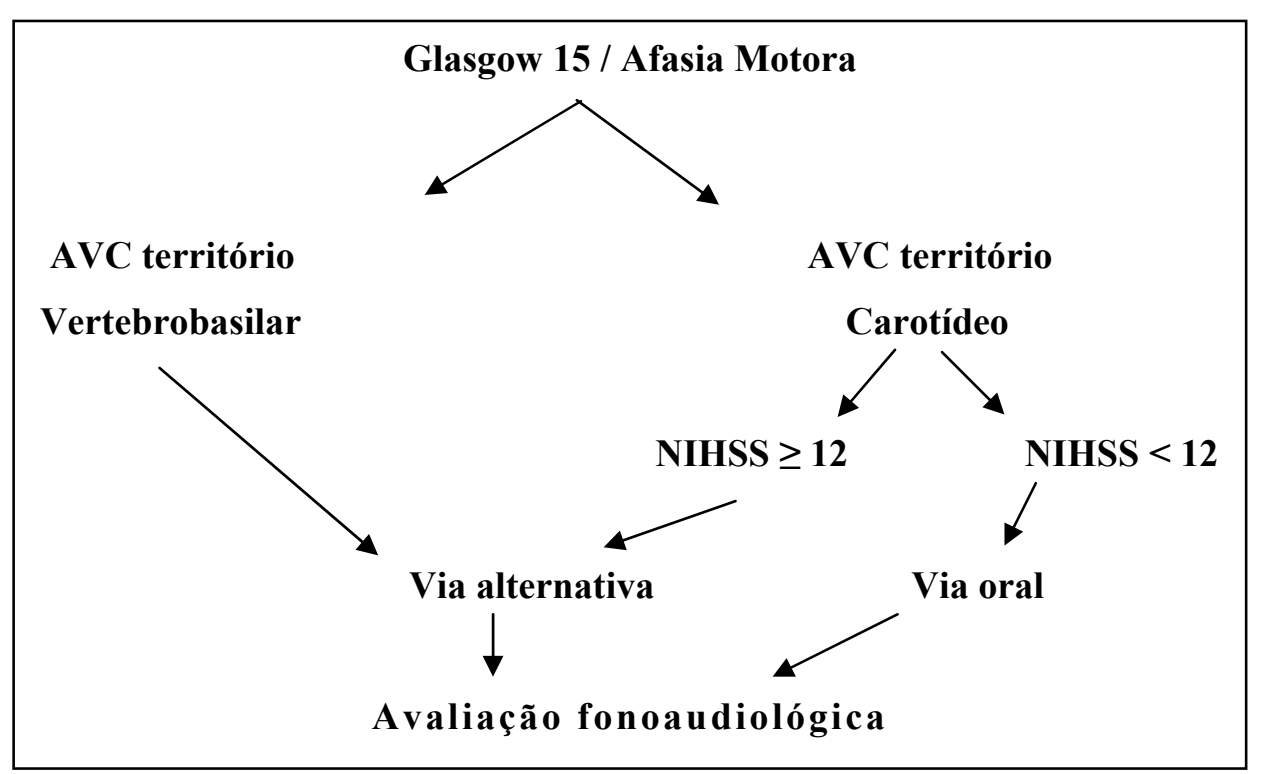


Para a realização do estudo, inicialmente, a pesquisadora realizou o treino on-line Media produced for the NINDS by training campus.com (TrainingCampus ${ }^{T M}$ ), para a aplicação da escala, no site $\underline{\text { www.nihstrokescale.org; } \quad \underline{\text { htp}} \text { ://nihss- }}$ english.trainingcampus.net/uas/modules/trees/windex.aspx, sendo certificada pelo National Institutes of Health.

A avaliação clínica foi realizada à beira do leito através de um protocolo constituído por uma primeira parte destinado a identificação do paciente contendo os dados pessoais referentes ao nome, data de nascimento, idade, data do início dos sintomas, data de entrada na Unidade de Emergência, escore da ECG e do NIHSS obtidos na avaliação neurológica inicial e no dia da avaliação, fatores de risco para AVC, achados clínicos obtidos na avaliação neurológica do paciente, resultado do exame de imagem (tomografia computadorizada ou ressonância magnética). A segunda parte foi destinada à escala do NIHSS sendo aplicada pela avaliadora e, por fim, a terceira parte constou da avaliação clínica da deglutição (apêndice B), sendo subdividida em estrutural e funcional.

A avaliação clínica da deglutição foi subdividida em duas partes. Esta, por sua especificidade, será descrita em maior detalhe.

A primeira parte foi relacionada à observação e avaliação de aspectos nutricionais, como a via de alimentação (jejum, via oral sem restrições, via oral com restrições, sonda nasoentérica ou nasogástrica, gastrostomia, jejunostomia, parenteral), presença ou não de complicações (desnutrição, desidratação); aspectos respiratórios (respiração espontânea, suporte de oxigênio, ventilação mecânica), presença ou não de afecções (pneumonia, doença pulmonar obstrutiva, insuficiência cardíaca crônica); nível de consciência (alerta, sonolento, confuso, estupor, coma); da comunicação (compreensão e expressão oral da fala e linguagem) obtidos através de conversa dirigida durante a anamnese ou da avaliação prévia do NIHSS; e das estruturas oromiofuncionais orofaciais. 
Nesta última foram observados dados de higiene oral, presença de dentes e/ou próteses dentárias assim como o estado de conservação dos mesmos; alterações de saliva (avaliação subjetiva); deglutição espontânea de saliva ou escape da mesma para fora da cavidade oral; força de língua avaliada com auxílio de uma espátula de madeira onde era solicitado que o paciente realizasse uma contra resistência a força realizada pela examinadora e, depois, que realizasse força de elevação de língua contra a espátula que a deprimia no assoalho bucal; mobilidade de língua para deglutição com a solicitação de realização de movimentos (lateralização de um lado e do outro, elevação e depressão com língua protruída); sensibilidade extra-oral, sendo solicitado que o paciente referisse a região dos lábios superiores, inferiores e da face que eram tocadas pela examinadora; sensibilidade de véu palatino, através do toque no palato mole pela espátula de madeira e mobilidade com a emissão de sons orais e nasais, consecutivamente, (/a/, /ã/); adequada elevação hiolaríngea ou não durante a deglutição de saliva; mímica facial (simetria ou assimetria); avaliação da tosse com a solicitação da mesma; qualidade vocal; e ausculta cervical antes da oferta de alimentos.

Para a avaliação funcional foram utilizadas as consistências alimentares pastosa, líquida e sólida (quando possível, dependo das condições apresentadas pelo paciente). O pastoso e o sólido foram oferecidos em volume controlado (utilizando-se uma seringa graduada, nos volumes de 3, 5 e $7 \mathrm{ml}$ ) e volume livre. O volume da oferta também dependeu das possibilidades apresentadas por cada paciente (viabilidade de aumento do volume ofertado, ou não). Para o sólido, utilizou-se uma bolacha do tipo maisena. Para o líquido foi oferecida água e, para o pastoso, utilizou-se uma "papa” (alimento na consistência pastosa), preparada pela diluição de $15 \mathrm{ml}$ de espessante alimentar Thick \& Easy ${ }^{\circledR}$ em $50 \mathrm{ml}$ de água. Nessa avaliação foram observados aspectos como vedamento labial, escape extra-oral dos alimentos, atraso ou não para iniciar a deglutição, perda prematura para hipofaringe (observada através da ausculta cervical), presença ou não de resíduos na cavidade oral após a 
deglutição, refluxo nasal, elevação hiolaríngea, presença de deglutições múltiplas, presença de pigarro, engasgos, tosse, fadiga, alterações respiratórias, mudança na qualidade vocal antes, durante e após a deglutição, necessidade do uso de manobras compensatórias para cada consistência oferecida. Antes, durante e após a oferta dos alimentos, foi realizada a ausculta cervical para obtenção de possíveis sinais clínicos sugestivos de penetração e/ou aspiração laríngea, caracterizando-a como sem alterações ou com alterações na presença destes.

Destaca-se aqui que, quando o paciente não colaborava ou não abria a boca para a avaliação, os itens cuja observação foi impossibilitada foram referidos como “impossível avaliar". Os pacientes que não apresentavam condições clínicas para a realização da avaliação, como os que se encontravam com intubação orotraqueal, estado de sonolência profunda ou em estado de coma, esta foi contra-indicada.

Após a avaliação clínica, com a obtenção dos dados estruturais e funcionais, concluiuse se havia alteração, ou não, ou seja, se a avaliação clínica da deglutição apresentava-se normal ou alterada.

Consideraram-se como sinais clínicos sugestivos de alteração da deglutição, a dificuldade de contenção oral, atraso no início da deglutição, dificuldade de propulsão do bolo, ausculta cervical alterada, mudança na qualidade vocal, presença de tosse, engasgos e/ou pigarro antes, durante ou após a deglutição, fadiga, alteração respiratória durante a alimentação e presença de deglutições múltiplas (SANTINI, 1999; SILVA, 1999; ZAFFARI, 2003), quando apresentados concomitantemente, não sendo necessária a presença de todos os sinais para caracterizá-la, além da confrontação destes achados com a condição clínica apresentada pelo paciente, principalmente, quanto ao nível de consciência. Concluiu-se como necessidade de indicação de via alternativa para a administração da dieta àqueles pacientes que apresentaram disfagia moderada e grave. Os que apresentaram alterações para determinado tipo de consistência foram referidos como um quadro leve de disfagia sendo 
sugerida a modificação da dieta ou realizada a orientação para controle de volume do alimento ingerido, quando esta se fez necessária, mantendo-se a alimentação por via oral.

O NIHSS contém a pontuação máxima de 42 pontos, e, ao contrário da ECG, quanto maior sua pontuação, maior será o grau de comprometimento do paciente. Permite a obtenção de dados relacionados a possíveis desordens neurológicas como nível de consciência, respostas verbais, respostas a comandos, melhor olhar conjugado, campo visual, paralisia facial, avaliação motora de mãos e pés, ataxia de membros, sensibilidade, negligência / inatenção, disartria, melhor linguagem (Anexo B).

A análise da topografia da lesão foi realizada através do resultado da tomografia computadorizada (TC) ou da ressonância magnética (RM) junto a um profissional capacitado para tal, sendo observado o acometimento em território cerebral carotídeo ou vertebrobasilar.

\section{ANÁLISE DOS DADOS}

Após a coleta dos dados e da avaliação à beira do leito nos pacientes internados, realizou-se a tabulação dos resultados obtidos de idade, gênero, escore do NIHSS, ECG, dados sobre comunicação dos pacientes, topografia de lesão, hemisfério cerebral acometido e resultado da avaliação clínica da deglutição.

Foi feita, inicialmente, a análise descritiva dos dados selecionados e, posteriormente, a associação entre as variáveis a fim de detectar grupos de risco para a presença de disfagia. Para tanto, cada variável foi correlacionada com a presença ou não de disfagia e, por fim, associou-se, juntamente a topografia de lesão e escore do NIHSS com disfagia. 
Para a análise estatística foi utilizado o procedimento PROC FREQ do software SAS (2002). Os dados de associação entre as variáveis com a necessidade de indicação de via alternativa foram analisados através do teste exato de Fisher, onde H0 não houve associação e H1 houve associação. Para avaliar se o escore do NIHSS caracterizava um indicador de fator de risco para a disfagia, foi construída a curva ROC (receiver operational characteristic curve), visando obter características quanto à sensibilidade e especificidade da escala para este propósito. Depois de obtidos os valores de sensibilidade e especificidade, foram calculados os valores preditivos positivos e os preditivos negativos, a fim de verificar a presença de resultados falsos-positivos e falsos-negativos para o corte do NIHSS sugerido no estudo. $\mathrm{O}$ valor preditivo positivo (VPP) é a probabilidade que uma pessoa tem de apresentar o evento dado que o resultado do teste empregado foi positivo. O valor preditivo negativo (VPN) é a probabilidade que uma pessoa tem de não apresentar o evento dado que o resultado do teste empregado foi negativo (GOMES, 2005).

Nas tabelas são fornecidos valores da freqüência de pacientes e freqüência relativa (\%). Foram considerados significativos valores de $\mathrm{p}<0,05$. Para a análise dos dados, foram referidos valores de 1 para ausência de disfagia e 0 para presença. 
Dos 50 pacientes avaliados, 16 (32,00\%) apresentaram disfagia. A caracterização dos pacientes, quanto as suas idades, escore obtido na aplicação no NIHSS, escore da ECG retirado do prontuário médico de cada paciente, a comunicação, topografia da lesão após a análise dos exames de imagem realizada por um neurologista junto à pesquisadora obtendo assim o hemisfério cerebral acometido e, por fim, o resultado da avaliação clínica da deglutição estão demonstrados no apêndice C.

Em cinco pacientes $(12,29,31,38$ e 49) não foi possível a realização da avaliação da comunicação, devido ao rebaixamento do nível de consciência, onde todos estes se encontravam em estado de coma, sendo considerados como apresentando quadro de comprometimento grave desta, como sugerido pelo NIHSS.

Fazendo referência a topografia da lesão, não foi possível a definição desta em quatro pacientes. Entretanto, estes apresentavam síndrome lacunar clássica associada com fator de risco (HAS, tabagismo, etilismo, AVC prévio, diabete melito), sendo incluídos, pela classificação do TOAST (GOLDSTEIN et al., 2001), como exames de imagem normais ou doença de pequenos vasos inespecífica.

Ao questionar os pacientes ou pela obtenção de dados na ficha de AVC da UEHCFMRP-USP contida no prontuário médico, observou-se que os pacientes apresentavam como fatores de risco: uso de contraceptivo oral (2,00\%); hipertensão arterial sistêmica (HAS) (72,00\%); diabete melito (20,00\%); tabagismo (36,00\%); etilismo (20,00\%); dislipidemia (4,00\%), fibrilação atrial $(6,00 \%)$, HIV positivo $(2,00 \%)$; doença vascular, entre elas, a doença cardíaca coronariana $(4,00 \%)$ [infarto agudo do miocárdio $(2,00 \%)$ e angina $(2,00 \%)$ ], o acidente vascular cerebral (24,00\%) [AVC I $(22,00 \%)$ e AVC H $(2,00 \%)$ ] e a doença arterial crônica $(2,00 \%)$; outras cardiopatias $(8,00 \%)$ [arritmia $(2,00 \%)$, cardiopatia chagásica (4,00\%), marcapasso $(2,00 \%)$, miocardiopatia de etiologia indeterminada $(2,00 \%)]$; outras doenças neurológicas (6,00\%) [mal de Alzheimer (2,00\%), doença de Parkinson (2,00\%), 
hidrocefalia de pressão normal $(2,00 \%)]$. Estes estavam associados ou não entre si (não totalizando $100,00 \%$ ), ou seja, cada paciente apresentou mais de um fator ou apenas um deles (Apêndice D).

Os pacientes que apresentaram quadro prévio de AVC ou outras doenças neurológicas que pudessem cursar com dificuldades de deglutição como as doenças de Parkinson e de Alzheimer foram incluídos no estudo sendo assegurados quanto a ausência de disfagia prévia.

Dos pacientes que apresentaram AVC prévio (12 pacientes) e outras doenças neurológicas (dois pacientes), apenas dois que tiveram quadro de AVC e os pacientes com doença de Parkinson e de Alzheimer apresentaram disfagia grave. Ressalta-se que, quando associado o escore do NIHSS e a topografia de lesão, os resultados condizem com a proposta do algoritmo inicial do estudo.

Na seqüência serão demonstradas as associações entre as variáveis.

A tabela 1 demonstra as freqüências entre o cruzamento das variáveis idade e disfagia.

Tabela 1 - Associação entre idade e disfagia.

\begin{tabular}{cccccc}
\hline \multirow{2}{*}{ Idade } & \multicolumn{4}{c}{ Disfagia } & Total \\
\cline { 2 - 5 } & \multicolumn{3}{c}{ Presença } & \multicolumn{2}{c}{ Ausência } \\
\cline { 2 - 5 } & Freqüência & $\begin{array}{c}\text { Freqüência } \\
\text { relativa (\%) }\end{array}$ & Freqüência & $\begin{array}{c}\text { Freqüência } \\
\text { relativa (\%) }\end{array}$ \\
\hline$\leq \mathbf{5 5}$ anos & 4 & 25,00 & 11 & 32,35 & 15 \\
$>\mathbf{5 5}$ anos & 12 & 75,00 & 23 & 67,65 & 35 \\
\hline Total & 16 & 100,00 & 34 & 100,00 & 50 \\
\hline
\end{tabular}

p-valor $=0,74$

Teste exato de Fisher 
Observa-se que, de todos os pacientes avaliados, 15 (30,00\%) constituíram o grupo de AVC em jovem, ou seja, com idade inferior a 55 anos.

A tabela demonstra que não houve diferença, estatisticamente, significante entre idade e presença de disfagia. Embora não tenha sido significante, houve maior incidência de presença de disfagia no grupo acima de 55 anos $(75,00 \%)$ quando comparado a sua presença à do grupo com idade igual ou inferior a esta $(25,00 \%)$.

Entretanto, dentro do grupo de jovens, quatro apresentaram disfagia. Destes, três apresentaram o escore do NIHSS acima de 12 pontos e apenas um teve o escore abaixo, sendo este de 11 pontos. Quando voltamos à ECG temos que somente este apresentou pontuação abaixo (11 pontos) de 14 (limite considerado como normalidade). Dos 12 pacientes acima de 55 anos que apresentaram disfagia, apenas um teve escore de 10 pontos, porém pontuação de 13 na ECG. De todos os pacientes sem disfagia (34 pacientes), aqueles com escore de 12 ou 13 no NIHSS tiveram resultados da ECG dentro da normalidade (igual a 14 ou 15 pontos).

A tabela 2 demonstra a associação entre as variáveis gênero e disfagia.

Tabela 2 - Associação entre gênero e disfagia.

\begin{tabular}{cccccc}
\hline \multirow{2}{*}{ Gênero } & \multicolumn{3}{c}{ Disfagia } & \multirow{2}{*}{ Total } \\
\cline { 2 - 5 } & \multicolumn{2}{c}{ Presença } & \multicolumn{2}{c}{ Ausência } & \\
\cline { 2 - 5 } & Freqüência & $\begin{array}{c}\text { Freqüência } \\
\text { relativa (\%) }\end{array}$ & Freqüência & $\begin{array}{c}\text { Freqüência } \\
\text { relativa (\%) }\end{array}$ & \\
\hline Feminino & 9 & 56,25 & 16 & 47,06 & 25 \\
Masculino & 7 & 43,75 & 18 & 52,94 & 25 \\
\hline Total & 16 & 100,00 & 34 & 100,00 & 50 \\
\hline
\end{tabular}

p-valor $=0,76$

Teste exato de Fisher 
Observamos nesta tabela que não houve relação significativa entre gênero e presença, ou não, de disfagia. Para o gênero feminino, todas com disfagia tiveram NIHSS superior a 12 pontos. O contrário, na ausência desta, apenas uma teve escore igual a 13, mas ECG igual à normalidade.

Para o gênero masculino, dois pacientes com disfagia apresentaram NIHSS igual a 10 e 11, mas ECG de 13 e 11, respectivamente. Na ausência de disfagia, dois deles com escores de 12 e 13 apresentaram pontuação dentro da normalidade na ECG.

A Tabela 3 demonstra a associação entre o escore do NIHSS e a presença ou não de disfagia.

Tabela 3 - Associação entre o escore entre o escore obtido no National Institutes of Health Stroke Scale (NIHSS) e disfagia.

\begin{tabular}{cccccc}
\hline \multirow{2}{*}{ NIHSS } & \multicolumn{3}{c}{ Disfagia } & \multirow{2}{*}{ Total } \\
\cline { 2 - 5 } & \multicolumn{2}{c}{ Presença } & \multicolumn{2}{c}{ Ausência } & \\
\cline { 2 - 5 } & Freqüência & $\begin{array}{c}\text { Freqüência } \\
\text { relativa (\%) }\end{array}$ & Freqüência & $\begin{array}{c}\text { Freqüência } \\
\text { relativa (\%) }\end{array}$ & \\
\hline$\geq \mathbf{1 2}$ pontos & 14 & 87,50 & 5 & 14,71 & 19 \\
$<\mathbf{1 2}$ pontos & 2 & 12,50 & 29 & 85,29 & 31 \\
\hline Total & 16 & 100,00 & 34 & 100,00 & 50 \\
\hline
\end{tabular}

p-valor $<0,01$

Teste exato de Fisher

Notamos que houve significância entre o escore do NIHSS e a presença de disfagia, onde $87,50 \%$ destes pacientes apresentaram escore de 12 pontos ou mais. Os demais $(12,50 \%)$ apresentaram escore de 10 e 11. Fazendo-se menção a ECG tiveram 13 e 11A pontos, respectivamente. 
Ainda na associação entre as variáveis, obtivemos que $85,29 \%$ dos pacientes sem disfagia apresentaram escore abaixo de 12 pontos. Os demais apresentaram cortes em cima ou com um ponto a mais do hipotetizado no estudo para o NIHSS, sendo estes iguais a 12 ou 13 , entretanto com pontuação máxima na ECG com exceção a um paciente que obteve 14 pontos.

A Tabela 4 associa o escore obtido na ECG e presença ou não de disfagia.

Tabela 4 - Associação entre escore obtido na escala de coma de Glasgow e disfagia.

\begin{tabular}{cccccc}
\hline Escore da ECG & \multicolumn{3}{c}{ Disfagia } & \multirow{2}{*}{ Total } \\
\cline { 2 - 5 } & \multicolumn{2}{c}{ Presença } & \multicolumn{2}{c}{ Ausência } & \\
\cline { 2 - 5 } & Freqüência & $\begin{array}{c}\text { Freqüência } \\
\text { relativa (\%) }\end{array}$ & Freqüência & $\begin{array}{c}\text { Freqüência } \\
\text { relativa (\%) }\end{array}$ & \\
\hline$<\mathbf{1 4}$ pontos & 11 & 68,75 & 2 & 5,88 & 13 \\
$\geq \mathbf{1 4}$ pontos & 5 & 31,25 & 32 & 94,12 & 37 \\
\hline \multicolumn{1}{c}{ Total } & 16 & 100,00 & 34 & 100,00 & 50 \\
\hline p-valor $<0,01$ & & & & & \\
Teste exato de Fisher & & & & &
\end{tabular}

A tabela permite observar que $94,12 \%$ dos pacientes sem disfagia apresentaram escore na ECG igual ou superior a 14 pontos. Em contrapartida, houve cinco pacientes com este escore que apresentaram o sintoma. Quando voltamos à caracterização destes pacientes podemos observar que o escore do NIHSS apresentado por eles foi igual ou superior a 12 , ou seja, dentro dos critérios iniciais para detecção da presença de disfagia, embora tenham resultado normal na EGC. Ressalta-se, ainda, que o escore obtido por dois destes pacientes foi, exatamente, 12.

Ao observar os escores abaixo de 14, apenas dois pacientes não apresentaram alterações de deglutição, como seria esperado, entretanto, estes apresentaram NIHSS abaixo 
de 12 pontos (escores 9 e 10). Dos 12 pacientes com escores menores que 14 com disfagia, apenas dois apresentaram NIHSS abaixo de 12 pontos, tendo como escores de 10 e 11.

Portanto, houve significância estatística entre o escore da ECG e a presença ou não de disfagia.

Na Tabela 5 foi realizada a associação entre as alterações de comunicação, separandoas em alteração de fala (disartria) e de linguagem (afasia) e aqueles pacientes sem alterações na oralidade.

Tabela 5 - Associação entre alteração de comunicação e disfagia.

\begin{tabular}{cccccc}
\hline \multirow{2}{*}{ Comunicação } & \multicolumn{4}{c}{ Disfagia } & Total \\
\cline { 2 - 5 } & \multicolumn{3}{c}{ Presença } & \multicolumn{2}{c}{ Ausência } \\
\cline { 2 - 5 } & Freqüência & $\begin{array}{c}\text { Freqüência } \\
\text { relativa (\%) }\end{array}$ & Freqüência & $\begin{array}{c}\text { Freqüência } \\
\text { relativa (\%) }\end{array}$ & \\
\hline Afasia & 11 & 68,75 & 4 & 11,76 & 15 \\
Disartria & 5 & 31,25 & 17 & 50,00 & 22 \\
\hline Sem alteração & 0 & 0,00 & 13 & 38,24 & 13 \\
\hline Total & 16 & 100,00 & 34 & 100,00 & 50 \\
\hline
\end{tabular}

p-valor $<0,01$

Teste exato de Fisher

Nesta tabela observamos que houve diferença estatisticamente significante entre presença de alteração de comunicação e presença de disfagia, havendo uma relação quanto à presença de disfagia em pacientes com afasia $(68,75 \%)$. Destes, apenas dois apresentaram escore abaixo de 12 na escala do NIHSS (valores de 10 e 11). Associando com a ECG, os valores obtidos foram de 11A e 13, respectivamente. Dos quatro pacientes sem disfagia, apenas um apresentou 13 pontos no NIHSS sendo esperada a alteração da função, porém 
obteve 15 pontos na ECG. Ressalta-se que estes pacientes com afasia apresentaram os maiores escores do NIHSS (acima de 15) de toda nossa amostra, podendo-se concluir, portanto, que foram os pacientes mais graves.

Com a prevalência de $31,25 \%$ dos pacientes com disartria que apresentaram disfagia, houve completa associação entre estes e o escore do NIHSS, ou seja, todos com pontuação acima de 12. Para os que não apresentaram disfagia, apenas dois tiveram 12 e 13 pontos na escala de AVC, com 15 e 14 na ECG.

Nenhum dos pacientes sem alterações de comunicação apresentou disfagia. Apenas um teve escore de 12 no NIHSS com 15 pontos na ECG. Com exceção feita a dois dos 13 pacientes sem alterações, que obtiveram escores de 11 e 12 no NIHSS, observamos que $84,61 \%$ destes tiveram os menores escores da amostra (igual ou inferior a seis pontos), sendo, os menos acometidos.

A Tabela 6 demonstra a associação entre topografia da lesão e presença ou não de disfagia.

Tabela 6 - Associação entre topografia da lesão e disfagia.

\begin{tabular}{cccccc}
\hline \multirow{2}{*}{ Topografia } & \multicolumn{3}{c}{ Disfagia } & \multirow{2}{*}{ Total } \\
\cline { 2 - 5 } & Freqüência & $\begin{array}{c}\text { Freqüência } \\
\text { relativa (\%) }\end{array}$ & Freqüência & $\begin{array}{c}\text { Freqüência } \\
\text { relativa (\%) }\end{array}$ & \\
\cline { 2 - 5 } & 16 & 100,00 & 20 & 58,82 & 36 \\
Carotídeo & 0 & 0,00 & 10 & 29,41 & 10 \\
\hline Vertebrobasilar & 0 & 0,00 & 4 & 11,76 & 4 \\
\hline NPD & 16 & 100,00 & 34 & 100,00 & 50 \\
\hline Total & & & & & \\
\hline
\end{tabular}

p-valor $<0,01$

NPD: não foi possível definir a topografia

Teste exato de Fisher 
Observamos que houve significância estatística entre a topografia da lesão e presença de disfagia, pois todos $(100,00 \%)$ os pacientes com disfagia apresentaram lesões em território carotídeo. Destes, apenas dois tiveram NIHSS abaixo de 12 pontos, sendo de 11 e 10, com ECG igual a 11A e 13, respectivamente. Não houve pacientes com disfagia e lesões em território vertebrobasilar ou com lesões inespecíficas.

Dos pacientes sem disfagia, 58,82\% apresentaram acometimento em território carotídeo, 29,41\% em vertebrobasilar e em 11,76\% não foi possível a definição da topografia da lesão. Podemos observar que a grande maioria $(85,00 \%)$ apresentou escore do NIHSS abaixo de 12 e três pacientes $(15,00 \%)$ apresentaram valores de 12 e 13 , com pontuação referente à normalidade na ECG $(\geq 14)$.

Os pacientes com lesões em território vertebrobasilar apresentaram igualmente baixa pontuação na escala de AVC com exceção a dois pacientes com escores de 13, porém com 15 pontos na ECG.

Finalmente, aqueles pacientes em quem não foi possível definir a topografia da lesão, $100,00 \%$ apresentaram NIHSS inferior a 11 pontos.

Ressaltamos ainda, que $72,00 \%$ dos pacientes da amostra apresentaram lesão em território carotídeo.

Foi feita, ainda, a associação entre hemisfério cerebral acometido e a presença, ou não, de disfagia (Tabela 7). 
Tabela 7 - Associação entre hemisfério cerebral e disfagia.

\begin{tabular}{cccccc}
\hline \multirow{2}{*}{ Hemisfério } & \multicolumn{3}{c}{ Disfagia } & \multirow{2}{*}{ Total } \\
\cline { 2 - 5 } & \multicolumn{3}{c}{ Presença } & & \\
\cline { 2 - 5 } & Freqüência & $\begin{array}{c}\text { Freqüência } \\
\text { relativa (\%) }\end{array}$ & Freqüência & $\begin{array}{c}\text { Freqüência } \\
\text { relativa (\%) }\end{array}$ & \\
\hline Direito & 9 & 56,25 & 17 & 50,00 & 26 \\
Esquerdo & 7 & 43,75 & 13 & 38,24 & 20 \\
\hline NPD & 0 & 0,00 & 4 & 11,76 & 4 \\
\hline Total & 16 & 100,00 & 34 & 100,00 & 50 \\
\hline
\end{tabular}

p-valor $=0,47$

NPD: não foi possível definir a topografia

Teste exato de Fisher

Quando observado o hemisfério cerebral acometido, não houve diferença estatisticamente significante na sua associação com presença, ou não, de disfagia.

De todos os pacientes com disfagia, 56,25\% correspondiam a lesões no hemisfério direito e os demais $43,75 \%$ no esquerdo. Buscando a associação com o escore do NIHSS, todos tiveram pontuação abaixo de 12. Dos 26 pacientes acometidos neste hemisfério, 17 não apresentaram disfagia e apenas quatro destes tiveram escores igual ou superior a 12 pontos, porém mantendo-se próximos a este corte, com escores dentro da normalidade na ECG.

Voltando às lesões do hemisfério esquerdo, 43,75\% dos pacientes apresentaram disfagia. Destes, dois tiveram NIHSS abaixo de 12 (11 a 10) com pontuação de 11A e 13 na ECG. Os 13 pacientes sem disfagia e lesão cerebral à esquerda tiveram escore compatível com o corte proposto para a ausência de alterações com exceção de um paciente que apresentou 13 pontos, com ECG de 15.

Como já observado na tabela 6 , naqueles pacientes em que não foi possível definir a topografia da lesão, 100,00\% apresentaram NIHSS inferior a 11 pontos. 
Não houve predomínio aparente entre hemisfério cerebral acometido em nossa amostra.

Por fim, associou-se topografia de lesão e escore do NIHSS com a presença, ou não, de disfagia (Tabela 8).

Tabela 8 - Associação entre topografia de lesão e escore do NIHSS e disfagia.

\begin{tabular}{|c|c|c|c|c|c|}
\hline \multirow[t]{3}{*}{ Hemisfério } & \multicolumn{4}{|c|}{ Disfagia } & \multirow[t]{3}{*}{ Total } \\
\hline & \multicolumn{2}{|c|}{ Presença } & \multicolumn{2}{|c|}{ Ausência } & \\
\hline & Freqüência & $\begin{array}{l}\text { Freqüência } \\
\text { relativa }(\%)\end{array}$ & Freqüência & $\begin{array}{l}\text { Freqüência } \\
\text { relativa }(\%)\end{array}$ & \\
\hline Carotídeo + 0 & 14 & 87,50 & 3 & 8,82 & 17 \\
\hline Carotídeo + 1 & 2 & 12,50 & 17 & 50,00 & 19 \\
\hline Vertebrobasilar + 0 & 0 & 0,00 & 2 & 5,88 & 2 \\
\hline Vertebrobasilar + 1 & 0 & 0,00 & 8 & 23,53 & 8 \\
\hline NPD + 1 & 0 & 0,00 & 4 & 11,76 & 4 \\
\hline Total & 16 & 100,00 & 34 & 100,00 & 50 \\
\hline $\begin{array}{l}p \text {-valor }<0,01 \\
0: \text { NIHSS } \geq 12 \\
\text { 1: NIHSS }<12 \\
\text { Teste exato de Fisher }\end{array}$ & & & & & \\
\hline
\end{tabular}

Nesta tabela pode ser observado que houve significância estatística, em que todos os pacientes $(100,00 \%)$ que apresentaram disfagia tinham acometimento em território carotídeo, sendo que $87,50 \%$ apresentaram escore do NIHSS igual ou superior a 12 e apenas dois pacientes $(12,50 \%)$ abaixo de 12 (escores 10 e 11). Realizando a mesma correlação feita nas variáveis isoladas, estes pacientes apresentaram pontuação da ECG de 13 e 11A, respectivamente. 
Já os pacientes sem disfagia, 58,82\% apresentaram lesão em território carotídeo, 29,41\% em território vertebrobasilar e 11,76\% não apresentaram definição da topografia. Primeiramente, dos pacientes com lesão em território carotídeo tiveram uma alta porcentagem $(50,00 \%)$ de escore do $\mathrm{NIH}$ inferior a 12 ; dos três pacientes $(8,82 \%)$ com escore igual ou superior a 12, não apresentaram disfagia, conforme esperado, mas seus escores foram de 12 , 12 e 13, com ECG igual a 15, 15 e 14, respectivamente.

No total de 10 pacientes com acometimento em território vertebrobasilar, oito $(23,53 \%)$ apresentaram escores abaixo de 12 e os dois pacientes restantes tiveram valores de 13 no NIHSS e de 15 na ECG.

Naqueles em que não foi possível definir a topografia da lesão, todos tiveram escores menores que 12 pontos na escala de AVC.

Após a comparação entre as variáveis, intencionamos testar qual a sensibilidade para detectar presença de disfagia quando consideramos o escore do NIHSS que, segundo a nossa hipótese inicial, deveria ter uma pontuação mínima de 12 e a especificidade, para que não houvesse a presença de disfagia em escores abaixo deste corte. Para tanto, realizou-se a curva ROC cujos resultados são apresentados na tabela 9, quanto ao número de corte considerando a presença de disfagia e seus respectivos valores de sensibilidade e especificidade, ilustrando também os valores preditivos positivos (VPP) e preditivos negativos (VPN) para cada pontuação do NIHSS obtida na amostra do estudo. 
Tabela 9 - Resultados da curva ROC, valores preditivos positivos e valores preditivos negativos.

\begin{tabular}{|c|c|c|c|c|c|}
\hline Corte & sensibilidade & VPP (\%) & especificidade & VPN (\%) & 1-especificidade \\
\hline 0 & 1,00 & 0,00 & 0,00 & 0,33 & 1,00 \\
\hline 1 & 1,00 & 0,00 & 0,06 & 0,35 & 0,94 \\
\hline 2 & 1,00 & 0,00 & 0,21 & 0,36 & 0,79 \\
\hline 3 & 1,00 & 0,00 & 0,38 & 0,33 & 0,62 \\
\hline 4 & 1,00 & 0,00 & 0,44 & 0,32 & 0,56 \\
\hline 5 & 1,00 & 0,00 & 0,47 & 0,35 & 0,53 \\
\hline 6 & 1,00 & 0,00 & 0,53 & 0,32 & 0,47 \\
\hline 7 & 1,00 & 0,00 & 0,56 & 0,32 & 0,44 \\
\hline 8 & 1,00 & 0,00 & 0,59 & 0,35 & 0,41 \\
\hline 9 & 1,00 & 0,00 & 0,71 & 0,33 & 0,29 \\
\hline 10 & 1,00 & 0,33 & 0,77 & 0,32 & 0,24 \\
\hline 11 & 0,94 & 0,50 & 0,82 & 0,31 & 0,18 \\
\hline 12 & 0,88 & 0,50 & 0,85 & 0,30 & 0,15 \\
\hline 13 & 0,75 & 0,00 & 0,91 & 0,34 & 0,09 \\
\hline 15 & 0,75 & 1,00 & 1,00 & 0,29 & 0,00 \\
\hline 16 & 0,63 & 1,00 & 1,00 & 0,31 & 0,00 \\
\hline 18 & 0,56 & 1,00 & 1,00 & 0,31 & 0,00 \\
\hline 19 & 0,50 & 1,00 & 1,00 & 0,31 & 0,00 \\
\hline 24 & 0,44 & 1,00 & 1,00 & 0,31 & 0,00 \\
\hline 35 & 0,38 & 1,00 & 1,00 & 0,29 & 0,00 \\
\hline 37 & 0,25 & 1,00 & 1,00 & 0,31 & 0,00 \\
\hline 38 & 0,19 & 1,00 & 1,00 & 0,31 & 0,00 \\
\hline 39 & 0,13 & 1,00 & 1,00 & 0,31 & 0,00 \\
\hline 40 & 0,06 & 1,00 & 1,00 & 0,31 & 0,00 \\
\hline
\end{tabular}

VPP: valor preditivo positivo

VPN: valor preditivo negativo 
No corte, inicialmente proposto, de 12 , houve uma sensibilidade de $88,00 \%$ e uma especificidade de $85,00 \%$. Quando modificamos este corte para menos, conforme alguns resultados de associação nos sugerem, tomando-se o corte de 10, observamos um aumento na sensibilidade para $100,00 \%$ e uma queda na especificidade para $77,00 \%$. Por outro lado, na tentativa de aumentar este corte, por exemplo, para 13 ocorreu o inverso, havendo uma queda na sensibilidade e um aumento na especificidade.

Pelo cálculo do VPP e VPN obtido a partir da associação entre o escore do NIHSS e a presença, ou não, de disfagia, temos que VPP é igual a 50,00\% e o VPN é de 30,00\% quando consideramos o corte de 12 pontos na escala, ou seja, um paciente com escore do NIHSS igual a 12 e com disfagia tem $50,00 \%$ de chance de não apresentar a disfagia; por outro lado, se este paciente não apresentar disfagia a chance disto ocorrer é de 30,00\%.

Podemos observar que quanto menor é a freqüência de disfagia, menor é o VPP e maior o VPN; quanto maior sua freqüência, maior é o VPP e menor é o VPN.

Apenas como ilustração, os gráficos 1 e 2 constituem a curva ROC, baseadas nos resultados da tabela 8 .

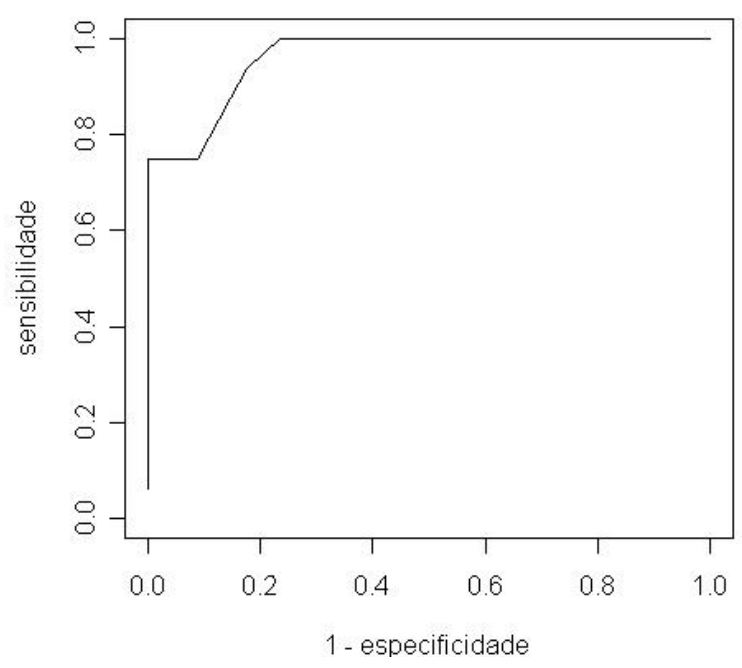

GRÁFICO 1 - Curva ROC relacionando o escore do NIHSS e a presença de disfagia. 
É importante salientar que um instrumento de medida, no caso o escore do NIHSS, será melhor quanto a curva mais se aproximar do canto superior esquerdo, que serão os valores máximos para sensibilidade (capacidade de detectar algo) e especificidade (capacidade de não detectar eventos inexistentes) para aquele valor de corte. Para a constituição da curva, é necessária a utilização do valor de 1-especificidade. Para uma melhor compreensão, deve-se verificar o valor de interesse na tabela quanto à especificidade e sua correlação na coluna de 1-especificidade. A partir de então, busca-se o ponto em que sensibilidade e especificidade se encontram no gráfico, concluindo-se a avaliação do teste.

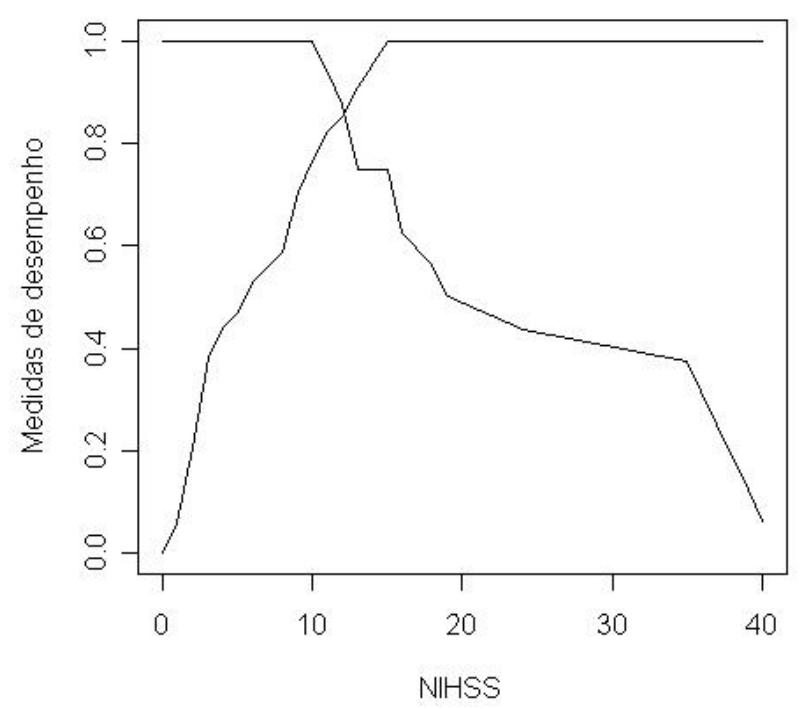

GRÁFICO 2 - Sensibilidade e especificidade relacionadas ao escore do NIHSS.

Neste gráfico podemos, mais uma vez, observar a sensibilidade e especificidade quanto ao corte do escore do NIHSS. 
As alterações de deglutição são manifestações comuns decorrentes dos quadros de AVC. Encontra-se, principalmente, o comprometimento da fase oral e faríngea da deglutição, as denominadas disfagias orofaríngeas, em seus diversos graus. Em estudo realizado com pacientes com AVCI dentro de cinco dias do início do evento ficou demonstrado que a disfagia ocorreu em $65 \%$ dos pacientes, sendo que 36\% tinham disfagia moderada a severa e severa, $28 \%$ disfagia moderada e 36\% disfagia leve (DANIELS et al., 1998).

O principal problema causado pela presença de disfagia é a aspiração, cujo risco é maior dentro dos primeiros dias após o AVC (DANIELS et al., 1998; KIDD et al., 1993), entretanto, muitos estudos se preocupam em determinar, exclusivamente, a presença de aspiração e esquecem que a disfagia pode ser evidenciada pela presença de outras manifestações.

Martino, Pron e Diamant (2000), em sua revisão na literatura sobre publicações de avaliação clínica para disfagia orofaríngea em adultos com AVC, focaram na detecção de desta, incluindo o uso de métodos invasivos. Encontraram limitações nos métodos empregados, pois, em muitos estudos, foi utilizada a aspiração como um marcador de diagnóstico para a disfagia, enquanto esta é, comumente, uma conseqüência da disfagia. Dessa forma, outros problemas clínicos de deglutição foram ignorados. Os autores afirmaram que a disfagia pode estar presente sem a presença de aspiração, mas a aspiração é dependente da presença de disfagia.

A disfagia apresenta alta incidência nos primeiros dias após o AVC (BROADLEY et al., 2005; GRESHAM, 1990), havendo uma redução nos dias subseqüentes (BROADLEY et al., 2005; KIDD et al., 1995), sendo que poucos pacientes a apresentarão após um mês do episódio (BROADLEY et al., 2005; DANIELS et al., 1998; SMITHARD et al., 1996).

Além da elevada taxa de mortalidade, a disfagia pode também acarretar graves complicações que podem, eventualmente, comprometer a recuperação funcional. O tempo avaliável após o início dos sintomas do AVC para uma efetiva intervenção para reverter ou 
limitar danos cerebrais isquêmicos deve ser mais curto. A possibilidade de que a disfagia leva a uma mortalidade potencialmente reversível oferece uma oportunidade para o benefício da intervenção numa escala de tempo de dias ao invés de minutos ou horas, justificando maiores investigações (BARER, 1989).

Smithard et al. (1997), em estudo prospectivo de 121 pacientes com AVC avaliados dentro de 24 horas do início do quadro, evidenciaram que 51\% dos pacientes, quando avaliada sua deglutição, apresentaram risco de aspiração na sua admissão hospitalar; muitos problemas foram solucionados em sete dias, embora ainda alguns pacientes $(27 \%)$ tenham persistido com risco de aspiração; acima de seis meses, a maioria dos problemas tinha sido solucionada, sendo que $6 \%$ tinham dificuldades persistentes e a minoria dos pacientes $(3 \%)$ desenvolveu dificuldades com a evolução do quadro de AVC até seis meses.

Variações quanto à incidência da disfagia encontradas na literatura podem ser devidas às diferentes definições, método de avaliação da função da deglutição, tempo decorrido do AVC, tipo e número de pacientes avaliados (TERRÉ; MEARIN, 2006). Entretanto, cada vez mais se tem descrito sobre as dificuldades de deglutição e manifestações clínicas apresentadas por pacientes com AVC. Se não forem adequadamente identificadas na fase aguda do AVC, essas dificuldades de deglutição podem acarretar complicações no quadro geral destes pacientes. A função da deglutição deveria ser avaliada em todos os pacientes com AVC (MANN; HANKEY; CAMERON, 1999).

A presença de disfagia reflete no aumento da gravidade do AVC (KIDD et al., 1995), entretanto, um protocolo de screening formal deveria ser oferecido para todos os pacientes com AVC, sem se considerar a gravidade deste (HINCHEY et al., 2005).

Revisões prévias sobre a detecção de dificuldades de deglutição após o AVC não têm sido focadas em métodos de screening não invasivos e não instrumentais para serem aplicáveis 
por profissionais, nem tem focado nas dificuldades gerais de alimentação (WESTERGREN, 2006).

Este estudo teve por objetivo a detecção de dificuldades de deglutição na fase aguda do AVC que pudesse auxiliar na prática clínica. Para tanto, formulou-se um algoritmo para indicação de via mais segura de alimentação durante a fase aguda de AVC, enquanto o paciente aguardava a avaliação fonoaudiológica mais detalhada da deglutição, com o uso da escala de AVC proposta pelo National Institutes of Health (NIHSS - National Institutes of Health Stroke Scale). Propusemos, a partir de itens hipoteticamente relevantes na avaliação da adequada deglutição, um escore que representasse um indicador de risco para disfagia. Um protocolo formal de detecção da disfagia diminui a incidência de pneumonia em pacientes hospitalizados por AVCI (HINCHEY et al., 2005).

Diversos fatores podem acarretar uma piora do quadro de AVC e a sua caracterização pode contribuir significativamente para melhorar o prognóstico através do seu tratamento e correção. A maioria dos trabalhos cita taxas ao redor de $30 \%$ de piora dos doentes com AVC nos primeiros sete dias. Causas neurológicas e complicações sistêmicas podem acometer estes pacientes. Dentre as causas sistêmicas existem os distúrbios respiratórios como graves complicações, citando-se principalmente, a pneumonia lobar, a embolia e o excesso de secreção tráqueo-brônquica (GAGLIARDI, 1988).

A pneumonia aspirativa é um fenômeno multifatorial, e depende de várias características preditivas. Langmore et al. (1998) descreveram que disfagia e aspiração são condições necessárias, mas não suficientes para o desenvolvimento de pneumonia. Katzan et al. (2003) relataram que o índice de pneumonia foi mais alto em pacientes com maior severidade do AVC e características específicas indicam comprometimento do estado clínico geral. Pacientes com nível de consciência alterado não apenas têm maior prejuízo neurológico, mas também são menos capazes de proteger, efetivamente, sua via aérea. 
A infecção pulmonar ocorre mais comumente no primeiro mês após o AVC (MANN; HANKEY; CAMERON, 1999), condizente com o período de maior freqüência de apresentação de disfagia.

Em decorrência da presença de vários fatores que podem levar à presença de pneumonia aspirativa, é importante a identificação precoce e confirmação da aspiração por métodos objetivos, por exemplo, a videofluoroscopia (SMITH et al., 2000).

As avaliações da deglutição são, geralmente, divididas entre avaliação clínica à beira do leito e investigação instrumental. Devido ao fato de cada método fornecer diferentes dados com variável acurácia, a incidência da disfagia pode variar dependendo de qual avaliação foi utilizada. A melhor prática corrente seria a avaliação clínica à beira do leito com um baixo limiar para o exame instrumental ambos para identificar aspiradores silentes e para orientar no manejo das disfagias (SINGH; HAMDY, 2006).

Em verdade, todos os métodos apresentam vantagens e desvantagens, havendo, muitas vezes, necessidade de realização de mais de um deles para elucidação diagnóstica.

Os métodos objetivos mais solicitados e utilizados habitualmente por profissionais que trabalham com disfagia alta (orofaríngea) são a nasovideoendoscopia e a videofluoroscopia, que avaliam a dinâmica da deglutição, estruturas anatômicas, possibilitam ao profissional a verificação do resultado das manobras facilitadoras posturais e de limpeza de recessos faríngeos, assim como escolha da consistência de alimento mais adequada ao paciente. A avaliação endoscópica tem por finalidade observar as características da mucosa, avaliação estrutural e funcional da deglutição, sensibilidade e por objetivo localizar, topograficamente, as alterações mais evidentes e significantes durante a função da deglutição (MANRIQUE, 1999).

A videofluoroscopia é importante para o esclarecimento da presença de aspiração ou microaspiração, observação na dinâmica das estruturas associadas à deglutição durante suas fases (GONÇALVES; VIDIGAL, 1999); permanece como padrão ouro para avaliação da 
aspiração, mas, infelizmente, não é universalmente disponível nem apropriada para todos os pacientes com AVC na fase aguda e falta disponibilidade geral, com limitada indicação (MANN; HANKEY; CAMERON, 2000; SMITHARD et al., 1996; SMITH et al., 2000). A condição de padrão ouro, no entanto, é motivo de debate, merecendo estudos melhor elaborados (MANN; HANKEY; CAMERON, 2000).

Outro método freqüentemente solicitado é a manometria, para elucidação diagnóstica de fenômenos motores que ocorrem no esôfago, espontaneamente ou em conseqüência de estímulos. Sua maior indicação ocorre no paciente com disfagia quando os exames radiológico e endoscópico não forem completamente esclarecedores (DANTAS, 1998).

Destacam-se alguns estudos realizados com seus respectivos achados.

Em estudo realizado com a utilização de um sistema de classificação clínico da disfagia estabelecido para avaliar o seu resultado em pacientes com AVCI, quando comparados com os resultados da videofluorosocopia, identificaram seis fatores preditivos de risco para disfagia que consistiam de disfonia, disartria, tosse voluntária alterada, reflexo de vômito alterado, tosse após a deglutição e mudança na qualidade vocal após a deglutição, onde a presença de dois ou mais fatores apresentaram deglutição normal ou disfagia leve e os que apresentaram dois fatores ou mais tinham disfagia moderada ou severa. Concluíram que o uso de critérios clínicos, seguramente determina qual paciente não necessita de avaliação adicional da deglutição, com 78\% de precisão. A identificação de duas características clínicas ou mais distingue pacientes com risco de aspiração após a deglutição daqueles com mínimo risco. A sensibilidade $(69,9 \%)$ e especificidade $(84,4 \%)$ são, em combinação, superiores àqueles obtidos por qualquer um preditor isolado (DANIELS et al., 1998; DANIELS et al., 2000).

McCullough, Wertz e Rosenbek (2001) estudaram 60 pacientes com AVC entre uma e 42 semanas do início do quadro, com o propósito de investigar a sensitividade e especificidade 
de sinais clínicos da avaliação à beira do leito como preditores de aspiração confirmados na avaliação videofluoroscópica da deglutição, realizada dentro de 24 horas do término da avaliação clínica. Baixa sensitividade e especificidade resultam, em parte, do fato de que a aspiração, em e de si mesmo, pode não ser visualizada até mesmo por examinadores experientes. Por várias razões, apesar dos autores apresentarem uma certa unanimidade quanto à identificação de sinais clínicos sugestivos de aspiração, é difícil saber o que se conclui destes. Um problema é que muitos pesquisadores não estimam a sensibilidade e especificidade; além disto, utilizam diferentes critérios de registros o que pode diferir na análise dos resultados dependendo da metodologia empregada.

Broadley et al. (2005) realizaram um estudo para validar um indicador de prognóstico para disfagia em AVCI e AVCH denominado Royal Adelaide Prognostic Index for Dysphagia Stroke (RAPIDS) utilizando características clínicas e radiográficas. Demonstraram que é possível predizer a disfagia prolongada com alta especificidade (92\%) dentro de 24 a 48 horas da admissão.

A avaliação clínica tem suas limitações quanto à definição da presença de aspirações, devido à possibilidade destas ocorrerem de forma silenciosa. A previsão do risco de aspiração realizando a avaliação clínica tem obtido variável sucesso (DANIELS et al., 1998; MARTINO; PRON; DIAMANT, 2000; LEDER; ESPINOSA, 2002; RAMSEY; SMITH et al., 2000; SMITHARD; KALRA, 2003) e são limitadas as evidências literárias dos benefícios dessa avaliação (MARTINO; PRON; DIAMANT, 2000; McCULLOUGH et al., 2000; PERRY; LOVE, 2001).

É o fonoaudiólogo que, por intermédio da avaliação clínica, verifica a necessidade ou não de realizar algum exame objetivo, contra-indicando sua realização em pacientes com grave estado clínico, nível de consciência rebaixado e/ou com evidências quanto aos riscos de aspiração (BARROS et al., 2006). Além disso, é importante relevar a detecção não somente da 
presença, ou não, de aspiração, mas sim dos fatores de riscos apresentados pelos pacientes que poderiam contra-indicar a alimentação segura por via oral (McCULLOUGH; WERTZ; ROSENBEK, 2001; SILVA; VIEIRA, 1998; SILVA; GATTO; COLA, 2003). O quadro clínico, a identificação eficaz de pacientes com disfagia pós AVC representam o primeiro passo vital no seu apropriado gerenciamento (PERRY; LOVE, 2001).

Smithard et al. (1998) demonstraram que a avaliação da deglutição à beira do leito carece de uma sensitividade necessária para ser utilizada como instrumento de screening na fase aguda do AVC.

Perry e Love (2001) revisaram 248 artigos relacionados à identificação de melhor evidência atual para a caracterização da disfagia em pacientes com AVC na fase aguda. Concluíram que a falta de uniformidade nas pesquisas realizadas com pacientes que apresentaram AVC representa um obstáculo para a adequada avaliação crítica dos resultados, especialmente quanto à idade, etnia, comorbidades e representação do subtipo de AVC. As condições dos pacientes e o potencial para a recuperação espontânea variam; durante os estágios iniciais do AVC deve ainda estar em formação ou o edema cerebral pode complicar a sua apresentação; mais tarde, a expansão ou novo infarto ou hemorragia pode ocorrer. Todos estes fatores podem influir na gravidade do AVC e na recuperação da função.

Westergren (2006) realizou uma revisão de literatura sobre publicações referentes a métodos de avaliação não instrumentais (além da oximetria de pulso) e não invasivos para detecção à beira do leito de dificuldades de alimentação entre pessoas que tiveram AVC. Constatou que o oxímetro de pulso representa um método não invasivo de teste de deglutição, podendo ser um importante complemento, especialmente na detecção de aspiração silente. Uma desaturação de mais do que $2 \%$ da linha de base esteve relacionada à presença de aspiração no exame de videofluoroscopia da deglutição (SMITH et al., 2000). 
Em muitas avaliações clínicas publicadas observamos que a avaliação da função da deglutição foi realizada com o uso de líquidos, reconhecidamente a consistência alimentar mais difícil de ser deglutida em pacientes neurologicamente acometidos. O limitado controle sobre o tipo e viscosidade do bolus deglutido na avaliação à beira do leito e na videofluoroscopia descritos em diversos estudos parece denunciar uma hipótese que tal controle não é importante (McCULLOUGH; WERTZ; ROSENBEK, 2001), o que não é verdadeiro. A observação clínica do paciente com AVC agudo mostra que muitos deles têm mais problemas na deglutição de líquido do que de semi-sólidos. Por esta razão, é essencial avaliar a capacidade de deglutição de semi-sólidos antes da de líquidos porque este procedimento passo-a-passo minimiza o risco de aspiração durante o teste e identifica pacientes que toleram a ingesta de semi-sólidos, mas não de líquidos (TRAPL et al., 2007).

Trapl et al. (2007) desenvolveram um protocolo de screening à beira do leito simples, passo a passo, que permite um índice de graduação com avaliações separadas por texturas não fluidas e nutrição fluidas começando pelas não fluidas. Este procedimento de avaliação tem por objetivo reduzir o risco de aspiração durante o teste para mínimo e permitindo uma avaliação graduada; tem substancial a excelente concordância interavaliadores para todas as categorias de classificação. É um instrumento válido para predizer risco de aspiração ainda mais quando utilizado por profissionais não especializados.

Este estudo não teve o objetivo de detectar a presença, ou não, de aspiração laringotraqueal, mas sim o de observar dados clínicos gerais que fornecessem indicadores de riscos para a presença de disfagia em pacientes com AVC I na fase aguda, com a intenção de evitar complicações clínicas nesta fase, através da indicação precoce, porém não definitiva, de via alternativa de alimentação, que pudesse ser realizada por diversos profissionais que atuam com estes pacientes. A detecção precoce e tratamento da disfagia são esperados não apenas para beneficiar os pacientes através da redução do período de recuperação do AVC, mas 
também para reduzir os custos de reabilitação em geral. É esperado que a detecção precoce de alterações na fisiologia da deglutição e subseqüente intervenção precoce reduzam as complicações médicas potenciais em geral do comprometimento pulmonar, desidratação ou má nutrição e, conseqüentemente, redução do custo geral para a reabilitação seguida do AVC (MARTINO; PRON; DIAMANT, 2000). A disfagia é uma alteração fisiológica na deglutição orofaríngea e a aspiração é uma conseqüência desta, mais do que um marcador diagnóstico (WESTERGREN, 2006).

O principal propósito para a avaliação clínica é identificar pacientes com risco para disfagia orofaríngea e ser a referência inicial precoce para o diagnóstico e tratamento para prevenir o sofrimento dos sintomas disfágicos e minimizar riscos de morte (MARTINO; PRON; DIAMANT, 2000). A disfagia detectada à beira do leito é um fator preditor independente de mortalidade e ocorrência de infecção pulmonar e serve para identificar pacientes com risco de uma nutrição inadequada (SMITHARD et al., 1996).

Para a avaliação do comprometimento neurológico nos casos de AVC, várias escalas são utilizadas para o acompanhamento clínico da evolução do paciente e em decisões terapêuticas. Caneda et al. (2006) estudaram 51 indivíduos com AVC, visando a confirmação da confiabilidade de três escalas utilizadas: a escala de Rankin, o índice de Barthel e o NIHSS, demonstrando, de maneira geral, confiabilidade clinicamente aceitável e de boa aplicabilidade em nosso meio.

O índice de Barthel foi utilizado nos estudos de Smithard et al. (1996) e Broadley et al. (2005) e o NIHSS por Hinchey et al. (2005).

Entretanto, em poucos estudos faz-se a correlação destas com a disfagia. O NIHSS, assim como as demais escalas, pode ser utilizado em ensaios clínicos, e para a padronização da avaliação diagnóstica e prognóstica na assistência de pacientes com AVC no Brasil (CANEDA et al., 2006). 
Hinchey et al. (2005) realizaram um estudo prospectivo na coleta de dados de 15 instituições, quanto à presença de avaliações da deglutição em pacientes com AVC, visando caracterizar se alguns fatores poderiam ser detectáveis na fase aguda para a prevenção do desenvolvimento de pneumonia, supostamente em decorrência de quadros disfágicos, correlacionando métodos de avaliação, prevalência de pneumonia e gravidade do AVC utilizando, como referência, o NIHSS. Quanto ao grau de comprometimento pela escala do NIH, evidenciaram que um comprometimento leve apresenta NIHSS de 0-8, moderado de 9-16 e severo $>17$. Com o aumento de um ponto na escala há aumento da chance de pneumonia em $12 \%$.

Embora tenha sido descrito que a prevalência de disfagia aumenta de acordo com a gravidade do AVC, não fíca claro qual seria o escore limite entre a possível presença de alteração de disfagia, ou não, havendo falhas quanto aos métodos empregados. Os dados de concordância entre resultados de estudos são variáveis; isto pode ser atribuível em parte à diversidade dos métodos de avaliação utilizados como o exame clínico inicial e a classificação formal e informal da disfagia (HINCHEY et al., 2005).

Em nosso estudo, pretendeu-se associar os achados da escala do NIHSS com a possibilidade da presença de alterações de deglutição. Apesar da evidência de disfagia como parte das manifestações na fase aguda do AVC, sua detecção e manejo são inadequados em muitos hospitais.

O NIHSS é um reflexo do déficit neurológico. O escore inicialmente obtido pode ser um indício da seqüela neurológica que o paciente apresentará. Mudanças do escore nas primeiras 24 horas, fortemente correlacionada com este fato observado dentro de sete a dez dias, sugerem que estas mudanças precoces no escore podem ser um fator de recuperação. O grau de recuperação espontânea e a influência do subtipo de AVC têm implicações importantes no planejamento de futuros tratamentos (WITYK et al., 1994). 
Adams et al. (1999) utilizaram dados coletados de 1281 pacientes registrados no estudo clínico, onde o subtipo de AVC foi categorizado utilizando a classificação de TOAST, comparando o escore do NIHSS como preditor de prognóstico no período de sete dias a três meses do AVCI. Concluíram que o escore do NIHSS fornece informação diagnóstica podendo ser utilizado por médicos, pacientes e familiares, permitindo também ser empregado como critério de inclusão ou exclusão de pacientes em tratamentos para AVC. Os dados demonstraram que pacientes com comprometimentos graves (escore do NIHSS > 15), têm menos que $20 \%$ de chance de obter uma recuperação excelente. Concluíram, então, que pacientes com escore baixo, têm um prognóstico favorável. Em particular, os exames de imagem devem fornecer informações adicionais na avaliação clínica de pacientes que apresentam escores do NIHSS nos extremos da escala $(<5$ ou $>15)$. Até o momento, o escore do NIHSS continua sendo o preditor mais poderoso de evolução clínica do AVC isquêmico. Um escore $\geq 16$ prediz uma alta probabilidade de morte ou grave incapacidade, enquanto que um escore $\leq 6$ prediz uma boa recuperação.

Kasner et al. (1999) selecionaram 39 pacientes que tiveram seus escores do NIHSS formalmente medidos na admissão e na alta. Comprovaram a alto grau de credibilidade e validade do escore do NIHSS, onde pacientes com leve ou nenhum déficit neurológico (NIHSS $\leq 5)$ poderiam ser distinguidos com uma sensibilidade de $72 \%$ e especificidade de $89 \%$. Em contrapartida, pacientes com déficits graves (NIHSS > 20) seriam identificados com uma sensitividade de $25 \%$ e especificidade de $99 \%$.

Hipoteticamente, foram atribuídos valores aos itens de avaliação da escala que poderiam influenciar na performance da função, comprometendo-a. Assim, consideraram-se os itens referentes ao nível de consciência; melhor olhar; paralisia facial; motor para mãos e pés; ataxia de membros; linguagem; disartria; extinção e inatenção, sendo pontuados. 
Para a constituição do algoritmo, foram consideradas, inicialmente, a pontuação na ECG e a presença de alterações de linguagem. Posteriormente, separaram-se os prováveis territórios de acometimento neurológico, o escore obtido no NIHSS e, por fim, a indicação de via alternativa de alimentação, uma vez que fosse suposta a presença de disfagia; caso contrário, a indicação seria de dieta por via oral. Na fase aguda do AVC uma importante consideração é se há ou não um risco de aspiração e se é apropriada a alimentação por via oral (WESTERGREN, 2006).

Assim, foram realizadas associações entre as variáveis idade, gênero, escore do NIHSS, ECG, dados sobre comunicação dos pacientes, topografia de lesão, hemisfério cerebral acometido e resultado da avaliação clínica da deglutição para observação da associação existe entre estas e a presença de disfagia.

Nos pacientes em que apresentaram quadros de disfagia leve, como dificuldade para determinada consistência alimentar, foi sugerida a modificação da dieta ou realizada a orientação para controle de volume do alimento ingerido, quando esta se fez necessária, mantendo-se a alimentação por via oral. A diferenciação entre disfagia com risco e sem risco de aspiração é importante porque pode levar a diferentes recomendações de dietas específicas (TRAPL et al., 2007).

Em cinco pacientes que não apresentavam condições clínicas para a realização da avaliação, como os que se encontravam com intubação orotraqueal, estado de sonolência profunda ou em coma, esta foi contra-indicada, sendo considerados como apresentando quadro de comprometimento grave, como sugerido pelo NIHSS. Para uma adequada avaliação fonoaudiológica, é necessário que o estado em que o paciente se encontra ofereça condições mínimas de avaliação (FURKIM, 1999), caso contrário pode-se obter alterações que não condizem com o quadro real do paciente; além disso, o nível de consciência é um dos 
preditores ao desenvolvimento de problemas na deglutição (LANGMORE et al., 2002; RADANOVIC, 2000;).

A avaliação da deglutição deve aguardar a melhora do nível de consciência e o posterior desmame da ventilação mecânica, uma vez que o rebaixamento do nível de consciência, por si só, elimina a possibilidade de avaliação da deglutição funcional (SILVA; GATTO; COLA, 2003).

Inicialmente, quando os pacientes foram avaliados no leito, foi observado que os fatores de risco isolados mais encontrados no paciente com AVC foram a HAS $(72,00 \%)$, seguido pelo tabagismo $(36,00 \%)$, etilismo $(20,00 \%)$ e diabete melito $(20,00 \%)$, sendo observados também o uso de contraceptivo oral (2,00\%); dislipidemia $(4,00 \%)$, fibrilação atrial $(6,00 \%)$, HIV positivo $(2,00 \%)$. Destaca-se ainda a presença de outros fatores de risco como a doença vascular, entre elas, a doença cardíaca coronariana $(4,00 \%)$ [infarto agudo do miocárdio $(2,00 \%)$ e angina $(2,00 \%)]$, o acidente vascular cerebral $(24,00 \%)$ [AVC I $(22,00 \%)$ e AVC H (2,00\%)] e a doença arterial crônica (2,00\%); outras cardiopatias $(8,00 \%)$ [arritmia $(2,00 \%)$, cardiopatia chagásica $(4,00 \%)$, marcapasso $(2,00 \%)$, miocardiopatia de etiologia indeterminada (2,00\%)]; outras doenças neurológicas $(6,00 \%)$ [mal de Alzheimer (2,00\%), doença de Parkinson (2,00\%), hidrocefalia de pressão normal $(2,00 \%)]$.

A HAS, o tabagismo, diabetes, dislipidemias e o etilismo aumentam o risco relativo de desenvolvimento de um AVC, em ordem de grandeza variável. A presença de arritmias cardíacas - especialmente de fibrilação atrial crônica - e cardiopatias trombogênicas (chagásicas, aneurismas), de complicações clínicas da HAS e da doença arteriosclerótica doença coronariana, vascular periférica ou estenose carotídea assintomática - também associa o aumento de risco. Pacientes que podem padecer de ataque isquêmico transitório (AIT) estão sob risco extremo de novos e graves insultos isquêmicos. Além destes, também pode ser citado o uso de anticoncepcionais orais (ANDRÉ, 1999). 
As doenças cardíacas constituem o segundo fator de risco importante para AVC. Dentre as cardiopatias (correspondente a 41,9\%), a mais encontrada foi a fibrilação atrial com freqüência relativa de $22,1 \%$ dos casos de AVCI, a doença isquêmica coronariana foi constatada em $10,6 \%$. Outros fatores de risco encontrados foram o diabete melito $(23,3 \%)$ e a HAS (60,5\%), sendo considerado o principal fator de risco preditivo para o AVC (RADANOVIC, 2000).

Os resultados do estudo sobre fatores de risco para o AVC demonstram que a HAS é significativamente freqüente $(87,8 \%)$ entre pacientes idosos (acima de 60 anos), independentemente da faixa etária e sexo. Tabagismo $(46,9 \%)$ e etilismo $(35,1 \%)$ revelaram fatores de risco, principalmente entre homens; as cardiopatias $(27,0 \%)$, o diabete melito $(19,9 \%)$ e as dislipidemias (15,6\%), em ambos os sexos e faixas etárias (PIRES; GAGLIARDI; GORZONI, 2004).

Flumignan et al. (2001) descreveram que o fator de risco mais prevalente encontrado nos pacientes com AVC foi a HAS estando em 63,80\% dos pacientes, o tabagismo em 60,30\%, o etilismo em $19,85 \%$ e uso de anticoncepcionais orais $13,58 \%$. Entre as doenças do metablismo: dislipidemia em 23,47\% e diabete melito em 13,58\%, entre outras. Fibrilação atrial foi encontrada em 2,14\% dos pacientes, diagnóstico de doença de Chagas com miocardiopatia foi em $2,86 \%$.

O processo da deglutição é afetado como um todo pela idade, com mudanças quanto às características gerais da função. Isto significa que, apesar dos idosos manterem, funcionalmente, todos os aspectos relacionados à deglutição, estes ocorrem diferentemente do observado em pessoas mais jovens, o que, comprovadamente, ocorre devido a mudanças fisiológicas e estruturais do organismo em processo de envelhecimento (ISSA, 2003). Pacientes mais velhos são mais prováveis de apresentarem problemas iniciais de deglutição, com alta taxa de mortalidade entre pacientes idosos com disfagia (BARER, 1989). 
Igualmente ao demonstrado na literatura, encontramos maior incidência de disfagia $(75,00 \%)$ em pacientes mais idosos quando comparado com o grupo de jovens $(25,00 \%)$, embora não tenha sido significante quando comparada idade com disfagia, corroborando com os achados de Smithard et al. (1996) e Teasell et al. (2002) que não observaram diferença significante entre disfagia quanto ao gênero e idade. Em contrapartida, Paciaroni et al. (2004), Hinchey et al. (2005) e Walter et al. (2007) concluíram que a idade é um preditor de disfagia, havendo correlação entre a presença de disfagia e idade, estatisticamente comprovada. Okubo et al. (2007) descreveram o aumento de risco de aspiração com o aumento da idade.

Além disto, esta alta prevalência também pode ser relacionada ao fato do grupo de pacientes acima de 55 anos ter constituído 70,00\% de nossa casuística. Embora a definição etária para AVC em jovem seja variável na literatura, tendo sido estabelecidos como limites superiores entre 40 a 55 anos de idade (OVEREL et al., 2000). Flumignan et al. (2001) em seu estudo sobre AVC em pacientes jovens considerou a faixa etária de 15 a 49 anos, relatando que a idade limite para se considerar AVC em adultos jovens não está estabelecida.

Ainda confrontando com os resultados do estudo de Smithard et al. (1996) e Teasell et al. (2002), nos achados do presente estudo também não se observou diferenças estatisticamente significantes entre gênero e presença de disfagia, com resultados similares nos dois grupos; contrariamente, Barros, Fábio e Furkim (2006) relataram que a presença de disfagia foi observada com maior freqüência no gênero feminino (62\%).

Fazendo uma análise descritiva de nossa amostra, temos que 19 pacientes apresentaram escores do NIHSS iguais ou superiores a 12. Quando comparamos os valores obtidos na escala com a presença de disfagia, observamos que houve diferença estatisticamente significante, sendo que 14 pacientes $(87,50 \%)$ com a pontuação de 12 ou mais apresentaram disfagia. 
Os cinco pacientes que não apresentaram disfagia tinham pontuação de 12 ou 13 no NIHSS. Estes mesmos indivíduos, no entanto, foram melhor identificados quando foram submetidos à avaliação conjunta com a ECG. Assim, estes pacientes apresentaram pontuação de 12 ou 13 no NIHSS e de 14 ou 15 na ECG, ou seja, valores dentro da normalidade.

Os demais pacientes $(12,50 \%)$ que apresentaram disfagia com escore do NIHSS abaixo de 12 (10 e 11) tiveram 13 e 11A pontos na ECG, demonstrando graus de alteração, segundo os critérios para interpretação da escala. Ainda assim, a grande maioria $(85,29 \%)$ dos pacientes com escores abaixo de 12 pontos, não apresentou alterações de deglutição.

Observa-se que quando as variáveis apresentam associações diferentes do que inicialmente se supôs, os valores de escores são próximos ao pré-determinado, com um ponto para cima ou para baixo, ou, no máximo, dois como demonstra o escore do paciente acima descrito ou ainda, apresentam, exatamente, a pontuação de corte. Provavelmente, estes são aqueles achados falsos-positivos e falsos-negativos dentro de um estudo, que serão discutidos mais adiante.

O estudo de Hinchey et al. (2005) realizado em uma tentativa de responder questões relacionadas à aplicação de instrumentos de classificação de disfagia e prevenção de pneumonia em pacientes com AVC, utilizou o NIHSS para correlacionar com a prevalência de pneumonia relativa à severidade dos déficits; considerou as categorias no NIH como leve de 08, moderado de 9-16 e severo acima de 17. Concluiu que NIHSS foi importante preditor do desenvolvimento de pneumonia, sendo encontrada em pacientes com escores mais altos. Porém, os autores não definiram quais seriam estes escores. Para Paciaroni et al. (2004) o escore do NIHSS $\geq 15$ é considerado um fator preditor de disfagia.

$\mathrm{Na}$ associação entre a pontuação da ECG e disfagia constatamos que 94,12\% dos pacientes sem disfagia apresentaram escores iguais ou superiores a 14 pontos, considerados a normalidade. Em contrapartida, houve cinco pacientes com este escore que apresentaram o 
sintoma. Quando voltamos à caracterização destes pacientes temos que os apresentaram escore do NIHSS maiores ou iguais a 12, estando dentro dos critérios iniciais para identificação de disfagia. Ressalta-se, porém, que o escore obtido por dois destes pacientes foi, exatamente, 12 .

Observando os escores abaixo de 14, temos dois pacientes sem alterações de deglutição. Estes apresentaram NIHSS abaixo de 12 pontos (escores 9 e 10). Dos 12 pacientes com escores menores que 14 com disfagia, apenas dois apresentaram NIHSS abaixo de 12 pontos, tendo como escores de 10 e 11.

Portanto, houve significância estatística entre o escore da ECG e a presença ou não de disfagia. Considerando que a ECG é utilizada para avaliar o nível de consciência, são considerados comprometidos pacientes com escore abaixo de 13 (WALTER et al., 2007). A presença de sonolência, caracterizando um rebaixamento do nível de consciência, é um preditor de disfagia (PACIARONI et al., 2004).

A ECG pode parecer que foi mais sensível na detecção das alterações de deglutição, porém o intervalo existente entre os valores de pontuação máxima e mínima é menor que no NIHSS, sendo que esta apresenta caráter mais esclarecedor na detecção de disfagia.

As alterações de fala e linguagem (disartria e afasia) apresentaram associação, estaticamente significante, com a presença de disfagia.

Houve uma preponderância quanto à presença de disfagia em pacientes com alterações de linguagem (68,75\%). Destes, apenas dois apresentaram escore abaixo de 12 na escala do NIH (valores iguais a 10 e 11). Correlacionando a ECG, temos valores de $11 \mathrm{~A}$ e 13, respectivamente. Dos quatro pacientes sem disfagia, apenas um apresentou 13 pontos no NIHSS sendo esperada a alteração da função, porém obteve 15 pontos na ECG. No estudo de Barer (1989) com 357 pacientes com AVC admitidos na enfermaria do hospital, houve uma 
forte correlação entre a presença de disfagia e alteração de linguagem (compreensão e expressão).

Ressalta-se que estes pacientes com afasia apresentaram os maiores escores do NIHSS (acima de 15) de toda nossa amostra, podendo-se concluir, portanto, que foram os pacientes mais graves. Corroborando com os resultados do estudo de Barer (1989) indicando que dificuldades moderadas de deglutição, as quais usualmente recebem pouca atenção da equipe médica, estão associadas a uma recuperação funcional pior, ou seja, a gravidade do AVC em geral.

Pacientes com lesões no hemisfério esquerdo, dominante para a linguagem, terão NIHSS maior devido ao provável comprometimento desta. Descrevem ainda, que o NIHSS pode ser mais sensível a lesões no hemisfério esquerdo, considerando que dos 42 pontos possíveis, sete estão diretamente relacionados à avaliação da linguagem (WOO et al., 1999).

Com a prevalência de $31,25 \%$ dos pacientes com disartria que apresentaram disfagia, houve completa correlação entre estes e o escore do NIHSS, ou seja, todos com pontuação acima de 12. Para os que não apresentaram disfagia, apenas dois tiveram 12 e 13 pontos na escala de AVC, com 15 e 14 na ECG.

A disartria é considerada como um fator preditivo de risco para aspiração na avaliação clínica dentre os seis fatores identificados (DANIELS et al., 1998; DANIELS et al., 2000). Nestas, observa-se comprometimento do controle motor da fala (MURDOCH, 1997), fato este que pode levar a disfunções de deglutição, principalmente na fase oral desta, devido à participação de estruturas comuns. Como exemplo ressalta-se a importância da língua na fala, na preparação e na retropropulsão do bolo alimentar. Barer (1989) também ressaltou a correlação entre disfagia e paralisia facial, sendo este último um comprometimento comum nos quadros disártricos. Sintomas da fala também podem estar presentes em pacientes com risco de aspiração (McCULLOUGH; WERTZ; ROSENBEK, 2001). 
Nenhum dos pacientes sem alterações de comunicação apresentou disfagia. Apenas um teve escore de 12 no NIHSS com 15 pontos na ECG. Com exceção feita a dois dos 13 pacientes sem alterações, que obtiveram escores de 11 e 12 no NIHSS, observamos que $84,61 \%$ destes tiveram os menores escores da amostra (igual ou inferior a seis pontos), sendo, os menos acometidos.

Ao serem associadas à topografia da lesão e presença de disfagia houve significância estatística, sendo que a disfagia esteve presente em todos os pacientes com lesões em território carotídeo.

Dos pacientes sem disfagia, 58,82\% apresentaram acometimento em território carotídeo, 29,41\% em vertebrobasilar e em $11,76 \%$ não foi possível definir a topografia da lesão. Podemos observar que a grande maioria $(85,00 \%)$ dos pacientes com lesões em território carotídeo apresentaram escore do NIHSS abaixo de 12 e três pacientes $(15,00 \%)$ apresentaram valores de 12 e 13, com pontuação referente à normalidade na ECG igual a 14 ou 15.

Os pacientes com lesões em território vertebrobasilar igualmente apresentaram baixa pontuação na escala de AVC com exceção a dois pacientes com escores de 13, porém com 15 pontos na ECG.

Finalmente, aqueles pacientes em que não foi possível definir a topografia da lesão, $100,00 \%$ apresentaram NIHSS inferior a 11 pontos.

Ressaltamos ainda, que $72,00 \%$ de nossos pacientes apresentaram lesão em território carotídeo e 20,00\% em território vertebrobasilar. Existem poucos pacientes com lesão em artéria carótida interna e/ou circulação posterior para análises significantes (WITYK et al., 1994).

A presença de disfagia está fortemente associada com o subtipo de AVC. Lesões da circulação cerebral anterior apresentam alta incidência de disfagia no período de uma semana 
do evento, representando $75,00 \%$ dos pacientes com disfagia dois dias após o AVC e 90,00\% dos que persistiram com alteração após uma semana (LANGDON; LEE; BINNS, 2007). Infartos com envolvimento de artéria cerebral anterior são primariamente responsáveis pela disfagia porque afetam áreas representacionais para a deglutição (PACIARONI et al., 2004). Há prevalência de lesões em território carotídeo, sendo o mais envolvido em $76 \%$ dos pacientes disfágicos, porém sem significância estatística (BARROS; FÁBIO; FURKIM, 2006).

Não houve pacientes com disfagia e lesão em território vertebrobasilar ou com lesões inespecíficas, impossíveis de serem definidas sua localização. Langdon, Lee e Binns (2007) observaram que pacientes com infartos lacunares não apresentaram disfagia nos dias que se sucederam ao evento, havendo apenas a necessidade de modificação da consistência alimentar. Barros, Fábio e Furkim (2006) encontraram que o território vertebrobasilar foi mais afetado em pacientes com deglutição funcional (43\%), ou seja, aqueles sem alterações de deglutição ou alterações em fase oral que não implicassem em riscos de penetração e/ou aspiração laringotraqueal. Para Horner et al. (1988) a presença de aspiração não está limitada a lesões no tronco cerebral ou em lesões bilaterais. Por outro lado, Terré e Mearin (2006) referiram que pacientes com lesões em território posterior têm maior risco de apresentarem aspiração. Walter et al. (2007) mostraram que o acometimento em território vertebrobasilar é preditor de pneumonia.

Teasell et al. (2002) identificaram apenas 20 (3,6\%) pacientes com AVC predominantemente bulbar dos 563 admitidos no hospital. O AVC de tronco cerebral é uma síndrome que ocorre como conseqüência da insuficiência vertebrobasilar.

AVCs de tronco cerebral são menos comuns em relação às outras regiões (HORNER et al., 1988).

Horner et al. (1991) estudaram 23 pacientes com AVC de tronco cerebral confirmado pelo exame de ressonância magnética através da realização da videofluoroscopia da 
deglutição após 46 dias do AVC. O objetivo do estudo foi observar a freqüência de disfagia, correlatos neurológicos e evolução. Na amostra, mais que $80 \%$ dos pacientes reiniciaram a alimentação por via oral sem morbidade. Concluíram que apesar da gravidade do quadro inicial de AVC de tronco cerebral, estes pacientes apresentam uma boa evolução.

A última associação entre cada variável isolada foi feita verificando a relação hemisfério cerebral acometido e disfagia, não havendo diferença estatisticamente significante, estando de acordo com o estudo de BARROS, FÁBIO e FURKIM (2006) relatando que a localização hemisférica não está associada com a presença ou não de disfagia.

De todos os pacientes com disfagia, 56,25\% correspondiam a lesões no hemisfério direito e os demais $43,75 \%$ no esquerdo. Buscando a associação com o escore do NIHSS, todos tiveram pontuação abaixo de 12. Dos 26 pacientes acometidos neste hemisfério, 17 não apresentaram disfagia e, apenas quatro destes tiveram escores igual ou superior a 12 pontos, porém mantendo-se próximos a este corte, com escores dentro da normalidade na ECG.

Voltando às lesões do hemisfério esquerdo, 43,75\% dos pacientes apresentaram disfagia. Destes, dois tiveram NIHSS abaixo de 12 (11 a 10) com pontuação de $11 \mathrm{~A}$ e 13 na ECG. Os 13 pacientes sem disfagia e lesão cerebral à esquerda tiveram escore compatível com o corte proposto para a ausência de alterações com exceção a um paciente que apresentou 13 pontos, com ECG igual a 15.

Como já observado naqueles pacientes em que não foi possível definir a topografia da lesão, 100,00\% apresentaram NIHSS inferior a 11 pontos.

Não houve predomínio significante na lateralidade do hemisfério cerebral acometido em nossa amostra, em concordância com Barer (1989); Paciaroni et al. (2004); Barros, Fábio e Furkim (2006); Terré e Mearin (2006).

Hamdy et al. (1997) realizaram um estudo com 20 pacientes com AVC hemisférico unilateral através da avaliação clínica da deglutição junto à eletroneuromiografia com o 
estudo da resposta do músculo milohióideo, representando a musculatura da fase oral da deglutição e os músculos da faringe. Concluíram que a tentativa de correlacionar características de lesões unilaterais com dificuldades de deglutição não demonstrou achados consistentes. Pacientes disfágicos com AVC hemisférico unilateral têm uma menor resposta faríngea do hemisfério não afetado em relação àqueles sem disfagia, desconsiderando o lado e nível (cortical ou subcortical) da lesão. Os achados do estudo indicaram que a inervação hemisférica bilateral do tronco cerebral para ambos os centros corticais da deglutição não é essencial para a adequada função da deglutição e que sua preservação pode ser determinada por um importante número de neurônios faríngeos corticais inervando o centro da deglutição no tronco cerebral.

Finalmente, com a intenção de observar a prevalência de disfagia e a relação da topografia e escore do NIHSS com a presença ou não de disfagia, fez-se a associação entre estas variáveis agrupadas, sendo encontradas diferenças estatiticamente significantes, em que todos os pacientes $(100,00 \%)$ que apresentaram disfagia tinham acometimento em território carotídeo, sendo que $87,50 \%$ apresentaram escore do NIHSS igual ou superior a 12 e apenas dois pacientes $(12,50 \%)$ abaixo de 12 . Nestes temos escores de 10 e 11 . Realizando a mesma correlação que nas variáveis isoladas, estes pacientes apresentaram pontuação da ECG de 13 e $11 \mathrm{~A}$, respectivamente.

Já os pacientes sem disfagia, 58,82\% apresentaram lesão em território carotídeo, 29,41\% em território vertebrobasilar e 11,76\% não apresentaram definição da topografia. Primeiramente, os pacientes com lesão em território carotídeo tiveram uma alta porcentagem $(50,00 \%)$ de escore do NIH inferior a 12 ; dos três pacientes $(8,82 \%)$ com escore igual ou superior a 12, não apresentaram disfagia, conforme esperado, mas seus escores foram de 12 , 12 e 13 , com ECG igual a 15, 15 e 14, respectivamente. 
No total de 10 pacientes com acometimento em território vertebrobasilar, oito $(23,53 \%)$ apresentaram escores abaixo de 12 e os dois pacientes restantes tiveram valores de 13 no NIHSS e de 15 na ECG.

Naqueles em que não foi possível definir a topografia da lesão, todos tiveram escores menores que 12 pontos na escala de AVC. Em geral, pacientes com AVC lacunar têm menor escore quando comparados com AVC de outras causas. Apenas este subtipo de AVC, segundo a classificação de TOAST, apresenta prognóstico de recuperação independente do escore do NIHSS (ADAMS et al., 1999).

Como a proposição do estudo foi a criação de um algoritmo para a detecção de pacientes que apresentassem disfagia na fase aguda do AVC, havendo, nestes casos, contraindicação quanto à alimentação por via oral, com base no NIHSS, temos que analisar a sensibilidade e especificidade do valor corte determinado para esta apresentação.

Um instrumento é mais sensível quanto maior sua probabilidade de detectar um evento, o que implica, também, em sua capacidade de não fornecer resultados falsamente negativos. Por outro lado, a especificidade mede a capacidade que esse instrumento tem de não detectar eventos inexistentes. Portanto, um instrumento de alta especificidade é aquele que terá alta probabilidade de não fornecer resultados falsamente positivos (GOMES, 2005).

Para testar qual a sensibilidade de detecção da presença de disfagia quando consideramos o escore do NIHSS que, segundo a nossa hipótese inicial, deveria ter uma pontuação de 12 ou mais e a especificidade, para que não houvesse a presença de disfagia em escores abaixo deste corte, realizou-se a curva ROC.

O melhor valor considerado neste estudo foi aquele que demonstrou uma alta sensibilidade, ou seja, que o escore foi altamente sensível na detecção de disfagia, sendo este, o valor de 12 , inicialmente proposto. Neste corte temos uma sensibilidade de $88,00 \%$ e uma especificidade de $85,00 \%$. 
Walter et al. (2007) estudaram 236 pacientes com AVCI agudo admitidos em uma unidade de terapia intensiva (UTI) visando determinar preditores clínicos independentes para o desenvolvimento de pneumonia. Utilizaram, nas primeiras 24 horas da admissão, o NIHSS para avaliar a gravidade do déficit neurológico e a ECG para verificar o nível de consciência, sendo considerados como comprometidos pacientes com escore abaixo de 13 . O NIHSS $\geq 5$ teve menos especificidade para fator de risco clínico para o desenvolvimento de pneumonia do que o NIHSS $\geq 10$. Os dados obtidos demonstraram que a disfagia, o infarto de gânglio basal não lacunar e outras infecções além da pneumonia na admissão do paciente e NIHSS $\geq$ 10 são preditores clínicos iniciais independentemente da ocorrência de pneumonia associada ao AVC, especialmente na ocorrência precoce da infecção na fase aguda. A sensibilidade para o NIHSS $\geq 10$ foi de $82 \%$ e a especificidade de $71 \%$; para o NIHSS $\geq 5$, a sensibilidade foi de $96 \%$, porém a especificidade foi de $35 \%$.

Conforme alguns resultados de associação nos sugerem durante a descrição do estudo, tivemos alguma variância para mais ou para menos deste corte quando observada a presença de disfagia. Ao modificarmos este para menos, tomando-se o corte de 10, observamos um aumento na sensibilidade para $100,00 \%$ e uma queda na especificidade para $77,00 \%$. Por outro lado, na tentativa de aumentar este corte, por exemplo para 13, ocorre o inverso, havendo uma queda na sensibilidade e um aumento na especificidade.

Poderíamos então pensar que reduzir este corte para 10 seria o mais adequado. Porém, quando um resultado de sensibilidade ou especificidade se aproxima a 100,00\%, temos um aumento na chance de se encontrarem resultados falsamente positivos ou falsamente negativos, respectivamente.

Dessa forma, foram calculados os valores preditivos positivos (VPP) e preditivos negativos (VPN). O VPP é a probabilidade que uma pessoa tem de apresentar o evento dado 
que o resultado do teste foi positivo e o VPN é a probabilidade que uma pessoa tem de não apresentar o evento dado que o resultado empregado foi negativo (GOMES, 2005).

Constatamos que, referentemente ao corte de 12 pontos na escala do NIHSS, o VPP é igual a $50,00 \%$ e o VPN de $30,00 \%$, ou seja, um paciente com escore do NIHSS igual a 12 e com disfagia tem 50,00\% de chance de não apresentar este sintoma; por outro lado, se este paciente não apresentar disfagia a chance disto ocorrer é de $30,00 \%$.

Podemos observar que quanto menor é a prevalência de disfagia, menor é o VPP e maior o VPN; quanto maior sua prevalência, maior é o VPP e menor é o VPN.

Diante disto, o escore de 12 parece ser aceitável como preditor de disfagia, considerando os dados acima mencionados. Quando a escala no NIHSS não demonstrou sensibilidade para a detecção de disfagia, pudemos obter dados adicionais quanto à pontuação da ECG, conforme discutido na correlação entre as variáveis. Ainda que sensitividade sem especificidade e vice-versa possa ser utilizada em algumas situações, dependendo do que se considera mais importante, isto não poderia significar que medidas isoladas sejam suficientes para predizer aspiração em AVC na fase aguda (McCULLOUGH; WERTZ; ROSENBEK, 2001).

Um número maior de pacientes poderia aumentar os valores de sensibilidade e especificidade. Uma atenção poderia ser dada quanto à obtenção de uma homogeneidade em relação à idade, não analisando pacientes adultos jovens junto a idosos; e em relação à gravidade dos pacientes de acordo com o NIHSS, pois, em nosso estudo, 31 pacientes apresentaram pontuações abaixo de 12 e apenas 19 com escore igual ou superior a este. Adicionalmente, a distribuição do escore foi irregular acima de 12 pontos, representando um obstáculo para uma avaliação mais acurada.

O objetivo de formular um algoritmo baseado em escalas e critérios de diagnóstico, basicamente, clínicos, reforça ainda mais a justificativa para a escolha desta avaliação. A 
formulação do algoritmo tem o propósito de sugerir a indicação de via mais segura de alimentação na fase aguda do AVCI. Entretanto, o algoritmo apresentado na página 43 apresenta deficiências importantes. Nossos achados apontaram que o escore da ECG e a presença de alterações de fala e /ou linguagem (disartria e/ou afasia) não devem ser limitantes iniciais na detecção ou não de pacientes com disfagia e sim incorporados aos demais aspectos analisados para a caracterização destes indivíduos. Além disto, a distribuição territorial da vasculatura não deve ser considerada fator decisivo para a indicação de via alternativa de alimentação. Assim, a figura 2 apresenta o algoritmo incorporando várias modificações fundamentadas no nosso estudo.

FIGURA 2: Algoritmo para detecção de presença de disfagia grave na fase aguda do AVCI.

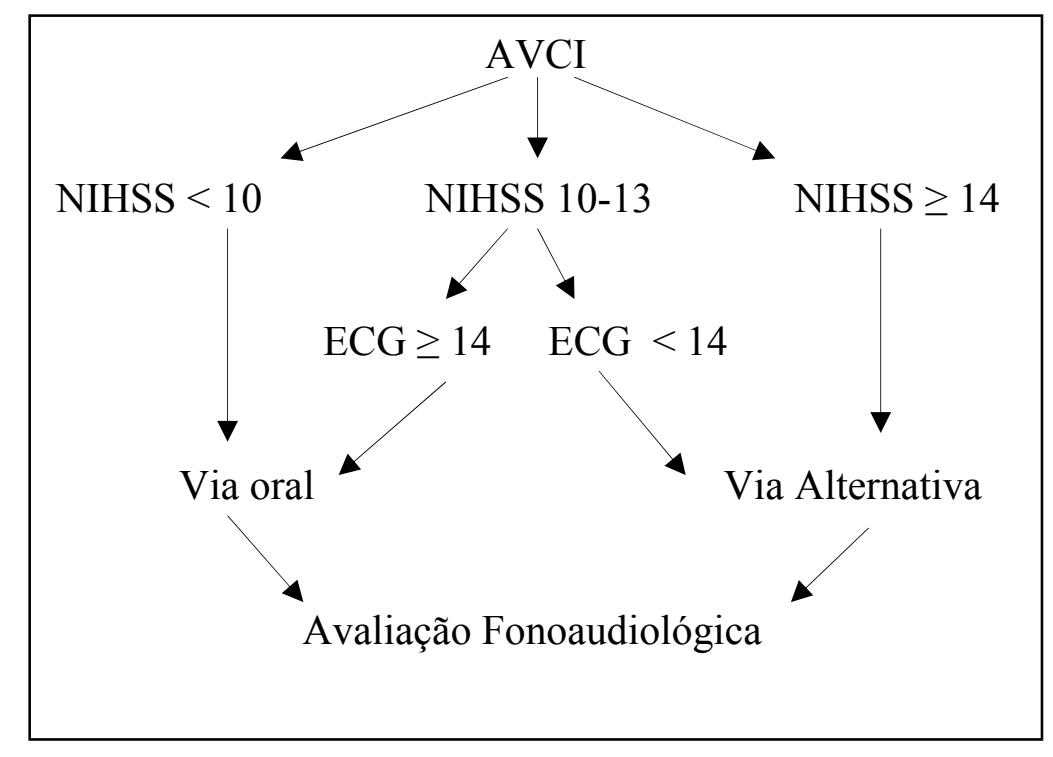

Para que não sejam tomadas condutas precipitadas e, muitas vezes, inadequadas, quando o escore do NIHSS for entre 10 e 13, o referencial para a indicação ou não de via alternativa de alimentação, demonstrou ser melhor caracterizado pelo resultado obtido na 
ECG, com valores iguais ou inferiores a13. Ressalta-se, ainda, que não se deve considerar, inicialmente, o valor desta escala, sendo apenas um critério diferencial.

A criação de um critério para a detecção de pacientes que apresentam disfagia, entretanto, não exclui a avaliação da deglutição realizada pelo profissional especializado, um fonoaudiólogo. A intenção é minimizar a ocorrência de complicações, pois concluir que a função da deglutição encontra-se alterada em determinado paciente exige uma série de ponderações de cunho prático.

Se o resultado da sensitividade do instrumento de avaliação for suficientemente preciso para permitir seu uso na rotina, possibilitará a identificação dos pacientes que não apresentam riscos de aspiração pela equipe médica ou de enfermagem e apenas os que apresentarem estes riscos permanecerão restritos a dieta zero por via oral (SMITHARD et al., 1998). Os fatores chaves para o manejo da disfagia são o diagnóstico e a intervenção precoce (HORNER et al., 1991).

O hábito, culturalmente, praticado de que a melhora clínica do paciente está diretamente vinculada a sua alimentação, deve ser repensado em algumas situações. A vítima de AVCI passa por um enorme risco de complicações ao ser alimentada, indevidamente, com demasiada precocidade (ou com alimentos de consistências inadequadas).

Esperamos que o presente estudo possa representar uma contribuição para a correta decisão sobre a segurança na oferta de alimentos, conscientes de que, até mesmo a eventual restrição total, possa ser a conduta mais acertada neste estado da doença. 
CONCLUSÕES

=


- A disfagia é uma manifestação freqüente na fase aguda do AVCI, estando presente em 32\% dos pacientes analisados.

- Idade, NIHSS, ECG, alterações de fala e linguagem e topografia da lesão são fatores preditivos de disfagia apresentando diferenças estatisticamente significantes, enquanto que gênero e hemisfério cerebral acometido não tiveram associação estatisticamente significante com a presença de disfagia.

- O NIHSS apresentou alta sensibilidade $(88,00 \%)$ e especificidade $(85,00 \%)$ para detecção de disfagia considerando 12 como valor de corte. Deve-se considerar que pacientes com escore igual ou superior a 14 não devem receber alimentos por via oral. Aqueles com pontuação entre 10 e 13, devem ser orientados pela pontuação da ECG.

- A formulação de um algoritmo para detecção de disfagia na fase aguda do AVCI foi viável, e poderá auxiliar na definição de condutas quanto à melhor via de administração da dieta enquanto se aguarda uma avaliação fonoaudiológica especializada. 
REFERÊNCIAS 
. MINISTÉRIO DA SAÚDE. INDICADORES E DADOS BÁSICOS - BRASIL 2006 - IDB 2006. Indicadores básicos para a saúde no Brasil: conceitos e aplicações. Disponível: http://tabnet.datasus.gov.br/cgi/idb2006/CapituloC.pdf. (acesso em 10/11/2007). $\overline{\text { Inc., } 2002 .}$. . SAS Institute Inc., SAS/STAT® User's Guide, Version 9, Cary, NC: SAS Institute . SCOTTISH INTERCOLLEGIATE GUIDELINES NETWORK. Management of patients with stroke: identification and management of dysphagia. A national guideline (disponível em: www.sign.ac.uk, acesso em 15 ago 2007) September, 2004.

ADAMS, H.P.; BENDIXEN, B.H.; KAPPELLE, L.J.; BILLER, J.; LOVE, B.B.; GORDON, D.L.; MARSH, E.E.; AND TOAST INVESTIGATORS. Classification of subtype of acute isquemic stroke: definitions for use in a multicenter clinical trial. Stroke 24: 35-41, 1993.

ADAMS, H.P.; DAVIS, P.H.; LEIRA, E.C.; CHANG, K.C.; BENDIXEN, B.H.; CLARKE, W.R.; WOOLSON, R.F.; HANSEN, M.D. Baseline NIH stroke scale score strongly predicts outcome after stroke: a report of the trial of org 10172 in acute stroke treatment (TOAST). Neurology 53: 126-131, 1999.

ANDRÉ C. Manual de AVC. Editora Revinter, 1999.

BARER, D.H. The natural history and functional consequences of dysphagia after hemispheric stroke. Journal of Neurology, Neurosurgery and Psychiatry. 52: 236-241, 1989.

BARROS, A.F.; FÁBIO, S.R.C.; FURKIM, A.M. Correlação entre os achados clínicos da deglutição e os achados da tomografia computadorizada de crânio em pacientes com acidente vascular cerebral isquêmico na fase aguda da doença. Arquivos de Neuropsiquiatria 64(4): 1009-1014, 2006.

BARROS, A.F.F.; OKUBO, P.C.M.I.; DOMENIS, D.R.; RICZ, H.M.; MELLO-FILHO, F.V. Comparação entre a avaliação clínica e objetiva da deglutição em pacientes com disfagia orofaríngea neurogênica. Revista da Sociedade Brasileira de Fonoaudiologia. 11(2): 90-95, 2006.

BATH, P.M.W.; BATH, F.J.; SMITHARD. Interventions for dysphagia in acute stroke (Cochrane Review). In: Cochrane Library, Issue 3, 2002. 
BRANDT, L.J. Gastrointestinal disorders in the elderly. In: ROSSMAN, I. Clinical Geriatrics, $3^{\text {rd }}$ edition, pp. 260-77, 1986.

BRITTON, M.; RODEN, A. Progression of stroke after arrival at hospital. Stroke. 16: 629632, 1985.

BROADLEY, S.; CHEEK, A.; SALONIKIS, S.; WHITHAM, E.; CHONG, V.; CARDONE, D.; ALEXANDER, B.; TAYLOR, J.; THOMPSON, P. Predicting prolonged dysphagia in acute stroke: the Royal Adelaide Prognostic Index for Dysphagia Stroke (RAPIDS). Dysphagia 20: 303-310, 2005.

BROTT, T.; ADAMS, H.P.; OLINGER, C.P.; MARLER, J.R.; BARSAN, W.G.; BILLER, J.; SPILKER, J.; HOLLERAN, R.; EBERLE, R.; HERTZBERG, V.; RORICK, M.; MOOMAW, C.J.; WALKER, M. Measurements of acute cerebral infarction: a clinical examination scale. Stroke july 20(7): 864-870, 1989.

BUSHNELL C.D.; JOHNSTON, D.C.C.; GOLDSTEIN, L.B. Retrospective assessment of initial stroke severity: comparison of the NIH stroke scale and the canadian neurological scale. Stroke 32(3): 656-660, 2001.

CAMBIER, J.; MASSON, M.; DEHEN, H. Patologia vascular cerebral. Manual de neurologia. Editora Medsi, p. 363-411, 1999.

CANEDA, M.A.G.; FERNANDES, J.G.; ALMEIDA, A.G.; MUGNOL, F.H. Confiabilidade de escalas de comprometimento neurológico em pacientes com acidente vascular cerebral. Arquivos de Neuropsiquiatria 64 (3-A): 690-697, 2006.

CASTELL, D.O. Distúrbios do trato gastrointestinal. In: ABRAMS, B.A.; BERKOW, R. Manual Merk de Geriatria, ed. Roca, pp. 530-41, 1995.

CRARY, M.A.; MANN, G.D.C.; GROHER, M.E. Initial psychometric assessment of a functional oral intake scale for dysphagia in stroke patients. Archives of Physical Medicine and Rehabilitation. 86: 1516-1520, 2005.

DANIELS, S.K.; BALLO, L.A.; MAHONEY, M.C.; FOUNDAS, A.L. Clinical predictors of dysphagia and aspiration risk: outcome measures in acute stroke patients. Archives of Physical Medicine and Rehabilitation 81: 1030-1033, 2000.

DANIELS, S.K.; BRAILEY, K.; PRIESTLY, D.H.; HERRINGTON, L.R.; WEISBERG, L.A.; FOUNDAS, A.L. Aspiration in patients with acute stroke. Archives Physical Medicine and Rehabilitation. 79: 14-19, 1998. 
DANIELS, S.K.; McADAM, C.P.; BRAILEY, K.; FOUNDAS, A.L. Clinical assessment of swallowing and prediction of dysphagia severity. American Journal Speech, Language and Pathology. 6(1): 17-21, 1997.

DANTAS, R.O. Papel da manometria no diagnóstico das doenças motoras do esôfago. In: MACEDO-FILHO, E.M.; PISSANI, J.C.; CARNEIRO, J.; GOMES, G. Disfagia: Abordagem Multidisciplinar. 2a ed. Frontis editorial, pp.139-142, 1998.

DeGRABA, T.J.; HALLENBECK, J.M.; PETTIGREW, K.D.; DUTKA, A.J.; KELLY, B.J. Progression in acute stroke: value of the inicial NIH stroke scale score on patient stratification in future trials. Stroke 30: 1208-1212, 1999.

DODDS, W. J.; LOGEMANN, J. A.; STEWART, E. T. Radiologic assessment of abnormal oral and pharyngeal phases of swallowing. American Journal of Radiology, 154: 965-74, may $1990 \mathrm{~b}$.

DODDS, W. J.; STEWART, E. T.; LOGEMANN, J. A. Physiology and radiology of the normal oral and phayngeal phases of swallowing. American Journal of Radiology, 154: 953-963, may 1990a.

DRAY, T.G.; HILLEL, A.D.; MILLER, R.M. Dysphagia caused by neurologic déficits. In: BASTIAN, R.W. Dysphagia in children, adults and geriatrics. Otoryngologic Clinics of North America 31(3): 507-524, 1998.

FEIJÓ, A.V.; RIEDER, C.R.M. Distúrbios da deglutição em idosos. In: JACOBI, J.S.; LEVY, D.S.; CORREA DA SILVA, L.M. Disfagia: Avaliação e Tratamento. Ed. Revinter, pp. 225$32,2003$.

FLUMIGNAN, V.H.; NÓVAK, E.M.; CAMARGO, C.H.F.; JÚNIOR, H.C.; CORAL, P.; MUZZIO, J.A.; IWAMOTO, F.M.; COLETA, M.V.D.; WERNECK, L.C. Acidente vascular cerebral em pacientes jovens: análise de 164 casos. Arquivos de Neuropsiquiatria. 59(3-B): 740-745, 2001.

FURKIM, A.M. Fonoterapia nas disfagias orofaríngeas. In: FURKIM, A. M; SANTINI, C. S. Disfagias Orofaríngeas. Carapicuiba, SP: Pró-Fono, pp. 229-58, 1999.

GAGLIARDI, R.J. Acidente vascular cerebral: fatores de piora dos doentes nos primeiros dias. Revista Brasileira Clínica e Terapêutica 17(5): 155-159, 1988. 
GOLDSTEIN, L.B.; JONES, M.R.; MATCHAR, D.B.; EDWARDS, L.J.; HOFF, J.; CHILUKURI, V.; ARMSTRONG, B.; HORNER, R.D. Improving the reliability of stroke subgroup classification using the trial of ORG 10172 in acute stroke treatment (TOAST) criteria. Stroke 32: 1091-97, 2001.

GOLDSTEIN, L.B.; SAMSA, G.P. Reliability of the national institutes of health stroke scale: extension to non-neurologists in the context of a clinical trial. Stroke feb 28 (2): 307-310, 1997.

GOMES, U.A. Características dos instrumentos de medida In: FRANCO, L.J.; PASSOS, A.D.C. (org.) Fundamentos de epidemiologia. Editora Manole. Cap. 7, p. 151-164, 2005.

GONÇALVES, MIR; VIDIGAL, MLN. Avaliação videofluoroscópica das disfagias. In: FURKIM, AM; SANTINI, CS. Disfagias Orofaríngeas. Carapicuiba, SP: Pró-Fono, pp. 189202, 1999.

GORMAN, R.C.; MORRIS, J.B.; KAISER, L.R. Esophageal disease in the elderly patient. In: ZENIL-MAN, M; ROSLYN, JJ. The Surgical Clinics of North America 74: 93-112, 1994.

GRESHAM, S.L. Clinical assessment and management of swallowing difficulties after stroke. The Medical Journal of Australia. 153: 397-399, 1990.

HAMDY, S.; AZIZ, Q.; ROTHWELL, J.C.; CRONE, R.; HUGHES, D.; TALLIS, R.C.; THOMPSON, D.G. Explaining oropharyngeal dysphagia after unilateral hemispheric stroke. Lancet 350: 686-692, 1997.

HINCHEY, J.A.; SHEPAHARD, T.; FURIE, K.; SMITH, D.; WANG, D.; TONN, S.; FOR THE STROKE PRACTIVE IMPROVEMENT NETWORK INVESTIGATORS. Stroke 36: 1972-1976, 2005.

HOLLINSHED, H.. Anatomy of the phariynx and esophagus, English, vol. 3, cap. 3, 1994.

HORNER, J.; BUOYER, F.G.; ALBERTS, M.J.; HELMS, M.J. Dysphagia following brainstem stroke: clinical correlates and outcome. Archives of Neurology. 48: 1170-1173, 1991.

HORNER, J.; MASSEY, E.W.; RISKI, J.E.; LATHROP, D.L.; CHASE, K.N. Aspiration following stroke: clinical correlates and outcome. Neurology. 38: 1359-1362, 1988. 
ISSA, P.C.M. Avaliação estrutural e funcional da deglutição de idosos, com e sem queixas de disfagia, internados em uma enfermaria geriátrica. 100p, 2003. Dissertação (Mestrado em Ciências Médicas), Universidade de São Paulo, Ribeirão Preto, 2003.

KASNER, S.E.; CHALETA, J.A.; LUCIANO, J.M.; CUCCHIARA, B.L.; RAPS, E.C.; McGARVEY, M.L.; CONROY, M.B.; LOCALIO, A.R. Reliability and validity of estimating the NIH stroke scale score form medical records. Stroke 30(8): 1534-1537, 1999.

KATZAN, I.L.; CEBUL, R.D.; HUSAK, S.H.; DAWSON, N.V.; BAKER, D.W. The effect of pneumonia on mortality among patients hospitalized for acute stroke. Neurology 60: 620$625,2003$.

KELLEY, R.E. Afecções dos vasos cerebrais. In: WEINER, W.J.; GOETZ, C.G. Neurologia para o não-especialista: fundamentos básicos da neurologia contemporânea. $4^{\mathrm{a}}$ edição, Editora Santos, p. 69-83, 2003.

KIDD, D.; LAWSON, J.; NESBIT, R.; MACMAHON, J. Aspiration in acute stroke: a clinical study com videofluoroscopy. Journal of Medicine. 86: 825-30, 1993.

KIDD, D.; LAWSON, J.; NESBIT, R.; MACMAHON, J. The natural history and clinical consequences of aspiration in acute stroke. QJM. 88: 409-413, 1995.

KIDD, D.; LAWSON, J.; NESBITT, R.; MacMAHON, J. The natural history and clinical consequences of aspiration in acute stroke. QJM. 88: 409-413, 1994.

LANGDON, P.C.; LEE, A.H.; BINNS, C.W. Dysphagia in acute ischaemic stroke: severity, recovery and relationship to stroke subtype. Journal of Clinical Neuroscience. 14: 630-34, 2007.

LANGMORE, S.E.; SKARUPSKI, K.A.; PARK, P.S.; FRIES, B.E. Predictors of aspiration pneumonia in nursing home residents. Dysphagia 17: 298-307, 2002.

LANGMORE, S.E.; TERPENNING, M.S.; SCHORK, A.; CHEN, Y.; MURRAY, J.T.; LOPATIN, D.; LOESCHE, W.J. Predictors of aspiration pneumonia: how important is dysphagia? Dysphagia 13: 69-81, 1998.

LEDER, S.B.; ESPINOSA, J.F. Aspiration risk after acute stroke: comparison of clinical examination and fiberotic endoscopic evaluation of swallowing. Dysphagia. 17(3): 214-8, 2002. 
LOGEMANN, J.A. Effects of aging on the swallowing mechanism. Otolaryngologic Clinic of North America, 23 (6): 1045-56, 1990.

LOGEMANN, J.A. Pneumonia in stroke patients: a retrospective study. Dysphagia. 15: 51$57,2000$.

LYDEN, P.D.; LU, M.; JACKSON, C.; MARLER, J.; KOTHARI, R.; BROTT, T.G.; ZIVIN, J.; AND THE NINIDS rtPA STROKE TRIAL INVESTIGATORS. Underlying structure of the national institutes of health stroke scale: results of a factor analysis. Stroke. 30: 23472354, 1999.

LYDEN, P.D; BROTT, T.; TILLEY, B.; WELCH, K.M.A.; MASCHA, E.J.; LEVINE, S.; HALEY, E.C.; GROTTA, J.; MARLER, J.; TPA STROKE STUDY GROUP. Improved reliability of the NIH stroke scale using video training. Stroke 25:2220-2226, 1994.

MACEDO-FILHO, E.D. Conceitos e fisiologia aplicada da deglutição. In: MACEDOFILHO, E.; PISSANI, J.C.; CARNEIRO, J.; GOMES, G. Disfagia: Abordagem Multidisciplinar, Centro de Pesquisa e Tratamento da Disfagia. Frôntis Editorial, $2^{\mathrm{a}}$ ed., pp. 3-18, 1998.

MANN, G.; HANKEY, G.J.; CAMERON, D. Swallowing disorders following acute stroke: prevalence and diagnostic accuracy. Cerebrovascular Disease. 10: 380-386, 2000.

MANN, G.; HANKEY, G.J.; CAMERON, D. Swallowing function after stroke: prognosis and prognostic at 6 months. Stroke 30: 744-748, 1999.

MANRIQUE, D. Avaliação otorrinolaringológica da deglutição. In: FURKIM, A.M.; SANTINI, C.S. Disfagias Orofaríngeas. Carapicuiba, SP: Pró-Fono, pp. 49-60, 1999.

MARCHESAN, I.Q. Deglutição - normalidade. In: FURKIM, A.M.; SANTINI, C.S. Disfagias orofaríngeas. Editora Pró-fono, p. 3-18, 1999.

MARCHESAN, I.Q. Disfagia. In: MARCHESAN, I.Q.; BOLAFFI, C.; GOMES, I.C.D.; ZORZI, J. L. Tópicos em Fonoaudiologia, vol. II - CEFAC, ed. Lovise, pp.161-6, 1995.

MARTINO, R; PRON, G; DIAMANT, N. Screening for oropharyngeal dysphagia in stroke: insufficient evidence guidelines. Dysphagia. 15(1): 19-30, 2000. 
McCUllOUGH, G.H.; ROSENBEK, J.C.; WERTZ, R.T.; McCOY, S.; MANN, G.; McCULLOUGH, K. Utility of clinical swallowing examination measures for detecting aspiration post-stroke. Journal of speech, language and hearing research. Vol 48, pp. 1280-93, dec 2005.

McCULlOUGH, G.H.; WERTZ, R.T.; ROSENBEK, J.C. Sensitivity and specificity of clinical/bedside examination signs for detecting aspiration in adults subsequent to stroke. Journal of Communication Disorders. 34: 55-72, 2001.

McCUlloUGH, G.H.; WERTZ, R.T.; ROSENBEK, J.C.; MILLS, R.H.; ROSS; K.B.; ASHFORD, J.R. Inter and intrajudge reliability of a clinical examination of swallowing in adultos. Dysphagia. 15(2): 58-67, 2000.

MUIR, K.W.; WEIR, C.J.; MURRAY, G.D.; POVEY, C.; LEES, K.R. Comparison of neurological scales and scoring systems for acute stroke prognosis. Stroke 27(10): 1817$1820,1996$.

MURDOCH, B.E. Desenvolvimento da Fala e Distúrbios da Linguagem: uma Visão Neuroanatômica e Funcional, ed. Revinter, 1997.

NASI, A.; CARVALHO, L.E.B.; CECCONELLO, I.; PINOTTI, H.W. Disfagia no indivíduo idoso. In: FILHO, E.M.; PISSANI, J.C.; CARNEIRO, J.; GOMES, G. Disfagia: Abordagem Multidisciplinar. $2^{\mathrm{a}}$ ed. Frontis editorial, pp.47-62, 1998.

NISHIWAKI, K.; TSUJI, .T; LIU, M; HASE, K; TANAKA, N; FUJIWARA, T. Identification of a simple screening tool for dysphagia in patients with stroke using factor analysis of multiple dysphagia variables. Journal of Rehabilitation Medicine 37: 247-251, 2005.

NOBRE, M.A. O sistema nervoso central. Disponível em: http://clientes.netvisao.pt/terapia/SNC.htm. (acesso em 02 nov. 2007), 2004.

OKUBO, P.C.M.I; DANTAS, R.O.; TRONCON, L.E.A.; MORIGUTI, J.C.; FERRIOLLI, E. Clinical and scintigraphic assessment of swallowing of older patients admitted to a tertiary care geriatric ward. Dysphagia 23: 1-6, 2008.

OVEREL, J.R.; BONÉ, I.; LESS, K.R. Interatrial Septal Abnormalities an Stroke. A meta analysis of case-control studies. Neurology 55:1172-1179, 2000. 
PACIARONI, M.; MAZZOTTA, G.; COREA, F.; CASO, V.; VENTI, M.; MILIA, P.; SILVESTRELLI, G.; PALMERINI, F.; PARNETTI, L.; GALLAI, V. Dysphagia following stroke. European Neurology. 51: 162-167, 2004.

PERRY, L.; LOVE, C.P. Screening for dysphagia and aspiration in acute stroke: a systematic review. Dysphagia. 16: 7-18, 2001.

PIRES, L.P.; GAGLIARDI, R.J.; GORZONI, M.L. Estudo das freqüências dos principais fatores de risco para acidente vascular cerebral isquêmico em idosos. Arquivos de Neuropsiquiatria. 62(3-B): 844-851, 2004.

RADANOVIC, M. Características do atendimento de pacientes com acidente vascular cerebral em hospital secundário. Arquivos de Neuropsiquiatria. 58(1): 99-106, 2000.

RAMSEY, D.J.; SMITHARD, D.G.; KALRA, L. Early assessment of dysphagia and aspiration risk in acute patients. Stroke. 34(5): 1252-7, 2003.

SANTINI, C.S. Disfagia Neurogênica. In: FURKIM, A.M; SANTINI, C.S. Disfagias Orofaríngeas. Carapicuiba. Editora Pró-Fono, pp. 19-34, 1999.

SCHLEGEL, D.; KOLB, S.J.; LUCIANO, J.M.; TOVAR, J.M.; CUCCHIARA, B.L.; LIEBESKIND, D.S.; KASNER, S.E. Utility of the NIH stroke scale as a predictor of hospital disposition. Stroke 34: 134-137, 2003.

SHAY, K.; SHIP, J.A. The importance of oral health in the older patient. Journal of American Geriatrics Society. 43: 1414-1422, 1995.

SILVA, R.G. Disfagia neurogênica em adultos: uma proposta para avaliação clínica. In: FURKIM, A.M.; SANTINI, C.S. Disfagias Orofaríngeas. Carapicuiba, SP: Pró-Fono, pp. 36-48, 1999.

SILVA, R.G.; GATTO, A.R.; COLA, P.C. Disfagia orofaríngea neurogênica em adultos avaliação fonoaudiológica em âmbito hospitalar. In: JACOBI, J.S.; LEVY, D.S.; SILVA, L.M.C. Disfagia: avaliação e tratamento. Ed. Revinter, cap. 13: 181-193, 2003.

SILVA, R.G.; VIEIRA, M.M. Disfagia orofaríngea neurogênica em adultos pós- acidente vascular encefálico: identificação e classificação. In: FILHO, E.M.; PISSANI, J.C.; CARNEIRO, J.; GOMES, G. Disfagia: Abordagem Multidisciplinar. $2^{\text {a }}$ ed. Frontis editorial, pp.29-46, 1998. 
SILVA-NETTO, C.R.S. Deglutição na Criança, no Adulto e no Idoso: Fundamentos para Odontologia e Fonoaudiologia, ed. Lovise, 2003.

SINGH, S.; HAMDY, S. Dysphagia in stroke patients. Postgraduate Medical Journal. 82: 383-391, 2006.

SMITH, H.A.; LEE, S.H.; O’NEILL, P.A.; CONNOLLY, M.J. The combination of bedside swallowing assessment and oxygen saturation monitoring of swallowing in acute stroke: a safe and humane screening tool. Age and Ageing. 29: 495-499, 2000.

SMITHARD, D.G.; O’NEIL, P.A.; ENGLAND, R.E.; PARK, C.L.; WYATT, R.; MARTIN, D.F.; MORRIS, J. The natural history of dysphagia following a stroke. Dysphagia 12: 188193, 1997.

SMITHARD, D.G.; O’NEIL, P.A.; PARK, C.L.; ENGLAND, R.E.; RENWICK, D.S.; WYATT, R.; MORRIS, J.; MARTIN, D.F. for THE NORTH WEST DYSPHAGIA GROUP. Can bedside assessment reliably exclude aspiration following acute stroke. Age and Ageing. 27: 99-106, 1998.

SMITHARD, D.G.; O’NEILL, P.A.; PARK, C.; MORRIS, J.; WYATT, R.; MARTIN, D.F. Complications and outcome after acute stroke: does dysphagia matter?. Stroke 27: 12001204, 1996.

TEASDALE, G.; JENNETT, B. Assessment of coma and impaired consciousness. A practical scale. Lancet jul 13; 2 (7872): 81-4, 1974. Disponível em: http://pt.wikipedia.org/wiki/Ecala de coma de Glasgow, acesso em 01 nov. 2007.

TEASELL, R.; FOLEY, N.; FISHER, J.; FINESTONE, H. The incidence, management and complications if dysphagia in patients with medullary strokes admitted to a rehabilitation unit. Dysphagia 17: 115-120, 2002.

TEASELL, R.W.; BACH, D.; McRAE, M. Prevalence and recovery of aspiration post-stroke: a retrospective analysis. Dysphagia. 9:35-39, 1994.

TERRÉ, R.; MEARIN, F. Oropharyngeal dysphagia after the acute phase of stroke: predictors of aspiration. Neurogastroenterology and Motility 18, pp. 200-205, 2006.

TIRSCHWELL, D.L.; LONGSTRETH, W.T.; BECKER, K.J.; GAMMANS, R.E.; SABOUNJIAN, L.A.; HAMILTON, S.; MORGENSTERN, L.B. Shortening the NIH stroke scale for use in the prehospital setting. Stroke 33: 2801-2806, 2002. 
TRAPL, M.; ENDERLE, P.; NOWOTNY, M.; TEUSCHL, Y.; MATZ, K.; DACHENHAUSEN, A.; BRAININ, M. Dysphagia bedside screening for acute-stroke patients. The gugging swallowing screening. Stroke. 38: 000-000 (published online), 2007.

WALTER, U.; KNOBLICH, R.; STEINHAGEN, V.; DONAT, M.; BENECKE, R.; KLOTH, A. Predictors of pneumonia in acute stroke patients admitted to a neurological intensive care unit. Journal of Neurology. (Pubmed - in process) 254: 1323-9, 2007.

WESTERGREN, A. Detection of eating difficulties after stroke: a systematic review. International Nursing Review. 53: 143-149, 2006.

WILLIAMS, L.S.; YILMAZ, E.Y.; LOPEZ-YUNEZ, A.M. Retrospective assessment of initial stroke severity with the NIH stroke scale. Stroke 31(4): 858-862, 2000.

WITYK, R.J.; PESSIN, M.S.; KAPLAN, R.F.; CAPLAN, L.R. Serial assessment of acute stroke using the NIH stroke scale. Stroke 25: 362-365, 1994.

WOO, D.; BRODERICK, J.P.; KOTHARI, R.U.; LU, M.; BROTT, T.; LYDEN, P.D.; MARLER, J.R.; GROTTA, J.C. Does the national institute of health stroke scale favor left hemisphere strokes? Stroke 30: 2355-359, 1999.

ZAFFARI, R.J. Disfagia orofaríngea neurogênica: orientações para cuidadores e familiares. In: JACOBI, J.S.; LEVY, D.S.; SILVA, L.M.C. Disfagia: avaliação e tratamento. Rio de Janeiro: Revinter. P. 197-208, 2003.

ZOHAR, Y.; GRUSKO, I.; SULKES, J.; MELLOUL, M. M. Oropharyngeal scintigraphy: a computerized analysis of swallowing in patients with obstructive sleep apnea. The Laryngoscope 108, pp. 37-41, 1998. 
BIBLIOGRAFIA CONSULTADA 
- American gastroenterological association medical position statement of oropharyngeal dysphagia. Gastroenterology. 116: 452-454, 1999.

. Sociedade Brasileira de Doenças Cerebrovasculares. Primeiro consenso brasileiro do tratamento da fase aguda do acidente vascular cerebral. Arquivos de Neuropsiquiatria. 59(4): 972-980, 2001.

BURTON, C.; PENNINGTON, L.; RODDAM, H.; RUSSELL, I.; RUSSELL, D.; SMITH, H.A. Assessing adherence to the evidence base in the management of poststroke dysphagia. Clinical Rehabilitation 20: 46-51, 2006.

CONOVER, W.J. Practical Nonparametric Statistics. $2^{\text {nd }}$ Edition. John Wiley \& Sons, 1980 .

FISHER, R.A. The logic of inductive inference. Journal of the Royal Statistical Society. Series A, *98*, 39-54, 1935.

HILKER, R.; POETTER, C.; FINDEISEN, N.; SOBESKY, J.; JACOB, S.; NEVELING, M.; HEISS, W.D. Nosocomial pneumonia after acute stroke: implications for neurological intensive care medicine. Stroke. 34: 975-981, 2003.

HOLAS, M.A.; DePIPPO, K.L.; REDING, M.J. Aspiration and relative risk of medical complications following stroke. Archives of Neurology 51: 1051-1053, 1994.

$\underline{\text { http://decs.brs.br/ }}$

http://www.profala.com/artavc1.htm

LOGEMANN, J.A. Update on clinical trials in dysphagia. Dysphagia. 116-120, 2006.

LOGEMANN, J.A.; VEIS, S.; COLANGELO, L. A screening procedure for oropharyngeal dysphagia. Dysphagia. 14: 44-51, 1999.

LYDEN, P.D.; LU, M.; LEVINE, S.R.; BROTT, T.G.; BRODERICK, J.; AND THE NINIDS rtPA STROKE STUDY GROUP. A modified national institutes of health stroke scale for use in stroke clinical trials: preliminary reliability and validity. Stroke. 32: 1310-1317, 2001.

MELO-SOUZA, S.E. Acidente vascular cerebral isquêmico. http://www.neurologico.com.br/neurologicodownload/Acidente $\% 20$ Vascular $\% 20$ Cerebral $\% 2$ OIsquemico1.pdf. (acesso em 31/10/07). 
METHENY, N.A.; CLOUSE, R.E. Bedside methods for detecting aspiration in tube-fed patients. Chest. 111: 724-31, 1997.

NÓVAK, E.M.; TERABE, F.; NASIMOTO, A.L.; CARVALHO, P.H.M.; LOPER, A.D.; BÜCHELE, F.S.; NOGARA, J.C. Correlação entre hipótese diagnóstica e laudo de tomografia axial computadorizada craniana. Arquivos de Neuropsiquiatria. 59 (3-B): 761 767, 2001.

PEREIRA, M.G. Epidemiologia: teoria e prática. Guanabara-Koogan. 1995.

THE NINDS t-PA STROKE STUDY GROUP. Generalized efficacy of t-PA for acute stroke: subgroup analysis of NINDS t-PA stroke trial. Stroke 28: 2119-2125, 1997.

WILLIAMS, L.S. Feeding patients after stroke: who, when and how. Annals of Internal Medicine. 144(1): 59-60, 2006.

ZWEIG, M.H.; CAMPBELL, G. Receiver-operating characteristic (ROC) plots: a fundamental evaluation tool in clinical medicine. Clinical Chemistry, v. 39, $n^{\circ}$ 4, p. 561-577, 1993. 
APÊNDICE 


\section{APÊNDICE A - Termo de Consentimento Livre e Esclarecido}

\section{HOSPITAL DAS CLÍNICAS DA FACULDADE DE MEDICINA DE RIBEIRÃO PRETO DA UNIVERSIDADE DE SÃO PAULO}

\section{Termo de consentimento livre e esclarecido}

Nome do projeto: "Intervenção nos problemas de deglutição na fase aguda do acidente vascular cerebral utilizando a escala de AVC proposta pelo National Institute of Health"

Este estudo pretende realizar a avaliação do paciente internado na Unidade de Emergência, em conseqüência de ter sofrido um derrame cerebral, logo após a sua internação. A avaliação será realizada à beira do leito e conterá algumas perguntas que serão realizadas aos pacientes e serão solicitados alguns movimentos de braços e pernas para que também realize. Uma entrevista será feita com o paciente ou com sua família para saber se o paciente tinha dificuldade para engolir antes do derrame ou se já teve outros derrames anteriormente.

Para a avaliação, o paciente irá engolir uma papa de alimento, uma bolacha e depois água. Durante esta avaliação serão observados alguns aspectos que possam demonstrar que o paciente apresenta, ou não, dificuldade para engolir. A avaliação no leito não promove desconforto e/ou risco para o paciente avaliado.

Pretendemos reconhecer através dessa avaliação se ele tem ou não dificuldades para engolir no momento da internação, necessitando de uma avaliação mais detalhada e um acompanhamento para treinar como deve se alimentar de maneira segura, evitando, assim, que piore o seu estado geral.

A avaliação somente será realizada se houver colaboração do paciente, podendo este recusar-se a realizá-la. Qualquer dúvida que o paciente ou acompanhante tenham acerca dos procedimentos, riscos, benefícios e outros relacionados com a pesquisa, será esclarecida. Comprometemo-nos a proporcionar informação atualizada durante o estudo, ainda que esta possa afetar a vontade de continuar autorizando a participação na pesquisa. A identidade do paciente será mantida confidencialmente. O paciente não terá nenhuma despesa para participar da pesquisa, sendo todas as avaliações realizadas, de total responsabilidade e custo dos pesquisadores. Em caso de desistência da participação, o tratamento não será prejudicado; da mesma forma não ocorrerão prejuízos no tratamento clínico instituído neste ambulatório, pois não serão substituídas ou modificadas quaisquer medicações por conta deste estudo. Não ocorrerão remunerações ou ressarcimentos para os participantes do trabalho, podendo os mesmos, caso se sintam de alguma forma lesados, solicitá-los judicialmente de acordo com as leis vigentes no país.

Pesquisador Responsável: Paula de Carvalho Macedo Issa Okubo - CRFa 9.136 - Pós-Graduanda na Área de Concentração Neurologia da FMRP -USP.

EU abaixo assinado, declaro ter sido devidamente esclarecido sobre todas as condições de que trata o projeto de pesquisa acima descrito, tendo pleno conhecimento dos direitos e das condições que me foram assegurados.

Declaro, ainda, que concordo inteiramente com as condições que me foram apresentadas e que, livremente, manifesto a minha vontade em participar do referido projeto.

Ribeirão Preto, de de 
APÊNDICE B - Avaliação clínica da deglutição

PROTOCOLO DE AVALIAÇÃO - PESQUISA DE DOUTORADO

Fonoaudióloga Paula de Carvalho Macedo Issa Okubo - CRFa 9136

\section{IDENTIFICAÇÃO}

Nome:

D.N. Idade atual:

Registro:

ECG entrada: NIHSS entrada: ECG avaliação:

Data avaliação: NIHSS avaliação:

Data do início dos sintomas: Data de entrada na U.E.:

Antecedentes: Exames: ( ) CT ( ) RM

Resultado:

Achados clínicos:

NIHSS

1.a. Nível de Consciência

(0) Alerta

(1) Não alerta, mas responde ao estímulo mínimo

(2) Não alerta, requer estimulação repetida (estupor)

(3) Responde apenas com reflexo motor (coma)

1.b. Perguntas de Nível de Consciência (0) Ambas respostas corretas

(1) Apenas uma resposta correta

(2) Ambas incorretas

1.c. Comandos de Nível de Consciência(0) Responde ambas as questões corretamente

(1) Responde a uma questão corretamente

(2) Não responde a nenhuma questão corretamente

2. Melhor Olhar

(0) Normal

(1) Paralisia parcial do olhar

(2) Desvio forçado ou paresia total do olhar

3. Visual

(0) Sem perda visual

(1) Hemianopsia parcial

(2) Hemianopsia completa

(3) Hemianopsia bilateral

4. Paralisia Facial

(0) Movimentos normais simétricos

(1) Paralisia leve

(2) Paralisia facial parcial ou central

(3) Paralisia completa 
5.a. Motor para a mão direita

5.b. Motor para a mão esquerda

6.a. Motor para o pé direito

6.b. Motor para o pé esquerdo

7. Ataxia dos Membros

9. Melhor Linguagem

10. Disartria

11. Extinção e desatenção
(0) Sem queda; mantém o membro $90^{\circ}$ por $10 \mathrm{seg}$.

(1) Queda; mantém o membro, mas cai antes

(2) Algum esforço contra a gravidade

(3) Nenhum esforço contra a gravidade, despenca

(4) Nenhum movimento

(0) Sem queda; mantém o membro $90^{\circ}$ por $10 \mathrm{seg}$.

(1) Queda; mantém o membro, mas cai antes

(2) Algum esforço contra a gravidade

(3) Nenhum esforço contra a gravidade, despenca

(4) Nenhum movimento

(0) Sem queda; mantém o membro $90^{\circ}$ por $5 \mathrm{seg}$.

(1) Queda; mantém o membro, mas cai antes

(2) Algum esforço contra a gravidade

(3) Nenhum esforço contra a gravidade, despenca

(4) Nenhum movimento

(0) Sem queda; mantém o membro $90^{\circ}$ por $5 \mathrm{seg}$.

(1) Queda; mantém o membro, mas cai antes

(2) Algum esforço contra a gravidade

(3) Nenhum esforço contra a gravidade, despenca

(4) Nenhum movimento

(0) Ausente

(1) Presente em um membro

(2) Presente em dois membros

(0) Normal, nenhuma perda

(1) Perda da sensibilidade leve a moderada

(2) Perda da sensibilidade grave ou total

(0) Sem afasia, normal

(1) Afasia leve a moderada

(2) Afasia severa

(3) Mudo, afasia global

(0) Normal

(1) Leve a moderada

(2) Grave

(0) Nenhuma anormalidade

(1) Desatenção parcial

(2) Profunda desatenção 


\section{AVALIAÇÃO CLÍNICA DA DEGLUTIÇÃO}

\section{Aspectos Nutricionais}

Via de alimentação:
( ) Via oral sem restrições
( ) SNE / SNG
( ) Gastrostomia
( ) Via oral com restrições
( ) Via mista
( ) Jejunostomia
( ) Parenteral

Complicações:

( ) ausência

( ) presença ( desidratação/ desnutrição)

\section{Aspectos Respiratórios:}

Respiração: ( ) Espontânea

( ) Suporte/Dependência de O2

( ) VM

Traqueostomia: ( ) Ausente

( ) Presente sem cuff

( ) Presente com cuff

Afecções:

( ) sem acometimento

( ) DPOC

() Pneumonia

( ) ICC

\section{Nível de consciência:}
( ) Alerta
( ) Sonolento
( ) Confuso
( ) Estupor
( ) Coma

\section{Comunicação:}

Compreensão Oral:
( ) Normal
( ) Gravemente alterada
( ) Levemente alterada
( ) Impossível avaliar
( ) Moderadamente alterada

Expressão Oral:

( ) Normal ( ) Levemente alterada ( ) Moderadamente alterada
( ) Gravemente alterada
( ) Impossível avaliar

- Condições de higiene oral:

- Alterações na cavidade oral:

( ) adequada ( ) inadequada

( ) impossível avaliar

( ) sim (ulcerações, fibrose, edema, retalhos cirúrgicos, outros: )

- Arcada dentária superior:

( ) impossível avaliar

( ) presença de dentes / prótese bem adaptada

( ) ausência de dentes / prótese mal adaptada

( ) impossível avaliar

- Arcada dentária inferior:
( ) presença de dentes / prótese bem adaptada
( ) ausência de dentes / prótese mal adaptada
( ) impossível avaliar

- Estado de conservação dentária: ( ) BEC ( ) MEC

- Saliva: ( ) normal ( ) alterada (reduzida, excessiva, espessa)

( ) impossível avaliar

- Deglutição espontânea de saliva: ( ) sim ( ) não

- Deglutição eficiente de saliva: ( ) sim ( ) não

- Escape de saliva pelos lábios: ( ) não ( ) sim

- Selamento labial:

( ) $\operatorname{sim}$ ( ) não

- Mobilidade de lábios: ( ) adequada ( ) inadequada (paresia, paralisia e apraxia oral)

( ) impossível avaliar

- Tonicidade de lábios:

( ) adequada ( ) inadequada/reduzida ( ) impossível avaliar

- Mobilidade de língua:

( ) adequada ( ) impossível avaliar

( ) alterada (paresia, paralisia, tremor, apraxia oral, fasciculação)

- Tonicidade de língua:
( ) adequada
( ) alterada
( ) impossível avaliar

- Mobilidade de véu palatino:

( ) presente ( ) limitado ( ) ausente ( ) impossível avaliar

- Sensibilidade de véu palatino:

( ) presente ( ) unilateral ( ) ausente ( ) imp. avaliar

- Presença de reflexo patológico:

( ) não ( ) sim Qual? 
- Elevação laríngea: ( ) adequada ( ) ausente

- Sensibilidade extra-oral: ( ) sim ( ) não lado

( ) alterada (reduzida / dificuldade de sustentação)

- Sensibilidade intra-oral: ( ) sim ( ) não lado

- Mímica facial:

( ) simétrica

( ) assimétrica: lado

- Ausculta cervical:

( ) adequada ( ) alterada

- Qualidade vocal:

( ) adequada ( ) alterada (rouca, soprosa, áspera, voz molhada)

( ) impossível avaliar

- Tosse voluntária:

( ) $\operatorname{sim}($ ) não

( ) ineficiente ( ) impossível avaliar

\section{AVALIAÇÃO FONOAUDIOLÓGICA FUNCIONAL}

Consistência testada:

Volume testado:

Consistência alterada:

( ) pastoso

( ) $3 \mathrm{ml}$

( ) pastoso

( ) líquido

( ) $5 \mathrm{ml}$

( ) líquido
( ) impossível avaliar

( ) impossível avaliar

Volume alterado durante a avaliação: ( ) 3ml

- Vedamento labial

( ) presente

( ) $5 \mathrm{ml}$

( ) sólido

( ) $7 \mathrm{ml}$

( ) sólido

( )livre

- Escape extra - oral

( ) ausente

( ) ausente

( ) $7 \mathrm{ml}$

( )livre

- Atraso no início da deglutição

( ) ausente

( ) presente

- Provável perda prematura

( ) ausente

( ) presente

- Resíduo na cavidade oral após deglutição

( ) ausente

( ) presente

- Refluxo nasal

( ) ausente

( ) presente

- Ausculta cervical alterada

( ) ausente

( ) presente

- Elevação laríngea:

( ) adequada

( ) presente (antes /durante /após)

( ) alterada (reduzida / dificuldade de sustentação)

- Deglutições múltiplas

( ) ausente ( ) presente

- Pigarro

( ) ausente

( ) presente (antes /durante /após)

- Para ausculta cervical alterada: sinais indicativos de clareamento da hipofaringe

( ) presente (após deglutições múltiplas / pigarro)

- Engasgos ( ) ausente ( ) presente (antes/durante /após)

- Tosse ( ) ausente ( ) presente (antes/durante /após)

- Fadiga ( ) ausente ( ) presente (antes /durante /após)

- Alterações respiratórias ( ) ausente ( ) presente (antes /durante /após)

- Mudança na qualidade vocal

( ) ausente ( ) presente (antes/durante /após)

( ) impossível avaliar

- Necessidade de manobra compensatória: ( ) não ( ) sim

- Paciente traqueostomizado: saída do alimento colorido pela traqueostomia ( ) ausente ( ) presente (aspiração evidente do alimento / necessidade de aspiração traqueal)

Conclusão da avaliação clínica: （ ） sem alteração de deglutição

( ) deglutição funcional

( ) disfagia

Conduta: 
APÊNDICE C - Caracterização dos pacientes avaliados

\begin{tabular}{|c|c|c|c|c|c|c|c|c|}
\hline $\mathbf{n}$ & Idade & Sexo & NIHSS & ECG & Comunicação & Topografia & $\begin{array}{c}\text { Hemisfério } \\
\text { cerebral }\end{array}$ & Disfagia \\
\hline 1 & 27 & $\mathrm{~F}$ & 7 & 15 & Disartria & $\mathrm{C}$ & $\mathrm{D}$ & Não \\
\hline 2 & 86 & $\mathrm{~F}$ & 13 & 15 & Disartria & VB & $\mathrm{E}$ & Não \\
\hline 3 & 65 & M & 1 & 15 & Sem alteração & VB & $\mathrm{E}$ & Não \\
\hline 4 & 65 & $\mathrm{~F}$ & 3 & 15 & Disartria & $\mathrm{C}$ & $\mathrm{E}$ & Não \\
\hline 5 & 82 & $\mathrm{~F}$ & 12 & 15 & Disartria & $\mathrm{C}$ & $\mathrm{D}$ & Sim \\
\hline 6 & 60 & $\mathrm{M}$ & 10 & 15 & Disartria & npd & npd & Não \\
\hline 7 & 84 & M & 0 & 15 & Sem alteração & $\mathrm{C}$ & $\mathrm{D}$ & Não \\
\hline 8 & 41 & $\mathrm{~F}$ & 2 & 15 & Afasia & $\mathrm{C}$ & $\mathrm{E}$ & Não \\
\hline 9 & 52 & $\mathrm{~F}$ & 8 & 15 & Disartria & $\mathrm{C}$ & $\mathrm{D}$ & Não \\
\hline 10 & 47 & $\mathrm{~F}$ & 0 & 15 & Sem alteração & npd & npd & Não \\
\hline 11 & 68 & M & 2 & 15 & Afasia & $\mathrm{C}$ & $\mathrm{E}$ & Não \\
\hline 12 & 72 & $\mathrm{M}$ & 38 & $3 \mathrm{~T}$ & Afasia & $\mathrm{C}$ & $\mathrm{D}$ & Sim \\
\hline 13 & 62 & $\mathrm{M}$ & 4 & 15 & Sem alteração & $\mathrm{C}$ & $\mathrm{D}$ & Não \\
\hline 14 & 60 & $\mathrm{M}$ & 2 & 15 & Sem alteração & npd & npd & Não \\
\hline 15 & 86 & $\mathrm{~F}$ & 24 & $9 \mathrm{~A}$ & Afasia & $\mathrm{C}$ & $E$ & Sim \\
\hline 16 & 50 & $\mathrm{M}$ & 12 & 15 & Disartria & $\mathrm{C}$ & $\mathrm{D}$ & Não \\
\hline 17 & 49 & $\mathrm{M}$ & 11 & $11 \mathrm{~A}$ & Afasia & $\mathrm{C}$ & $\mathrm{E}$ & Sim \\
\hline 18 & 77 & $\mathrm{~F}$ & 10 & $12 \mathrm{~A}$ & Disartria & VB & $\mathrm{D}$ & Não \\
\hline 19 & 50 & $\mathrm{M}$ & 15 & 14 & Disartria & $\mathrm{C}$ & $E$ & Sim \\
\hline 20 & 91 & $\mathrm{~F}$ & 12 & 14 & Disartria & $\mathrm{C}$ & $\mathrm{D}$ & Sim \\
\hline 21 & 71 & $\mathrm{M}$ & 2 & 15 & Sem alteração & $\mathrm{C}$ & $\mathrm{D}$ & Não \\
\hline 22 & 69 & M & 1 & 15 & Sem alteração & npd & npd & Não \\
\hline 23 & 54 & M & 5 & 15 & Disartria & VB & $E$ & Não \\
\hline 24 & 69 & $\mathrm{~F}$ & 8 & 14 & Disartria & $\mathrm{C}$ & $\mathrm{D}$ & Não \\
\hline 25 & 91 & $\mathrm{~F}$ & 1 & 15 & Sem alteração & VB & $E$ & Não \\
\hline 26 & 66 & M & 11 & 15 & Sem alteração & $\mathrm{C}$ & $\mathrm{D}$ & Não \\
\hline 27 & 38 & $\mathrm{M}$ & 6 & 15 & Sem alteração & $\mathrm{C}$ & $\mathrm{D}$ & Não \\
\hline 28 & 26 & $\mathrm{~F}$ & 1 & 15 & Sem alteração & VB & $\mathrm{E}$ & Não \\
\hline 29 & 88 & $\mathrm{~F}$ & 35 & 9 & Afasia & $\mathrm{C}$ & $\mathrm{D}$ & Sim \\
\hline 30 & 69 & $\mathrm{~F}$ & 9 & 15 & Disartria & $\mathrm{C}$ & $\mathrm{D}$ & Não \\
\hline 31 & 74 & $\mathrm{~F}$ & 37 & $3 \mathrm{~T}$ & Afasia & $\mathrm{C}$ & $E$ & Sim \\
\hline 32 & 57 & $\mathrm{M}$ & 9 & 12 & Afasia & $\mathrm{C}$ & $\mathrm{E}$ & Não \\
\hline 33 & 60 & $\mathrm{~F}$ & 2 & 15 & Disartria & $\mathrm{C}$ & $\mathrm{E}$ & Não \\
\hline 34 & 78 & $\mathrm{~F}$ & 16 & 14 & Disartria & $\mathrm{C}$ & $\mathrm{D}$ & Sim \\
\hline
\end{tabular}




\begin{tabular}{|c|c|c|c|c|c|c|c|c|}
\hline 35 & 80 & $\mathrm{M}$ & 18 & 14 & Afasia & $\mathrm{C}$ & $\mathrm{D}$ & Sim \\
\hline 36 & 66 & $\mathrm{M}$ & 13 & 15 & Afasia & VB & $\mathrm{D}$ & Não \\
\hline 37 & 75 & M & 35 & $11 \mathrm{~A}$ & Afasia & $\mathrm{C}$ & $\mathrm{E}$ & Sim \\
\hline 38 & 80 & $\mathrm{~F}$ & 39 & $3 \mathrm{~T}$ & Afasia & $\mathrm{C}$ & $\mathrm{D}$ & Sim \\
\hline 39 & 85 & $\mathrm{~F}$ & 2 & 15 & Disartria & $\mathrm{C}$ & D & Não \\
\hline 40 & 74 & $\mathrm{~F}$ & 3 & 15 & Disartria & VB & $\mathrm{E}$ & Não \\
\hline 41 & 50 & M & 19 & 13 & Disartria & $\mathrm{C}$ & D & Sim \\
\hline 42 & 71 & M & 5 & 14 & Disartria & VB & D & Não \\
\hline 43 & 46 & $\mathrm{~F}$ & 15 & $11 \mathrm{~A}$ & Afasia & $\mathrm{C}$ & $\mathrm{E}$ & Sim \\
\hline 44 & 81 & M & 10 & 13 & Afasia & $\mathrm{C}$ & $\mathrm{E}$ & Sim \\
\hline 45 & 55 & $\mathrm{~F}$ & 8 & 15 & Disartria & $\mathrm{C}$ & D & Não \\
\hline 46 & 54 & M & 12 & 15 & Sem alteração & $\mathrm{C}$ & $\mathrm{D}$ & Não \\
\hline 47 & 75 & M & 13 & 14 & Disartria & $\mathrm{C}$ & D & Não \\
\hline 48 & 54 & M & 1 & 15 & Sem alteração & VB & $\mathrm{E}$ & Não \\
\hline 49 & 56 & $\mathrm{~F}$ & 40 & $6 \mathrm{~T}$ & Afasia & $\mathrm{C}$ & $\mathrm{D}$ & Sim \\
\hline 50 & 59 & $\mathrm{~F}$ & 8 & 14 & Disartria & $\mathrm{C}$ & $\mathrm{E}$ & Não \\
\hline
\end{tabular}

C: carotídeo; VB: vertebrobasilar; Npd: não foi possível definir topografia; D: direito; E: esquerdo 
APÊNDICE D - Fatores de risco apresentados pelos pacientes

\begin{tabular}{|c|c|c|c|}
\hline \multicolumn{3}{|c|}{ Fator de risco } & Paciente \\
\hline \multicolumn{3}{|c|}{ Contraceptivo oral } & 1 \\
\hline \multicolumn{3}{|c|}{ Hipertensão arterial sistêmica } & $\begin{array}{l}2,3,4,6,7,8,9,10,11,12,13,14, \\
15,19,20,22,23,24,25,27,29,30, \\
31,32,33,35,36,39,40,42,43,44, \\
45,47,48,50\end{array}$ \\
\hline \multicolumn{3}{|c|}{ Diabete melito } & $4,11,22,26,29,30,32,34,35,40$ \\
\hline \multicolumn{3}{|l|}{ Tabagismo } & $\begin{array}{l}5,7,9,10,11,13,14,16,18,19,21, \\
22,27,32,37,41,45,46\end{array}$ \\
\hline \multicolumn{3}{|l|}{ Etilismo } & $6,10,13,16,19,22,23,27,32,47$ \\
\hline \multicolumn{3}{|l|}{ Dislipidemia } & 8,32 \\
\hline \multicolumn{3}{|c|}{ Fibrilação atrial } & $29,37,38$ \\
\hline \multicolumn{3}{|l|}{$\mathrm{HIV}$} & 46 \\
\hline \multirow{5}{*}{$\begin{array}{l}\text { Doença } \\
\text { vascular }\end{array}$} & \multirow{2}{*}{$\begin{array}{l}\text { Doença cardíaca } \\
\text { coronariana }\end{array}$} & Infarto agudo do miocárdio & 32 \\
\hline & & Angina & 47 \\
\hline & \multirow{2}{*}{$\begin{array}{l}\text { Acidente vascular } \\
\text { cerebral }\end{array}$} & AVC I & $4,8,10,11,18,22,27,32,33,35,44$ \\
\hline & & $\mathrm{AVCH}$ & 19, \\
\hline & \multicolumn{2}{|c|}{ Doença arterial crônica } & 11 \\
\hline \multirow{4}{*}{$\begin{array}{l}\text { Outras } \\
\text { cardiopatias }\end{array}$} & \multicolumn{2}{|l|}{ Arritmia } & 18 \\
\hline & \multicolumn{2}{|l|}{ Cardiopatia chagásica } & 28,38 \\
\hline & \multicolumn{2}{|l|}{ Marcapasso } & 28 \\
\hline & \multicolumn{2}{|c|}{ Miocardiopatia de etiologia indeterminada } & 34 \\
\hline \multirow{3}{*}{$\begin{array}{l}\text { Outras } \\
\text { doenças } \\
\text { neurológicas }\end{array}$} & \multicolumn{2}{|l|}{ Doença de Parkinson } & 49 \\
\hline & \multicolumn{2}{|l|}{ Mal de Alzheimer } & 29 \\
\hline & \multicolumn{2}{|c|}{ Hidrocefalia de pressão normal } & 42 \\
\hline \multicolumn{3}{|c|}{ Ausência de fatores de risco } & 17 \\
\hline
\end{tabular}


ANEXO A - Carta de Aprovação do Comitê de Ética em Pesquisa

HOSPITAL DAS CLINICAS DA FACULDADE DE MEDICINA
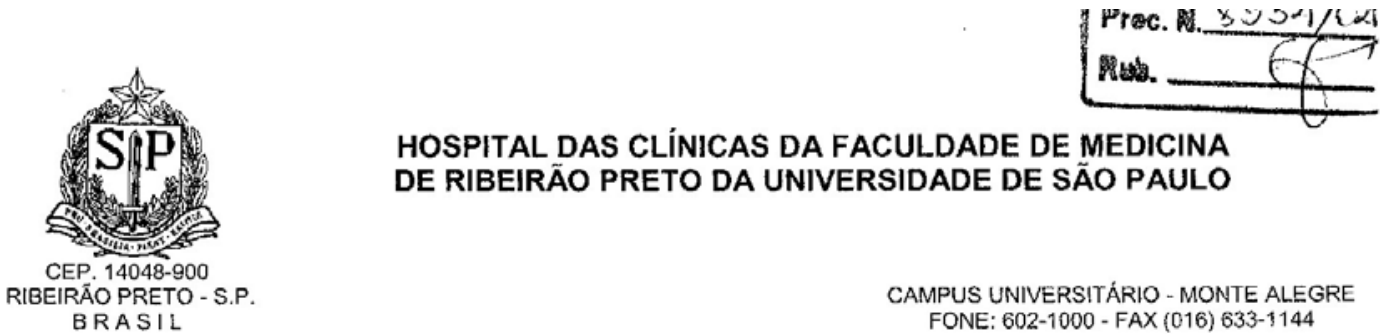

DE RIBEIRÃO PRETO DA UNIVERSIDADE DE SÃO PAULO

CAMPUS UNIVERSITÁRIO - MONTE ALEGRE FONE: 602-1000 - FAX (016) 633-1144

Ribeirão Preto, 29 de outubro de 2004

Oficio $n^{\circ} 2956 / 2004$

$\mathrm{CEP} / \mathrm{SPC}$

Prezada Senhora:

O trabalho intitulado

"INTERVENÇÃo NOS PROBLEMAS DE DEGLUTIÇÃo NA FASE AGUDA DO ACIDENTE VASCULAR CEREBRAL UTILIZANDO A ESCALA DE AVC PROPOSTA PELO NATIONAL INSTITUTE OF

HEALTH" foi analisado pelo Comitê de Ética em Pesquisa em sua $191^{a}$ Reunião Ordinária realizada em 25.10.2004, e enquadrado na categoria: APROVADO, de acordo com o Processo HCRP $n^{\circ}$ $8954 / 2004$.

Aproveito a oportunidade para apresentar a Vossa Senhoria protestos de estima e contsideração.

PROF. DR. SÉRGIO PEREIRA DA CUNHA Coordenador do Comitê de Ética em Pesquisa do HCRP e da FMRP-USP

Ilustrissima Senhora

PAULA DE CARVALHO MACEDO ISSA

PROF. DR. OSVALDO MASSAITI TAKAYANAGUI (Orientador)

Depto. de Neurologia, Psiquiatria e Psicologia Médica

Em mãos 
ANEXO B - NIHSS traduzido e adaptado (CANEDA et al., 2006).

1a. Nível de consciência

( ) 0 Alerta; reponde com vivacidade.

( ) 1 Não está alerta, mas desperta com estímulo menor, obedecendo e respondendo.

( ) 2 Não está alerta, necessita de estímulo repetido para atender ou está obnubilado, necessitando de estímulo forte ou doloroso para fazer movimentos (não estereotipados).

( ) 3 Responde somente com reflexos motores ou autonômicos ou totalmente irresponsivo, flácido, arreflexo.

1b. Nível de consciência (mês atual e idade)

( ) 0 Responde ambas questões corretamente.

( ) 1 Responde uma questão corretamente.

( ) 2 Nenhuma questão é respondida corretamente.

1c. Nível de consciência (fechar e abrir olhos, fechar e abrir mão)

( ) 0 Executa ambas tarefas corretamente.

( ) 1 Executa somente uma tarefa corretamente.

( ) 2 Nenhuma tarefa é executada corretamente.

2. Melhor movimentação ocular

( ) 0 Normal

( ) 1 Paralisia ocular parcial. O movimento ocular é anormal em um ou ambos olhos, mas não estão presentes o desvio forçado do olhar ou paresia total do movimento ocular.

( ) 2 Desvio forçado ou paresia ocular total não sobrepujada pela manobra oculocefálica.

3. Campos visuais

( ) 0 Sem perda visual

( ) 1 Hemianopsia parcial.

( ) 2 Hemianopsia total.

( ) 3 Hemianopsia bilateral (cegueira, incluindo cegueira cortical).

4. Paralisia facial

( ) 0 Movimento simétrico normal.

( ) 1 Paralisia leve (dobra nasolabial apagada, assimetria ao sorrir).

( ) 2 Paralisia parcial (paralisia total ou quase total da face inferior).

( ) 3 Paralisia completa de um ou ambos lados (ausência de movimento facial superior e inferior).

5. Motricidade dos membros superiores

D $\mathbf{E}$

( ) ( ) 0 Sem queda, o membro mantém os 90 ou 45 graus durante $10 \mathrm{seg}$.

( ) ( ) 1 Queda, o membro mantém os 90 ou 45 graus, cai antes dos $10 \mathrm{seg}$ mas não atinge a cama ou outro suporte.

( ) ( ) 2 Algum esforço contra a gravidade; o membro não atinge ou não consegue manter os 90 ou 45 graus; cai até a cama, mas existe algum esforço contra a gravidade.

( ) ( ) 3 Sem esforço contra a gravidade; o membro cai.

( ) ( ) 4 Sem movimento. 
( ) ( ) 9 Amputação, fusão articular, etc. Explique:

6. Motricidade dos membros inferiores

D $\mathbf{E}$

( ) ( ) 0 Sem queda, o membro mantém os 30 graus durante 5 seg.

( ) ( ) 1 Queda, o membro cai antes de $5 \mathrm{seg}$. mas não atinge a cama.

( ) ( ) 2 Algum esforço contra a gravidade; o membro cai na cama em $5 \mathrm{seg}$, mas existe algum esforço contra a gravidade.

( ) ( ) 3 Sem esforço contra a gravidade, o membro cai imediatamente.

( ) ( ) 4 Sem movimento.

( ) ( ) 9 Amputação, fusão articular, etc. Explique:

7. Ataxia

( ) 0 Ausente.

( ) 1 Presente em um membro.

( ) 2 Presente em dois membros.

Ataxia no:

Sim

( ) MSD ( ) MSD ( ) 9 amputação, fusão articular, explique:

( ) MSE ( ) MSE ( ) 9 amputação, fusão articular, explique:

( ) MID ( ) MID ( ) 9 amputação, fusão articular, explique:

( ) MIE ( ) MIE ( ) 9 amputação, fusão articular, explique:

8. Sensibilidade

( ) 0 Normal, sem perda de sensibilidade.

( ) 1 Perda da sensibilidade leve a moderada; o paciente sente que a fincada é menos aguda ou é romba no lado afetado, ou existe uma perda da dor superficial com a fincada mas o paciente está ciente que está sendo tocado.

( ) 2 Perda severa ou total da sensibilidade; o paciente não está ciente de ter sido tocado na face ou membros.

9. Melhor linguagem (figuras)

( ) 0 Sem afasia, normal

( ) 1 Afasia leve a moderada; alguma perda óbvia da fluência ou da facilidade de compreensão, sem limitação significativa nas idéias expressadas ou na forma de expressão. A redução da linguagem e/ou compreensão, entretanto, torna a conversação sobre o material apresentado difícil ou impossível. O examinador pode identificar no material apresentado figuras ou nomeações a partir das respostas do paciente.

( ) 2 Afasia severa; toda comunicação é através de expressão fragmentada; há grande necessidade de inferência, questionamento e adivinhação pelo examinador. A variedade de informação que pode ser trocada é limitada; o examinador carrega o fardo da comunicação. $O$ examinador não consegue identificar os materiais apresentados a partir das respostas do paciente.

( ) 3 Mudez, afasia global; sem linguagem aproveitável ou compreensão auditiva.

10. Disartria (frases e palavras)

( ) 0 Normal

( ) 1 Leve a moderada, o paciente arrasta pelo menos algumas palavras e, na pior situação, pode ser entendido com alguma dificuldade. 
( ) 2 Severa; a fala do paciente é tão arrastada que se torna ininteligível, na ausência ou desproporcional a qualquer disfasia, ou o paciente é mudo/anártrico.

( ) 9 Entubado ou outra barreira física. Explique:

11. Extinção e inatenção (prévia negligência)

( ) 0 Sem anormalidade

( ) 1 Inatenção ou extinção visual, tátil, auditiva, espacial ou pessoal à estimulação simultânea e bilateral em uma das modalidades de sensibilidade.

( ) 2 Hemi-inatenção profunda ou heminatenção a mais que uma modalidade. Não reconhece sua própria mão ou orienta-se somente a um lado do espaço.

\section{Frases traduzidas e adaptadas:}

1) Você sabe como (You know how)

2) Com os pés no chão (Down to earth)

3) Eu cheguei em casa do trabalho (I got home from work)

4) Perto da mesa da sala de jantar (Near the table in the dining room)

5) Eles o ouviram falar no rádio na noite passada. (They heard him speak on the radio last night)

\section{Lista de palavras:}

1) Mamãe (Mama)

2) Tip-top (Tip-top)

3) Foto - fato(Fifty-fifty)

4) Tanque (Thanks)

5) Rico

6) $\operatorname{Berro(Huckleberry)}$

7) Triste

8) Problema (Baseball Player) 
Lista de identificação para melhor linguagem

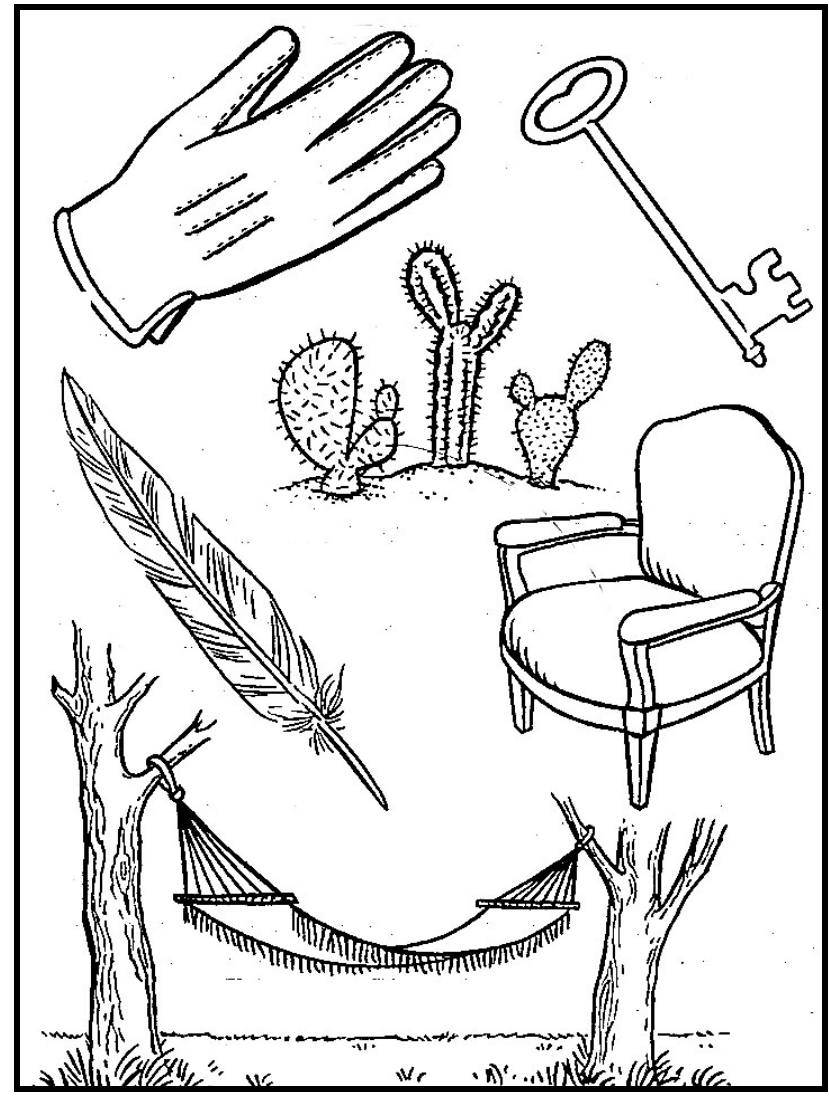

Figura para melhor linguagem

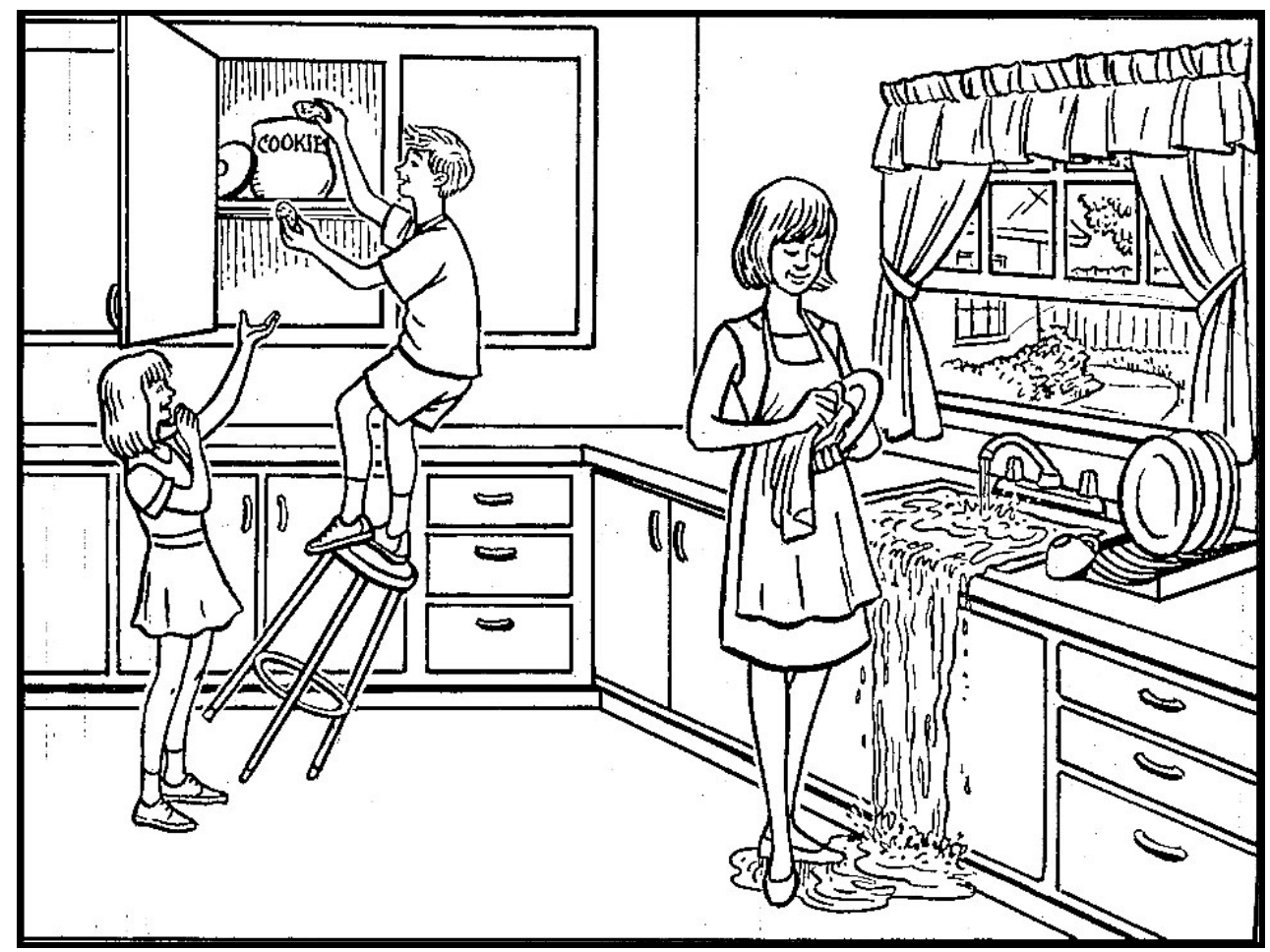


ANEXO C - Escala de coma de Glasgow

Elementos da escala:

Abertura Ocular (AO): existem quatro níveis

4. Olhos se abrem espontaneamente

3. Olhos se abrem ao comando verbal (não confundir com o despertar de uma pessoa adormecida; se assim for, deve-se marcar 4 e não 3 )

2. Olhos se abrem por estímulo doloroso

1. Olhos não se abrem

Melhor Resposta Verbal (MRV): existem cinco níveis

5. Orientado (o paciente responde coerentemente e apropriadamente às perguntas sobre seu nome e idade, onde está e porque, a data, etc)

4. Confuso (o paciente responde às perguntas coerentemente mas há alguma desorientação e confusão)

3. Palavras inapropriadas (fala aleatória, mas sem troca conversacional)

2. Sons ininteligíveis (gemendo, sem articular palavras)

1. Ausente

Melhor Resposta Motora (MRM): existem seis níveis

6. Obedece ordens verbais (o paciente faz coisas simples quando lhe é ordenado)

5. Localiza estímulo doloroso

4. Retirada inespecífica à dor

3. Padrão flexor à dor (decorticação)

2. Padrão extensor à dor (descerebração)

1. Sem resposta motora

Interpretação: pontuação total de 3 a 15

- 3: Coma profundo ( $85 \%$ de probabilidade de morte; estado vegetativo);

- 4: Coma profundo;

- 7: Coma intermediário

- 11: Coma superficial;

- 15: Normalidade 